\title{
Heparan sulphate compounds regulate cholesterol metabolism in neurodegenerative disease models
}

\author{
by \\ Rosemary Heathcott
}

\begin{abstract}
A thesis
submitted to the Victoria University of Wellington in fulfilment of the requirements for the degree of Master of Science in

Cell and Molecular Bioscience
\end{abstract}

Victoria University of Wellington 2015 


\begin{abstract}
Heparan sulphate proteoglycans (HSPG) are central to numerous processes of the mammalian cell. The highly charged negative side chains of the heparan sulphate (HS) oligosaccharides are essential for the regulatory and structural functions of the proteoglycan. Synthetic HS compounds have potential therapeutic value due to their ability to mimic naturally occurring HS. Niemann-Pick disease type C (NPC) is a fatal childhood neurodegenerative disease with characteristic cholesterol and sphingolipid accumulation in the late endosome or lysosome. Alzheimer's disease, another neurodegenerative disorder, shares alterations of cholesterol and amyloid $\beta$ metabolism with NPC. In this study, a set of novel heparan sulphate compounds with a range of structures and oligosaccharide side groups with a variety of degrees of sulphation was investigated with regards to their effects on cholesterol and amyloid $\beta$ metabolism in cell line models of these two diseases. Fluorescent staining of cholesterol and confocal microscopy showed highly sulphated compounds reduce the accumulation of cholesterol in the perinuclear lysosomal storage organelles in patient fibroblast cell lines. The compounds had no effect on secreted amyloid $\beta$ levels or amyloid precursor protein levels in a neuronal cell line model of early onset Alzheimer's disease. The mechanism of cholesterol reduction is unclear but may be related to a reduction in HSPGassociated endocytosis of LDL/cholesterol.
\end{abstract}




\section{Acknowledgements}

Firstly I would like to thank my supervisor Dr Andrew Munkacsi for all his guidance, encouragement, all round positivity, and for giving me the opportunity to do a Masters in the first place. I am very grateful to our collaborator Dr Olga Zubkova of the Ferrier Research Institute of Victoria University of Wellington for providing the heparan sulphate compounds used in this study. Thank you also to the US Alzheimer's Association for financial support.

I would particularly like to thank Prof Paul Atkinson for all his support and encouragement from the beginning.

I very much appreciated all the generous advice and assistance with confocal microscopy and analysis provided by Dr Peter Bircham and Dinindu Senanayake. Also thanks to Remy Schneider for sharing his technical expertise on numerous occasions.

Thanks to all the good friends I've made in the Chemical Genetics lab and SBS, in particular Natalie Hammond, Delaney Burnard, Bhumi Bhatt and Christina Roberts for helping to keep me sane when things got a little stressful. Thanks to Pirooz Zareie for his excellent music in the TC lab. Also thanks to my technician colleagues, Chris Thorn, Jennifer Howe and Richard Crerar for general hilarity, good advice and morning tea exactly when I needed it.

Thanks finally to my parents for always supporting me in everything I've wanted to do.

"A pessimist sees the difficulty in every opportunity; an optimist sees the opportunity in every difficulty."

Winston Churchill 


\section{Table of Contents}

Abstract

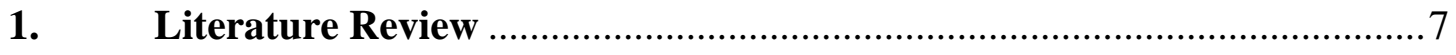

1.1 Heparan sulphate proteoglycans - Chemical structure, synthesis and

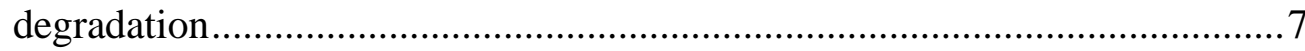

1.2 Functions of heparan sulphate proteoglycans ........................................

1.2.1 Extracellular matrix HSPGs - Organisation of basement membranes .......9

1.2.2 Cell-cell adhesion and cytoskeleton interactions .................................. 10

1.2.3 Secretory vesicles and endocytic receptors ........................................ 10

1.2.4 Modulation of lipid metabolism....................................................... 11

1.2.5 HSPG association with amyloid $\beta$ peptides in Alzheimer's disease........ 11

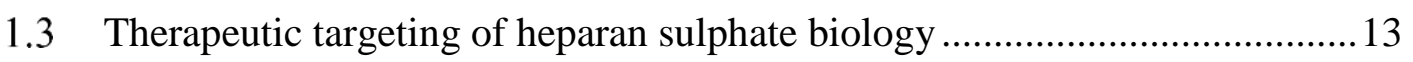

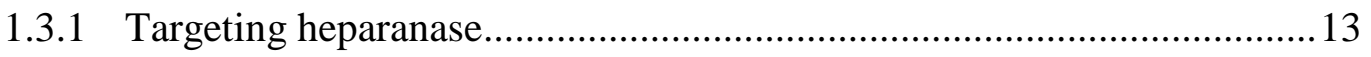

1.3.2 Compounds developed for promoting wound repair............................ 13

1.3.3 Compounds targeting amyloid protein aggregation ............................. 14

1.3.4 BACE1 inhibition by heparin and heparan sulphate compounds ............ 14

1.4 Alzheimer's disease and Niemann-Pick disease type $\mathrm{C}$ - the cholesterol

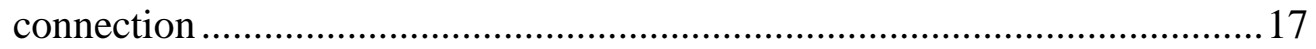

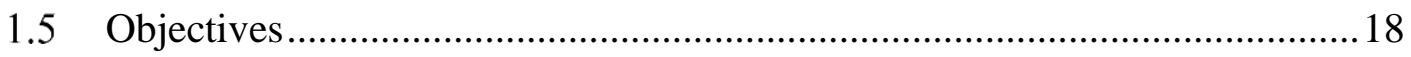

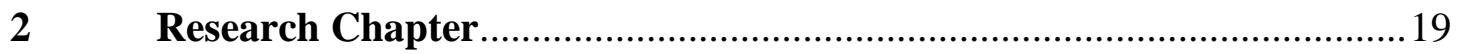

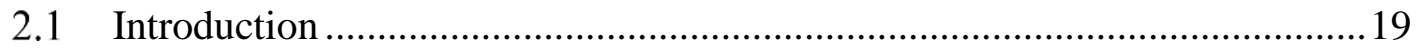

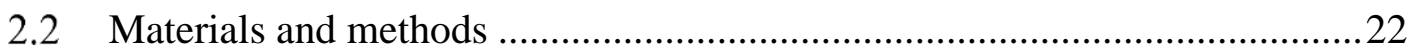

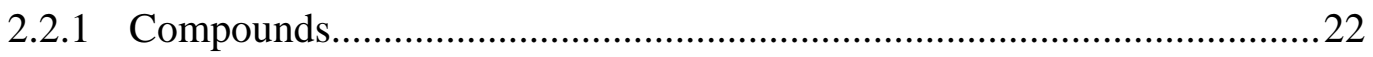

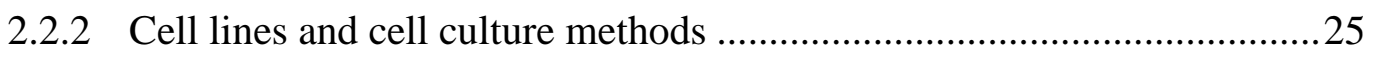

2.2.3 Filipin staining of free cholesterol in fixed cells ...................................2

2.2.4 Relative quantitation of free cholesterol in cultured cells using confocal

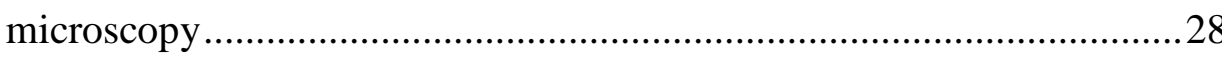


2.2.5 Enzyme-linked immunosorbent assay (ELISA) for A $\beta 40$ and $A \beta 42$......29

2.2.6 Western blot analysis of amyloid precursor protein (APP) .29

2.3 Results 30

2.3.1 Novel heparan sulphate compounds reduce cholesterol levels in cells derived from patients with Niemann-Pick type $\mathrm{C}$ disease and Alzheimer's disease 30

2.3.2 Amyloid beta levels are not affected with heparan sulphate compounds in the SH-SY5Y swAPP cell model of Alzheimer's disease 42

2.3.3 Amyloid precursor protein (APP) levels in SH-SY5Y swAPP cells are not affected with heparin treatment but are affected with SAHA treatment 46

2.4 Discussion .50

2.4.1 Novel heparan sulphate compound effects on cholesterol metabolism ...50

2.4.2 Lack of BACE1 inhibition in an SH-SY5Y cell line carrying the Swedish APP mutation..... .51

2.4.3 Amyloid precursor protein levels in an SH-SY5Y cell line carrying the Swedish APP mutation after heparin and SAHA treatment .52

$3 \quad$ Future Directions .54

4 Appendices .57

4.1 Appendix A: Script for analysis of OPERA confocal images .57

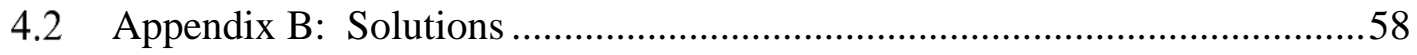




\section{Table of Figures}

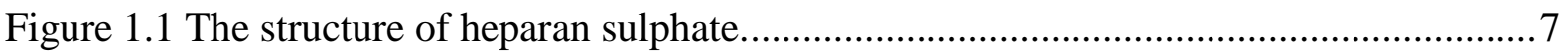

Figure 1.2 Heparan sulphate proteoglycans have a wide variety of functions in the cell..........9

Figure 1.3 Amyloid Precursor Protein (APP) metabolism by secretases .............................. 15

Figure 2.1 Novel heparan sulphate compounds used in this study ......................................25

Figure 2.2 Free cholesterol levels in the NPC cell line GM03123 treated with heparan

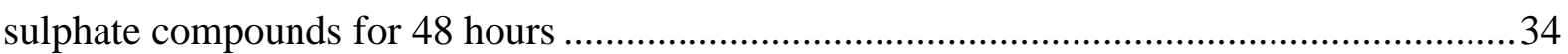

Figure 2.3 Confocal microscopy images of filipin stained free cholesterol in NPC (GM03123) and control (GM09503) patient derived fibroblast cell lines ................................................... 35

Figure 2.4 Confocal microscopy images of filipin stained free cholesterol in NPC (GM03123)

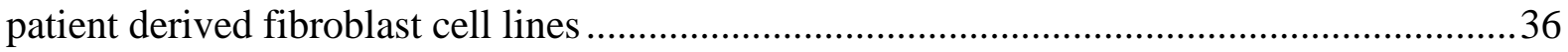

Figure 2.5 Confocal microscopy images of filipin stained free cholesterol in NPC (GM03123)

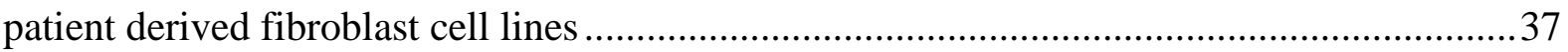

Figure 2.6 Free cholesterol levels in the AD cell line ND41001 treated with heparan sulphate compounds for 48 hours

Figure 2.7 Confocal microscopy images of filipin stained free cholesterol in Alzheimer's (ND41001) and control (ND38530) patient derived fibroblast cell lines

Figure 2.8 Confocal microscopy images of filipin stained free cholesterol in Alzheimer's (ND41001) patient derived fibroblast cell lines

Figure 2.9 Confocal microscopy images of filipin stained free cholesterol in Alzheimer's (ND41001) patient derived fibroblast cell lines

Figure 2.10 Relative quantitation of A 342 levels in media from SH-SY5Y swAPP cells after 24 hour heparan sulphate compound treatment $(n=2)$

Figure 2.11 Relative quantitation of A $\beta 42$ levels in media from SH-SY5Y swAPP cells after 24 hour heparin treatment $(n=2)$

Figure 2.12 Relative quantitation of A $\beta 42$ levels in media from SHSY5Y swAPP cells after 10 hour $\left(1^{\text {st }}\right.$ treatment $)$ and consecutive 12 hour $\left(2^{\text {nd }}\right)$ heparin treatments $(n=1)$. 
Figure 2.13 Relative quantitation of A $\beta 40$ levels in media from SH-SY5Y swAPP cells after 2nd consecutive heparin treatment $(n=1)$. 45

Figure 2.14 APP levels after heparin treatment in SH-SY5YswAPP cells 47

Figure 2.15 APP levels in SH-SY5Y cells increase after treatment with SAHA .48

Figure 2.16 Relative quantitation of A 342 levels in media from SH-SY5Y swAPP cells after 24 hour SAHA treatment $(n=2)$ 49 


\section{Literature Review}

\subsection{Heparan sulphate proteoglycans - Chemical structure, synthesis and degradation}

Heparan sulphate proteoglycans (HSPG) are glycoproteins with a diverse range of functions in the mammalian cell. Most heparan sulphate proteoglycans can be divided into either those present in the extracellular matrix (perlecan, agrin and collagen XVIII) or those associated with the cell surface (syndecans and glypicans) (Sarrazin et al. 2011). HSPGs are assembled in the Golgi through the covalent attachment of heparan sulphate chains to a core protein. Heparan sulphate (HS) is a glycosaminoglycan (GAG) which is assembled initially via the attachment of a xylose group to a specific serine group in the core protein. Specific enzymes then synthesize a tetrasaccharide with the serine-attached xylose group as a starting point (glucuronic acid-galactose-galactose-xylose). After the addition of an $\mathrm{N}$ acetylglucosamine (GlcNAc), further GlcNAc and glucuronic acid (GlcA) residues are added alternately to form the unmodified heparan sulphate strand. Specific enzymatic modifications to the GlcNAc and GlcA groups result in highly sulphated regions in the HS chain. Dglucuronic acid may also be epimerised to L-iduronic acid which can also be further sulphated (see Figure 1.1). These highly negatively charged regions give rise to the significant protein binding capacity of HSPG and are therefore crucial to their regulatory functions (Bishop et al. 2007).

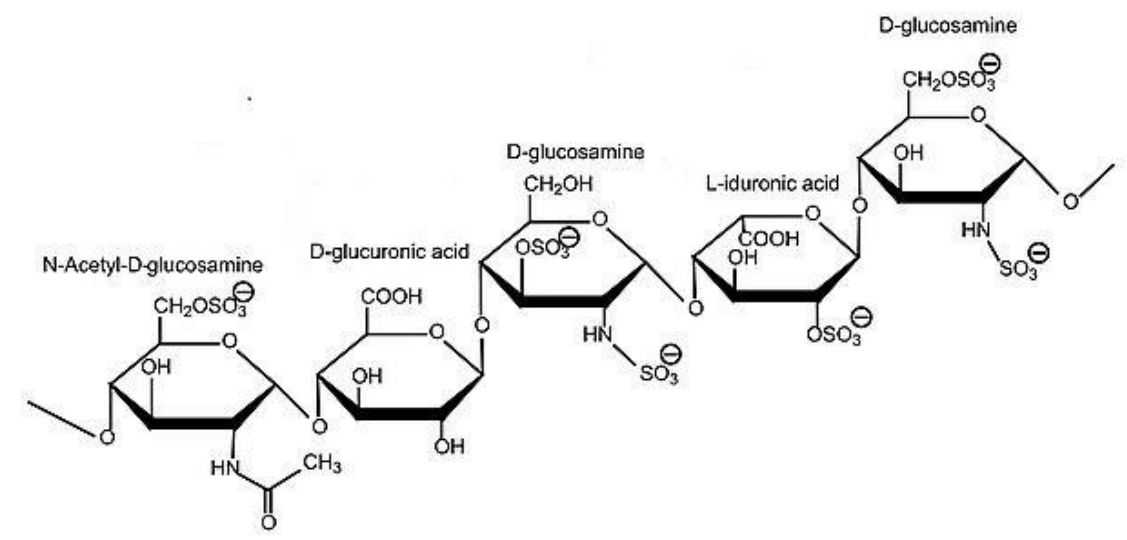

Figure 1.1 The structure of heparan sulphate. 
Mature HSPGs may be incorporated into the cell membrane or released into the extracellular matrix. HSPGs may also be directed to secretory vesicles (Turnbull et al. 2001; Sarrazin, Lamanna et al. 2011). HSPG on the cell membrane can be removed by the proteolytic cleavage of the core protein. HS side chains can be released with any attached ligands by the endoglycosidase, heparanase. Interestingly, heparanase has been shown to promote metastasis in cancer by the degradation of extracellular matrix in the endothelial cell layer of blood vessels by invading cells. Cell lines with higher heparanase activity also exhibit high metastatic potential (Vlodavsky et al. 1999). In addition to cancer, heparanase is involved in the development of atherosclerotic plaques due to its enzymatic action on heparan sulphate producing HS fragments that can promote atherosclerosis. Heparanase levels are also increased in patients who have suffered an acute myocardial infarction wherein heparanase activates macrophages resulting in the release of cytokines that are associated with plaque progression (Madonna and De Caterina 2014). 


\subsection{Functions of heparan sulphate proteoglycans}

The roles of HSPGs in the cell include involvement in the organisation of basement membranes, extracellular matrix and cytoskeleton interactions, secretory vesicles, signal transduction and ligand receptor clustering, storage of regulatory factors, and endocytosis (See Figure 1.2).

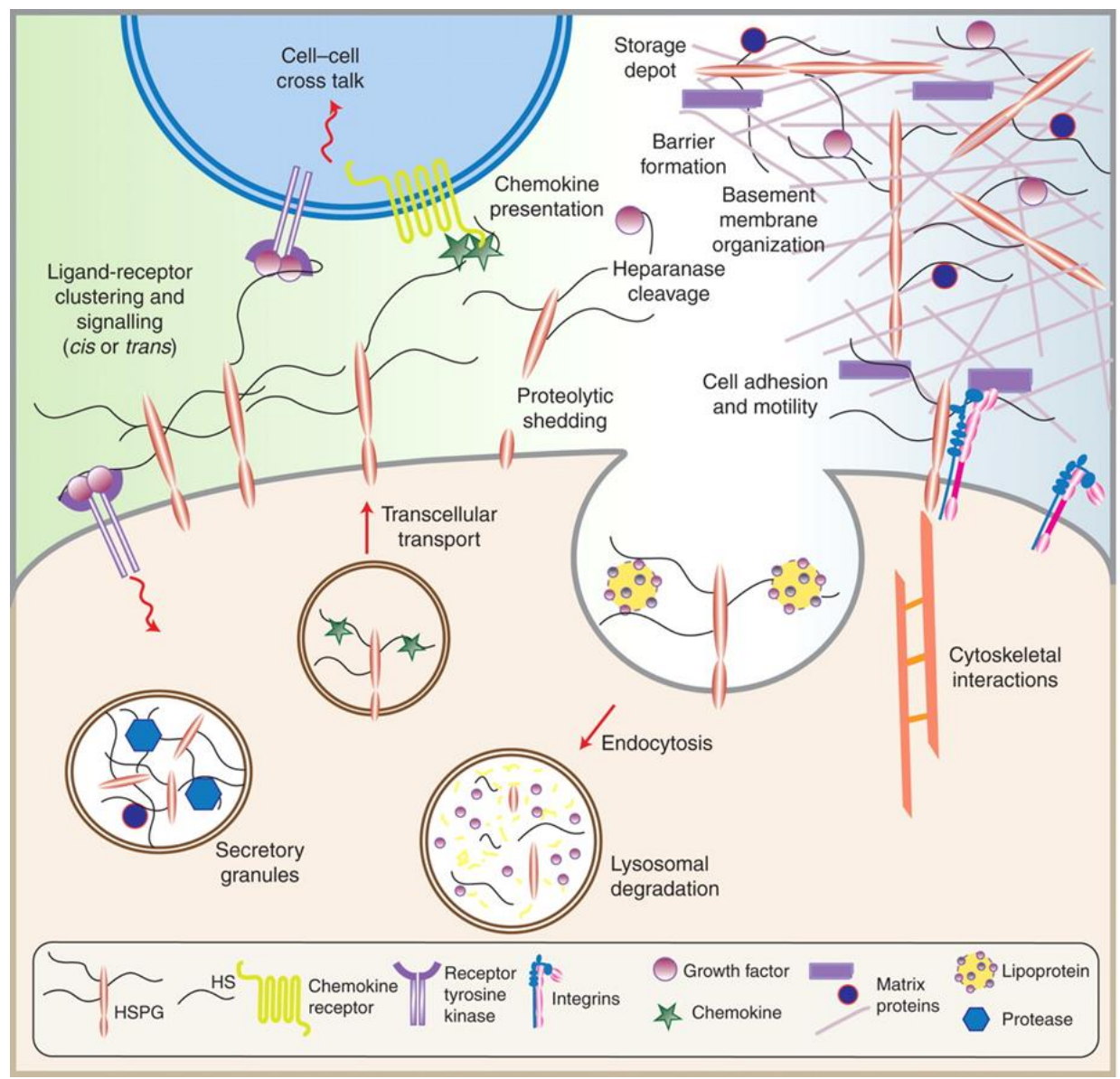

Figure 1.2 Heparan sulphate proteoglycans have a wide variety of functions in the cell. Reprinted with permission from Stephane Sarrazin et al. Cold Spring Harb Perspect Biol 2011.

\subsubsection{Extracellular matrix HSPGs - Organisation of basement membranes}

Basement membranes consist of extracellular matrix (ECM) that provides a physical scaffold for epithelial and endothelial cells. These membranes consist of a layered network of proteins including laminins, collagens and the HSPGs perlecan, agrin and collagen XVII. This network not only provides structure and protection from physical stress, but also 
provides a means for trafficking, transport and signalling between cells and the ECM (Yurchenco 2011).

Basement membranes are essential for the integrity of the lining of the intestine. Protein-losing enteropathy (PLE) is a condition associated with disorders such as Crohn's disease and coeliac disease. It results in leakage of serum proteins into the intestinal lumen and is often concurrent with elevated inflammatory cytokines. Loss of HS and the HSPG syndecan-1 from the basolateral surface of intestinal epithelial cells has been shown to occur during episodes of PLE, and heparin or heparin derivatives are considered a potential treatment for the condition. Although the exact mechanism is unknown, heparin binds inflammatory cytokines and blocks cytokine induced protein leakage in in vitro and mouse models of PLE (Bode et al. 2008). Heparan sulphates are also important in the glomerular basement membrane (GBM) of the kidney for the control of podocyte behaviour (Sarrazin, Lamanna et al. 2011). The charge on HS sidechains in the glomerular capillary wall is thought to selectively prevent large negatively charged molecules such as proteins to move from the bloodstream to the kidney filtrate. Disruptions of heparan sulphate in the GBM have been linked to proteinuria and human glomerular disease (Raats et al. 2000).

\subsubsection{Cell-cell adhesion and cytoskeleton interactions}

Membrane proteoglycans are involved in cell-cell attachments via interactions with extracellular matrix proteins such as integrins at heparin binding domains. These interactions occur generally through the glycosaminoglycan side chains on the HSPG core protein but also through interactions with the core protein allowing presentation or storage of ligands to receptors. There are four members of the transmembrane HSPG syndecan group and at least one is expressed in all cell types through development and adulthood. These HSPGs are particularly important in the generation of focal adhesions where integrin and other proteins form tight complexes providing a mechanical link between intracellular actin bundles and extracellular matrix. Through regulation of the actin cytoskeleton, syndecans play important roles in cell motility and spreading (Yoneda and Couchman 2003).

\subsubsection{Secretory vesicles and endocytic receptors}

HSPGs are present in the secretory vesicles of hematopoietic and mast cells. The HSPG serglycin is important in the generation of storage granules in mast cells. Proteases and histamine are stored and released from storage granules in association with serglycin, where 
it is involved in keeping proteases in an active state (Bishop et al 2007). The cell membraneassociated HSPG syndecan and glypican each have significant roles as endocytic receptors. The polyanionic nature of HS side chains, due to sulphate and carboxyl side groups, leads to the ability to bind a wide variety of ligands such as lipoproteins, viruses, growth factors and polycationic nucleic acid complexes. Endocytosed HSPGs and their ligands are degraded in lysosomes allowing recycling of degradation products or removal of unwanted bioactive molecules. HSPG-mediated endocytosis can be regulated by enzymatic shedding of proteoglycans from the cell surface. Shedding of syndecan from hepatocytes alters lipoprotein clearance. Some pathogens can produce proteases that cause shedding of syndecan which may act as a defence mechanism, preventing internalisation of microbial pathogens (Christianson and Belting 2014).

\subsubsection{Modulation of lipid metabolism}

HSPGs are involved in the metabolism of triglycerides in the circulation. These HSPGs attach lipases to endothelial cell surfaces where chylomicrons (containing dietary triglycerides and cholesterol) and VLDL (very low-density lipoprotein) are degraded to form cholesterol enriched lipoprotein remnants. In the liver, these remnants are endocytosed by hepatocytes mediated by LDL receptor and LDL receptor related protein (LRP1) facilitated by HSPG. This also occurs in other cells such as neurons where HSPG can act alone as an endocytic receptor (Mahley and Ji 1999). Mutations in an N-sulphotransferase enzyme, resulting in the reduction of sulphation of the HS side chains of HSPGs (N-sulphotransferase) in mice hepatocytes, interfered with the uptake of triglyceride rich and cholesterol rich lipoproteins independently of LDL receptors (MacArthur et al. 2007). Using proteoglycan deficient mice, syndecan-1 was shown to be the primary HSPG necessary for lipoprotein clearance in the liver (Stanford et al. 2009).

\subsubsection{HSPG association with amyloid $\beta$ peptides in Alzheimer's disease}

Amyloid $\beta(\mathrm{A} \beta)$ peptides are the main component of extracellular neuritic plaques which, along with intracellular neurofibrillary tangles of Tau protein, cerebral amyloid angiopathy (amyloid deposits in small blood vessels of the brain) and accumulated lipid granules, comprise the pathological features of Alzheimer's disease (AD). Undoubtedly, A $\beta$

peptides are associated with the neurodegenerative characteristics of the disease (Selkoe 2001). Amyloid plaques also contain other proteins including proteoglycans. Sulphated 
glycosaminoglycans were identified originally in neuritic plaques, tangles and cerebral amyloid angiopathy using Alcian blue, a dye which stains acidic polysaccharides (Snow et al. 1987).

HSPGs appear to be associated with the early stages of amyloidogenesis. In the brains of teenage Down's syndrome patients (who often develop neuritic plaques after the age of 35), heparan sulphate proteoglycans were detected by specific antibodies in diffuse "preamyloid" plaques implying that proteoglycans are involved early in the development of senile plaques. Diffuse plaques contain non fibrillary amyloid protein and are not associated with the axonal and dendritic injury of fibrillary $\mathrm{A} \beta$ containing neuritic plaques, but are thought to develop into neuritic plaques (Snow et al. 1990).

A number of studies have demonstrated an interaction between $A \beta$ fibrils and heparan sulphate or heparin, a highly sulphated version of heparan sulphate (Watson et al. 1997). Castillo et al. showed in vitro that perlecan binds amyloid $\beta$, and also promotes accelerated amyloid fibril formation and increased stability of fibrils (Castillo et al. 1997), suggesting it is important in the pathogenic process of AD. Heparan sulphate interaction with amyloid $\beta$ may also be important in the immunopathology of AD (Giulian et al. 1998). Cell culture experiments have shown that microglia become reactive in contact with amyloid plaques producing neurotoxins and resulting in death of neurons. The HHQK motif at the N-terminus of amyloid $\beta$ is a binding site for heparan sulphate and also a binding site for microglial cells which suggests HSPGs may be important in the interaction of $A \beta$ and microglial cells. Alternatively, another known A $\beta$ binding site on heparan sulphate consisting of an $N$-sulfated hexasaccharide domain may be involved in neuroprotection as it also binds the neuroprotective fibroblast growth factor FGF-2 (Lindahl et al. 1999).

Alterations in the cellular uptake of $\mathrm{A} \beta$ and its intracellular degradation are considered to be pivotal in the development of late onset (non-familial) AD. Kanekiyo et al demonstrated that both HSPG and LRP1 are involved in the mechanism of A $\beta$ uptake. LRP1 not only acts as a receptor for ApoE and LDL uptake, but also recognises A $\beta$. Knockdown of LRP1 reduces $A \beta$ uptake and over-expression increases uptake in neuronal cells. HSPG on the cell surface is critical to $A \beta$ uptake. Competition for binding of $A \beta$ with heparin reduced $\mathrm{A} \beta$ uptake in neuronal cells, and Chinese hamster ovary (CHO) cells deficient in HSPG were shown to have significantly reduced $A \beta$ uptake (Kanekiyo et al. 2011). 


\subsection{Therapeutic targeting of heparan sulphate biology}

\subsubsection{Targeting heparanase}

Controlling metastasis remains one of the biggest hurdles in the effective treatment of most cancers. The action of the endoglycosidase heparanase on the heparan sulphate side chains of HSPG has been implicated in the development of metastasis via its action on HSPG in the tumour environment and vasculature, which promotes cell migration from the primary tumour (Barash et al. 2010). Heparanase is upregulated in numerous cancers (McKenzie et al. 2000) and has been recognised as a potential target for cancer therapy. Heparin and low molecular weight heparin compounds inhibit heparanase and also inhibit P- and L-selectin, two cell adhesion proteins that also facilitate the metastatic process (Hostettler et al. 2007). Natural oligosaccharides and synthetic compounds have been investigated as anti-heparanase drugs. Phosphomannopentose sulfate (PI-88) is a yeast derived oligosaccharide that binds heparanase in competition with HS and has been trialled as a cancer treatment. As well as being an inhibitor of metastasis, it has anti-angiogenic properties (Koo et al. 2008). By competitively binding to heparanase it prevents the release of growth factors required for angiogenesis. Other small molecule inhibitors of heparanase have been isolated in high throughput screens of large chemical libraries providing a starting point for development of synthetic inhibitors. Neutralising antibodies have also been trialled as heparanase inhibitors (McKenzie 2007).

\subsubsection{Compounds developed for promoting wound repair}

Large dextran polymers have been developed to act as regenerating agents to aid wound repair by mimicking the action of HS. They mimic the HS of matrix proteoglycans by binding growth factors such as FGF and VEGF, protecting them from proteolysis and inhibiting enzymes such as heparanase and the endopeptidase plasmin to promote tissue regeneration. These compounds have been investigated for treating a number of medical conditions including myocardial infarction, gastric ulcers, periodontitis and bone defects (Gandhi and Mancera 2010). 


\subsubsection{Compounds targeting amyloid protein aggregation}

HSPGs and other GAGs bind to $\mathrm{A} \beta$, promoting amyloid aggregation and this association occurs early in the amyloidogenic process (Snow, Mar et al. 1990; Castillo, Ngo et al. 1997). HSPGs also associate with tau containing neurofibrillary tangles, and sulphated glycosaminoglycans promote the formation of hyper phosphorylated tau protein filaments (Perry et al. 1991; Goedert et al. 1996). Compounds have been developed to target the association of HSPG and $\mathrm{A} \beta$ as a therapeutic approach to the prevention of amyloid aggregation in the brain. One example is Tramiprosate (3-aminopropylsulfonic acid), a modified taurine molecule which can cross the blood brain barrier. It binds soluble A $\beta$ preventing it from forming amyloid fibrils. It has had some success in Phase II clinical trials where a lowering of levels of the amyloidogenic form of $A \beta(A \beta 42)$ in the cerebrospinal fluid of $\mathrm{AD}$ patients after three months treatment was achieved (Aisen et al. 2007). Unfortunately Phase III trials failed to demonstrate long term cognitive improvements in patients (Gandhi and Mancera 2010).

Eprodisate (1,3-propanedisulfonic acid disodium salt) is another sulphonated molecule that can mimic the binding of HS to amyloid proteins. It has been designed to bind serum amyloid protein A (AA). This protein accumulates as extracellular insoluble protein fibrils with HS and other GAGs in tissues in certain chronic inflammatory diseases such as rheumatoid arthritis and renal disease (Rumjon et al. 2012). The binding of GAG to AA is essential to protein aggregation (Kisilevsky et al. 1995). Trials have shown that eprodisate may slow the rate of progressive renal failure in patients with AA amyloidosis-related renal disease (Dember et al. 2007) .

\subsubsection{BACE1 inhibition by heparin and heparan sulphate compounds}

$\mathrm{A} \beta$ peptides are produced and released to the extracellular space by the cleavage of the trans-membrane amyloid precursor protein (APP) by BACE1 ( $\beta$ site APP cleavage protein 1 or $\beta$-secretase 1 ) and $\gamma$-secretase (Figure 1.3, below). BACE1 cleaves a large soluble ectodomain (sAPP $\beta$ ) into the extracellular space. The remaining transmembrane APP protein (C99) is processed by the intramembrane enzyme $\gamma$-secretase, resulting in a range of $\mathrm{A} \beta$ fragments and an APP intracellular $\mathrm{COOH}$-terminal domain (AICD). The 40 amino acid peptide, $\mathrm{A} \beta 40$, is the most abundant $\mathrm{A} \beta$ peptide cleaved by $\gamma$-secretase. The larger $\mathrm{A} \beta 42$ is less abundant but more highly amyloidogenic, meaning it is more likely to aggregate and 
form toxic amyloid plaques. (Cole and Vassar 2007; Haass and Selkoe 2007). APP is also cleaved by $\alpha$-secretase within the region that contains the amyloid $\beta$ protein sequences, releasing the ectodomain known as APPs $\alpha$ into the extracellular space and precluding A $\beta$ production. The remaining transmembrane peptide, C83, is also cleaved by $\gamma$-secretase. This pathway is predominant and is known as the non-amyloidogenic APP processing pathway (Lammich et al. 1999). For 20 years, both BACE1 and $\gamma$-secretase have been targets for candidate compounds to treat AD (Imbimbo 2008; Yan and Vassar 2014).

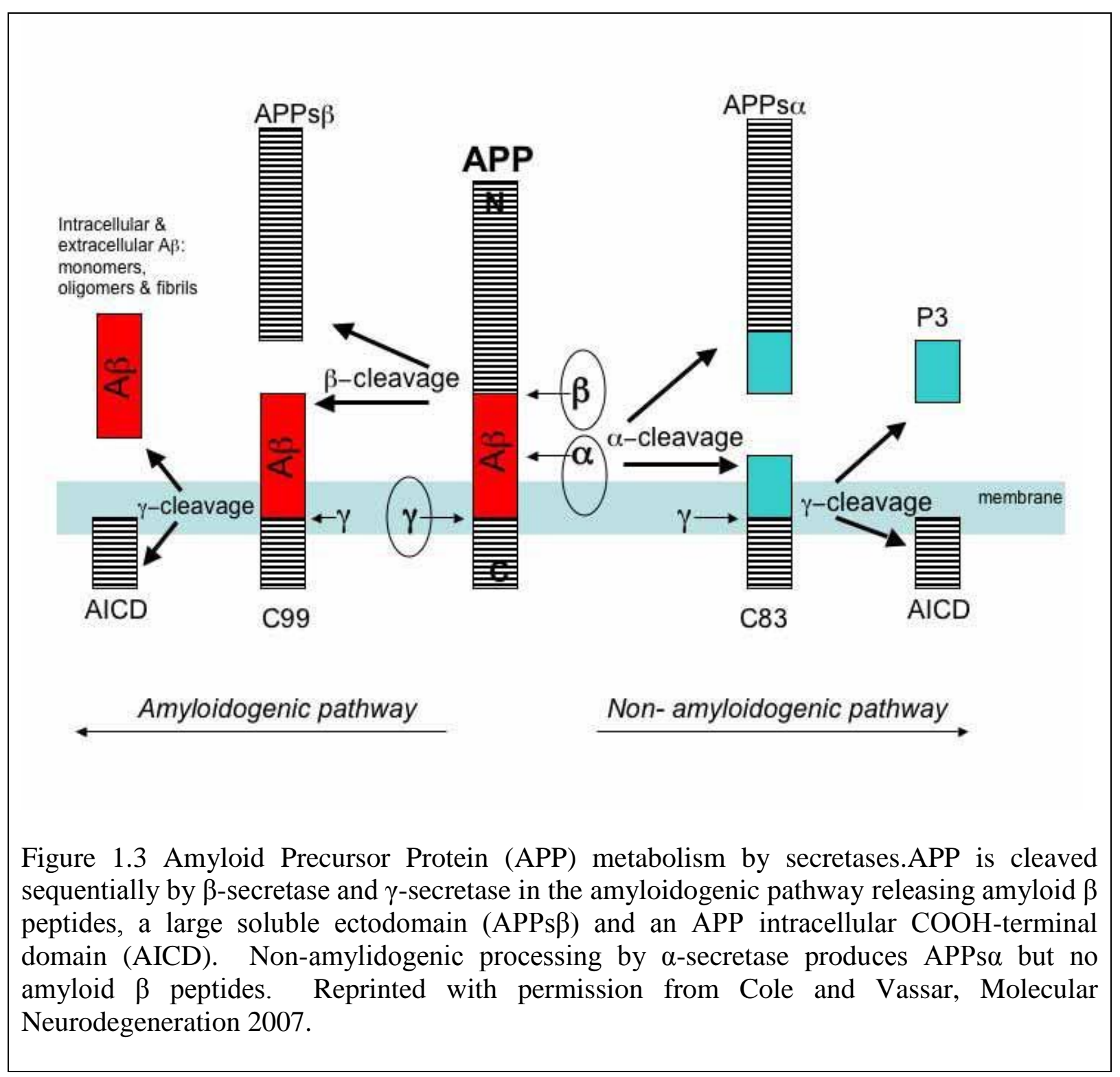


Leveugle et al (Leveugle et al. 1998) reported that low molecular weight (LMW) heparin fragments inhibited APP secretion. This was in contrast to the ability of full length heparin which had been shown to stimulate synthesis and secretion of APP and SAPP $\beta$ in a neuroblastoma cell line. The LMW heparin that crossed the blood-brain barrier also inhibited the binding of heparin to amyloid $\beta$, suggesting that low molecular weight heparin fragments, or similar compounds, may be useful as potential therapeutics by disrupting the role of heparan sulphate in amyloidogenesis (Leveugle et al. 1997; Leveugle, Ding et al. 1998).

Scholefield et al reported heparin and heparan sulphate as BACE1 inhibitors in both in vitro and in vivo experiments (Scholefield et al. 2003). They used a FRET (fluorescence resonance energy transfer) assay, where a weakly fluorescent peptide substrate becomes highly fluorescent upon enzymatic cleavage, to show in vitro inhibition of BACE1 by both heparin and HS. Cell culture experiments where cells were treated with a concentration range of HS showed a concentration dependent reduction of the secreted BACE1 cleavage products sAPP $\beta$ and A $\beta$ in the cell media by western blotting and ELISA assays, respectively, implying BACE1 inhibition. There was no reduction in APPs $\alpha$ implying no inhibition of $\alpha-$ secretase and therefore specificity to the amyloidogenic pathway involving inhibition of BACE1. Interestingly, the saccharide size and structures in the heparan sulphates affected the degree of inhibition.

Scholefield et al suggested the contradiction of their results with those seen by Leveugle et al (i.e., an increase in secretion of sAPP $\beta$ after heparin treatment) may be due to a lag time in the earlier experiments allowing the recovery of BACE1 activity after treatment. Scholefield et al provided further evidence that HS is a direct regulator of BACE1 processing of APP in vivo. They showed exogenous HS colocalises with BACE1 in the cell membrane and Golgi. Also disruption of endogenous HS by reduction of sulphation, or removal of cell surface HSPGs with heparitinases, resulted in an increase in BACE1 activity, suggesting HS negatively regulates BACE1 in vivo. These results suggest that heparan sulphate analogues would be useful as potential therapeutics in $\mathrm{AD}$ and other neurodegenerative diseases involving amyloid deposition without the anti-coagulant effects of unmodified heparin (Scholefield, Yates et al. 2003). 


\subsection{Alzheimer's disease and Niemann-Pick disease type $\mathrm{C}$ - the cholesterol connection}

Lipid granule accumulation in brain tissue was one of the pathological characteristics originally identified in the brain of Alzheimer's patients by Aloysius “Alois" Alzheimer over a hundred years ago, suggesting that alterations in lipid metabolism are significant in the development of the disease. Modern science confirmed this with the identification of the E4 isoform of the cholesterol transporter Apolipoprotein E (APOE) as the strongest known genetic risk factor for the sporadic form of the disease (Corder et al. 1993). APOE is the most important transporter of cholesterol around the brain. Lipoprotein transport across the bloodbrain barrier is inefficient and therefore the majority of cholesterol in the brain originates from de novo synthesis rather than the circulation.

The majority of cholesterol in the brain is present as cholesterol ester and recent research has shown that the balance between free unesterified cholesterol and cholesterol ester is linked to A $\beta$ metabolism (Di Paolo and Kim 2011). Excess free cholesterol in the cell is converted to cholesterol ester by the enzyme acyl CoA:cholesterol acyltransferase 1 (ACAT). In cell culture, an increase in cholesterol ester in the cell was shown to increase the release of $\mathrm{A} \beta$ from the cell. Also disruption of ACAT by an ACAT inhibitor not only decreased levels of cholesterol ester but also decreased amyloid accumulation in an AD mouse model (Hutter-Paier et al. 2004; Bhattacharyya and Kovacs 2010). Cholesterol esters either exist as intracellular droplets in the cell or are transported out of the cell and transferred to extracellular transporters such as APOE. The ATP binding cassette transporter A1 $(A B C A 1)$ is a regulator of this process. Increased levels of ABCA1 were shown to lower $A \beta$ levels and decreases of APOE lipidation were shown in mouse models to increase the levels of $A \beta$ plaques. This suggests that lipidation of APOE plays an important role in amyloidogenesis (Hirsch-Reinshagen et al. 2009). Cholesterol levels in membranes also affect the activity of secretases and therefore $A \beta$ production through the amyloidogenic processing of APP. Amyloidogenic processing of APP is concentrated in cholesterol and phospholipid rich membrane micro-domains described as lipid rafts. APP, BACE1 and $\gamma$ secretase are all associated with lipid rafts. Reducing levels of cholesterol in the membrane reduces the levels of BACE1 and $\gamma$-secretase which in turn reduces the levels of amyloid production (Di Paolo and Kim 2011). 
AD shares histopathological features and alterations in lipid metabolism with the rare neurodegenerative disease Niemann-Pick disease type C (NPC). NPC is an autosomal recessive disease caused by cholesterol and sphingolipid accumulation in the brain, liver and spleen resulting in hepatosplenomegaly and progressive and fatal neurodegeneration in childhood. The causative mutations in the genes $N P C 1$ or $N P C 2$ result in defective transport of free cholesterol in the cell and its accumulation in late endosomes or lysosomes (Ohgami et al. 2004). This prevents recycling of cholesterol to the endoplasmic reticulum (ER) or plasma membrane. A reduction of free cholesterol in the ER leads to an increase in cholesterol synthesis and a reduction in cholesterol esterification, further exacerbating the free cholesterol accumulation. Brain tissue from NPC patients contains distorted neurons and neurofibrillary tangles but does not show $\mathrm{A} \beta$ accumulation which is probably due to the young age of the patients (Walkley and Suzuki 2004). However, A $\beta$ accumulation was shown in NPC mouse brains and NPC model cells (Yamazaki et al 2001). Significantly, the intracellular aggregated $A \beta$ also accumulated in the late endosomes with the high levels of cholesterol characteristic of NPC cells (Yamazaki et al. 2001). Later studies showed that disruption of endocytic cholesterol trafficking affects APP processing and can increase A $\beta$ levels (Jin et al. 2004; Malnar et al. 2012). Therefore, studies in NPC have shown a clear link between $\mathrm{A} \beta$ metabolism and cholesterol levels, a phenomenon that also exists in AD.

\subsection{Objectives}

The objectives of this thesis are to explore the effects of a set of novel heparan sulphate oligosaccharide compounds on cholesterol metabolism in neurodegenerative diseases. The compounds were synthesised as non-coagulant potential BACE1 inhibitors and were obtained from Olga Zubkova of the Ferrier Research Institute, Victoria University of Wellington. First, I quantified the effects of these compounds on free cholesterol accumulation in fibroblasts derived from patients affected with Alzheimer's disease and NPC disease. Second, I assessed BACE1 inhibition by these compounds by measuring the levels of secreted amyloid beta and full length APP in a neuroblastoma cell line carrying the Swedish mutation that causes familial early onset Alzheimer's disease. 


\section{Research Chapter}

\subsection{Introduction}

The intracellular transport of cholesterol is critical to all eukaryotic cells, and when dysfunctional, disease can be the consequence. Notably, the presence of the E4 isoform of the lipid transporter APOE and hypercholesterolemia in middle age are risk factors for developing late onset sporadic Alzheimer's disease (Pappolla et al. 2003) which is the leading cause of dementia and the fifth leading cause of death in the over 65 age group in the United States (Alzheimer's_Association 2010). Lipid granule accumulation was one of the original observations made in AD neuronal tissue (Alzheimer et al. 1995; Foley 2010). Aggregation of amyloid $\beta(\mathrm{A} \beta)$ protein and the resulting formation of extracellular amyloid plaques, as well as intracellular tangles of hyperphosphorylated Tau protein, are believed to be pivotal in the development of the characteristic neuronal damage of AD. Moreover, the metabolism of amyloid precursor protein (APP) upstream of $A \beta$ metabolism is influenced by the relative levels of esterified and free unesterified cholesterol in neurons (Di Paolo and Kim 2011).

Lipid rafts are ordered subdomains of the plasma membrane rich in cholesterol and sphingolipid. Amyloidogenic A $\beta$ production occurs in lipid rafts where APP, BACE1 and $\gamma$ secretase, which are transmembrane proteins, all localise (Ehehalt et al. 2003). Endocytosis of APP is important in BACE1 production of $A \beta$ as the endosome is an optimal site for BACE1 activity. An increase in cholesterol in the membrane can reduce fluidity and increase endocytosis promoting $A \beta$ production. It can also increase $A \beta$ production by mediating the clustering of proteins in lipid rafts improving the accessibility of APP to BACE1 (Malnar et al. 2014).

Niemann-Pick type C (NPC) disease is also a fatal neurodegenerative disease caused by dysfunctional cholesterol metabolism and dysfunctional A $\beta$ metabolism. In NPC disease, mutations in $N P C 1$ or $N P C 2$, two genes coding for putative intracellular lipid transporters, result in accumulation of unesterified cholesterol and sphingolipids in the lysosome or late endosome (Ohgami, Ko et al. 2004). The downstream effects of this are a disruption of cholesterol recycling through the endoplasmic reticulum and plasma membrane, and an increase in cholesterol synthesis resulting in further cholesterol accumulation. NPC disease symptoms include progressive and fatal neurodegeneration, and hepatosplenomegaly with loss of life typically before adolescence. Similar to AD, the link between cholesterol and A $\beta$ 
accumulation exists in models of NPC disease. In humans affected with NPC disease, aggregated $\mathrm{A} \beta$ occurs in late endosomes in conjunction with accumulated cholesterol. Intriguingly, unlike human brains, the brains in murine models of NPC disease do not accumulate $A \beta$ with age yet do contain $A \beta$ aggregates (Yamazaki, Chang et al. 2001).

Heparan sulphate (HS) is a linear polysaccharide made up of repeating disaccharide subunits of modified $\mathrm{N}$-acetylglucosamine and glucuronic acid. It exists as the highly negatively charged sidechains of proteoglycan molecules in all mammalian cells. Heparan sulphate proteoglycans (HSPG) have numerous roles including involvement in cell adhesion, motility and cytoskeleton interactions, endocytosis, basement membrane organisation and extracellular presentation and storage of growth factors and cytokines. HSPG are essential to the transport of a number of macromolecules including lipoproteins into the cell through association with the LDL receptor related protein (LRP1) and also act as receptors (Bishop, Schuksz et al. 2007).

Heparin, a high molecular weight, highly sulphated analogue of heparan sulphate, is a direct inhibitor of BACE1 based on experiments in SH-SY5Y cells with the Swedish APP mutation that showed bovine lung heparin (BLH) and porcine mucosal heparan sulphate (PMHS) inhibited the production of the BACE1 cleavage product sAPP $\beta$ (Scholefield, Yates et al. 2003). The effects were dose-dependent and a 50\% reduction of sAPP $\beta$ peptide was achieved with $1 \mu \mathrm{g} / \mathrm{mL}$ BLH and $2 \mu \mathrm{g} / \mathrm{mL}$ PMHS, and there was also a decrease in A $\beta 42$ secretion. Specifically, BLH at a concentration of $12 \mu \mathrm{g} / \mathrm{mL}$ gave a $50 \%$ reduction in $\mathrm{A} \beta 42$ production. Similar decreases in A $\beta 40$ were observed with BLH and PMHS treatment.

Use of heparin therapeutically is problematic due to its potent anti-coagulant effects. Leading on from the above findings, heparin derivatives with significantly reduced anticoagulant effects but high BACE1 inhibition activity were investigated. Replacing $N$-acetyl groups with $\mathrm{N}$-sulphate groups on glucosamine residues and removal of specific 2-O and 6-O groups on uronic and glucosamine residues respectively were found to result in high BACE1 inhibition and very low anticoagulant activity in porcine intestinal mucosal heparin (PIMH) compared to unmodified PIMH (Patey et al. 2006). These modifications also reduced the inhibitory activity of the compound to pepsin, cathepsin D, and renin which are all aspartyl proteases structurally related to BACE1. Other studies of desulphated and chemically modified heparins showed that oligosaccharide structure as well as the degree of sulphation was important to BACE1 inhibition (Patey et al. 2008). 
The novel heparan sulphate compounds used in this study were synthesised at the Ferrier Research Institute, Victoria University of Wellington using recently developed and published methods (Schworer et al. 2013; Tyler et al. 2015). The compounds had a variety of structures including linear polysaccharides, and dimer and tetramer cores capped with a variety of heparan sulphate saccharides (glucosamine, glucuronic acid and iduronic acid). The compounds have a range of molecular weights from 1700 to 6700 with varying degrees of sulphation of the glucosamine residues (Figure 2.1, below).

Constitutional mutations in three genes, APP (amyloid precursor protein), PSEN1 (Presenilin-1) and PSEN2 (Presenilin-2) have been identified as the cause of familial early onset Alzheimer's disease (FAD). PSEN1 and PSEN2 code for catalytic sub-units of gamma secretase. Mutations in all three genes result in an increase in production of $A \beta$. Mutations in APP that cause FAD increase the production of A $\beta$ by changing the amino acid sequence at the site of BACE1 cleavage enhancing the action of the enzyme (Scheuner et al. 1996; Yan and Vassar 2014). A double mutation in APP, resulting in two amino acid substitutions (Lys670Asn, Met671Leu) adjacent to the BACE1 cleavage site, was identified in two large distantly related FAD families in Sweden (Mullan et al. 1992). It results in an increase in production and secretion of $A \beta 40$ and $A \beta 42$ (Johnston et al. 1994). According to the amyloid cascade hypothesis for Alzheimer's disease progression, an increase in production and secretion of aggregating amyloid beta or a decrease in clearance initiates amyloid deposition in the brain. The aggregation of $\mathrm{A} \beta 42$ oligomers into plaques and the associated inflammatory response is believed to lead to neuronal and synaptic disruption, neurofibrillary tangle formation, neuron dysfunction and death resulting in dementia (Haass and Selkoe 2007). Human cell lines and mouse models carrying FAD associated mutations have been used extensively in $\mathrm{AD}$ research.

Given that heparan sulphate oligosaccharides have potential therapeutic uses as they can mimic the natural biological functions of HS in the cell, and that there has been no investigation into the role of heparan sulphate in cholesterol metabolism in neurodegenerative disease, here I investigate a set of novel heparan sulphate compounds for their effects on the metabolism of cholesterol and APP in cell models of AD and NPC disease. To investigate A $\beta$ metabolism, I used an AD model neuroblastoma cell line (SH-SY5YswAPP) that carried the Swedish mutation and measured the effects of HS compounds on the levels of A $\beta 42$ and A $\beta 40$ as well the levels of full length APP protein. To investigate cholesterol metabolism, I 
measured the intracellular accumulation of unesterified cholesterol in fibroblast cells derived from patients with AD and NPC disease.

\subsection{Materials and methods}

\subsubsection{Compounds}

Twelve novel heparan sulphate oligosaccharide compounds were obtained from Dr Olga Zubkova, The Ferrier Research Institute of Victoria University of Wellington. The molecules have a variety of structures and molecular weights (Figure 2.1). Compounds were dissolved in sterile deionised $\mathrm{H}_{2} \mathrm{O}$ and stored at $-20^{\circ} \mathrm{C}$ (Schworer, Zubkova et al. 2013; Tyler et al. 2015).

\section{HS01 12-mer, dodeca sulphated}

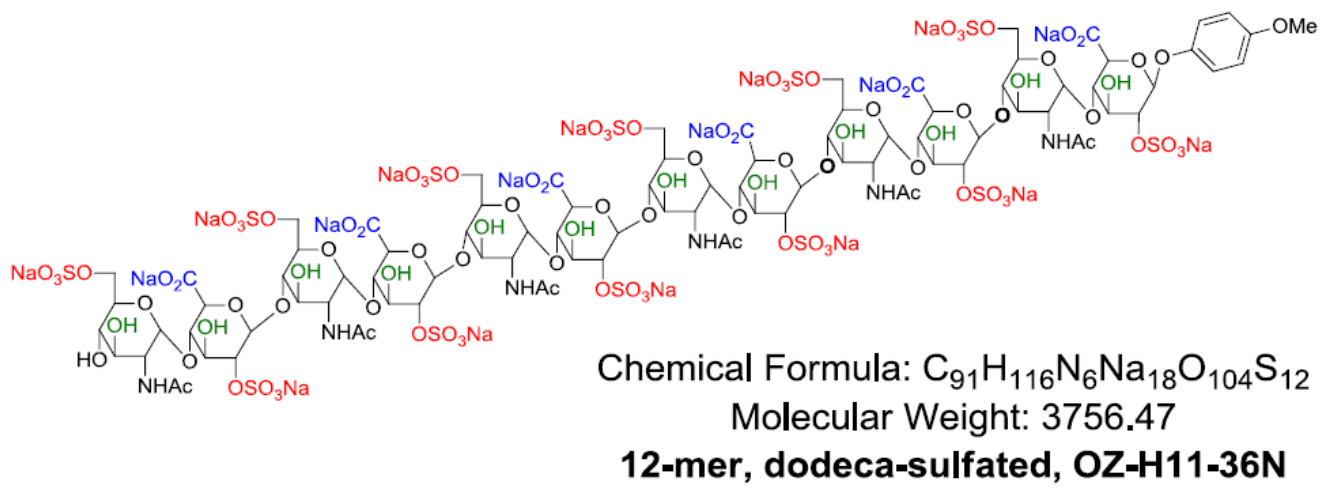

HS02 12mer, hexa-sulphated

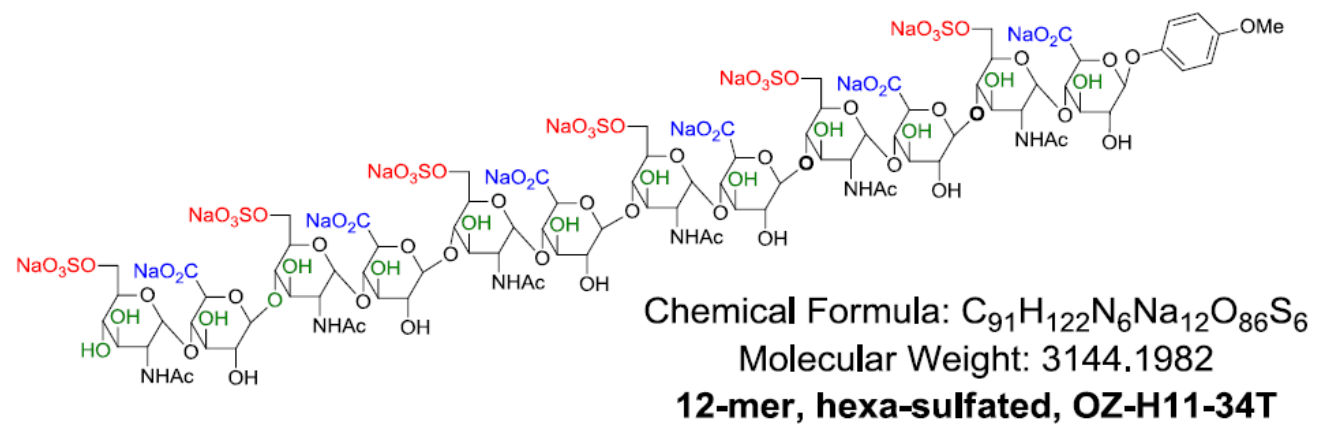


HS03 Short-armed tetramer with sulfated GIcNAcs attached

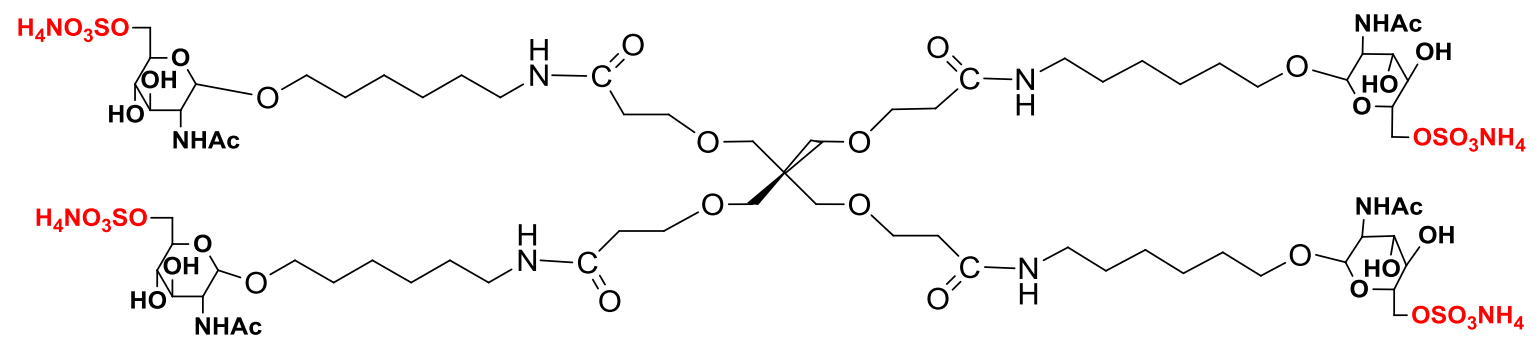

Chemical Formula: $\mathrm{C}_{73} \mathrm{H}_{144} \mathrm{~N}_{12} \mathrm{O}_{44} \mathrm{~S}_{4}$

Molecular Weight: 2022.24

OVZ/G10-079

HS04 Tetramer with disaccharides attached, tetra-sulfated

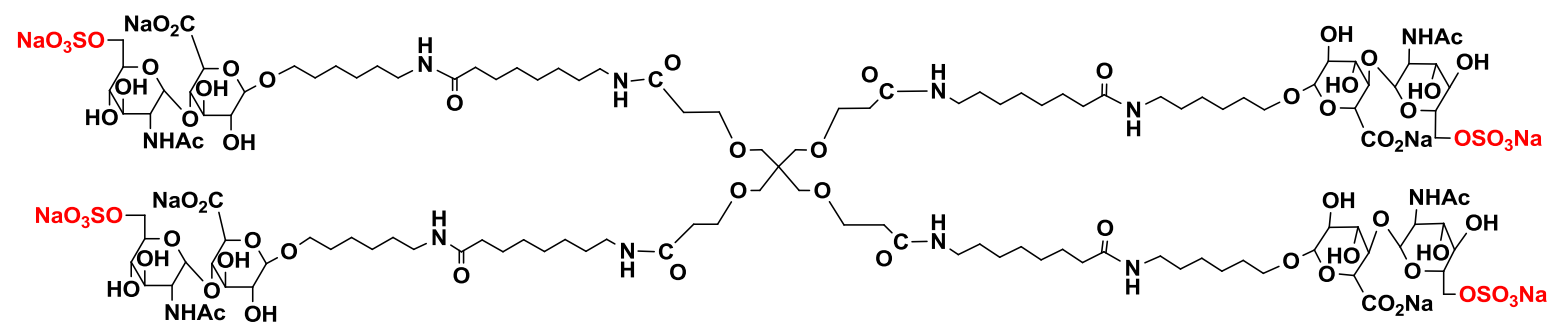

Chemical Formula: $\mathrm{C}_{129} \mathrm{H}_{216} \mathrm{~N}_{12} \mathrm{Na}_{8} \mathrm{O}_{72} \mathrm{~S}_{4}$

Molecular Weight: 3399.31

OVZ/G/11-04

HS05 Tetramer with disaccharides attached, octa-sulfated

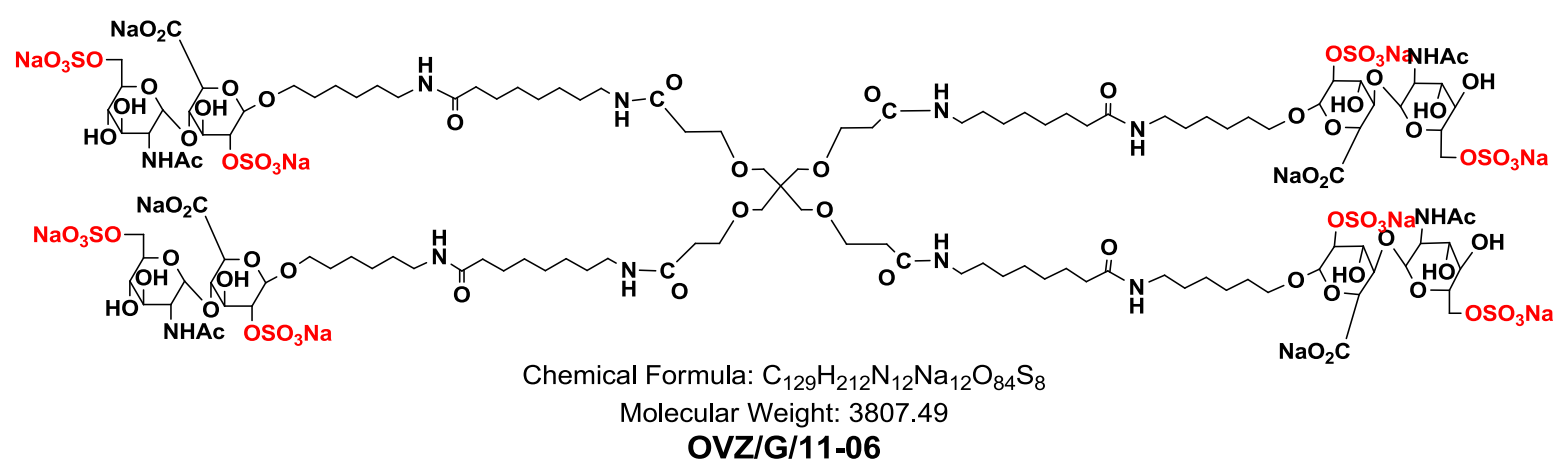




\section{HS06 Dimer with disaccharides, tetra-sulfated}

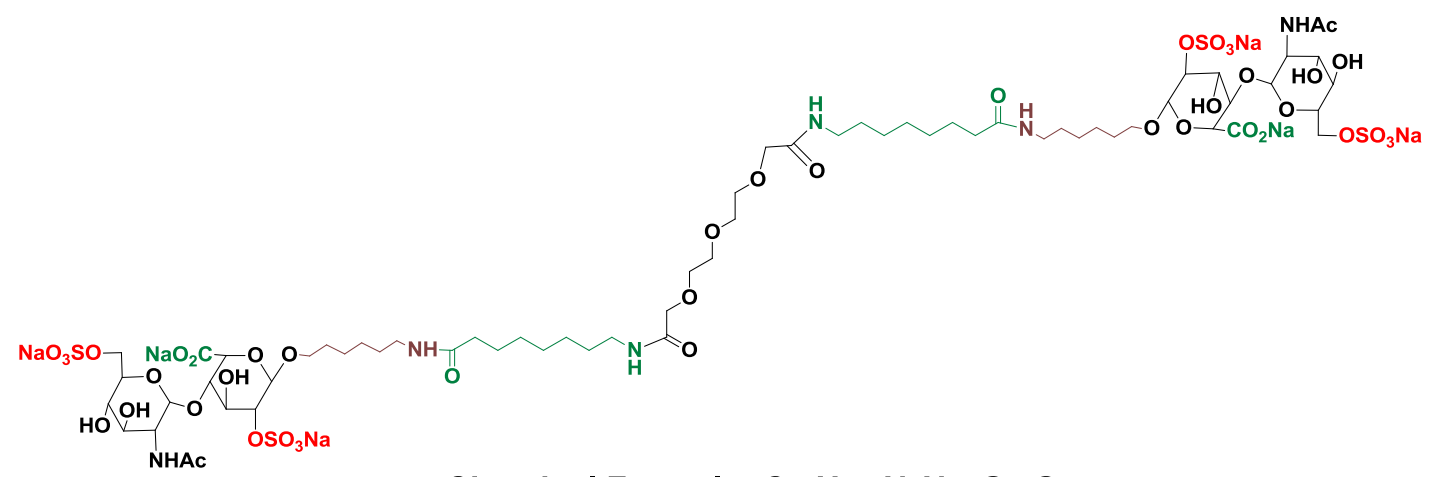

Chemical Formula: $\mathrm{C}_{64} \mathrm{H}_{106} \mathrm{~N}_{6} \mathrm{Na}_{6} \mathrm{O}_{43} \mathrm{~S}_{4}$

Molecular Weight: 1913.7395

OVZ/2012/G-41

HS07 Dimer with disaccharides, di-sulfated

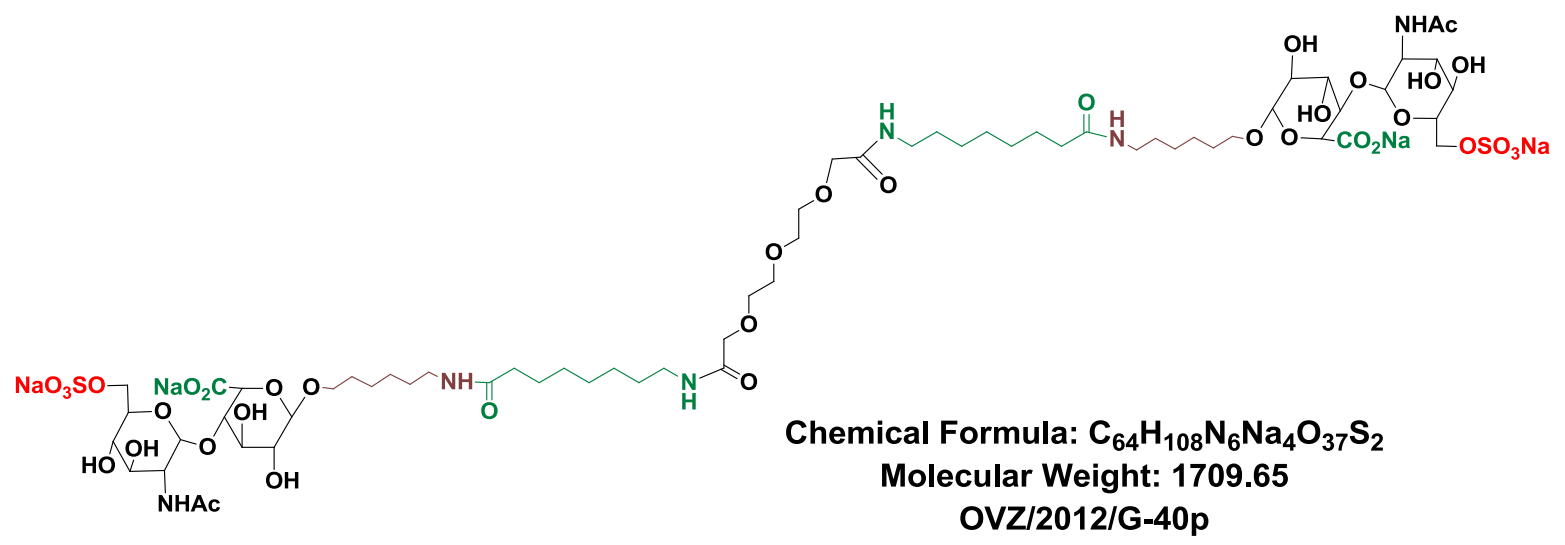

HS08 Tetramer with tetrasaccharides attached, octa-sulfated

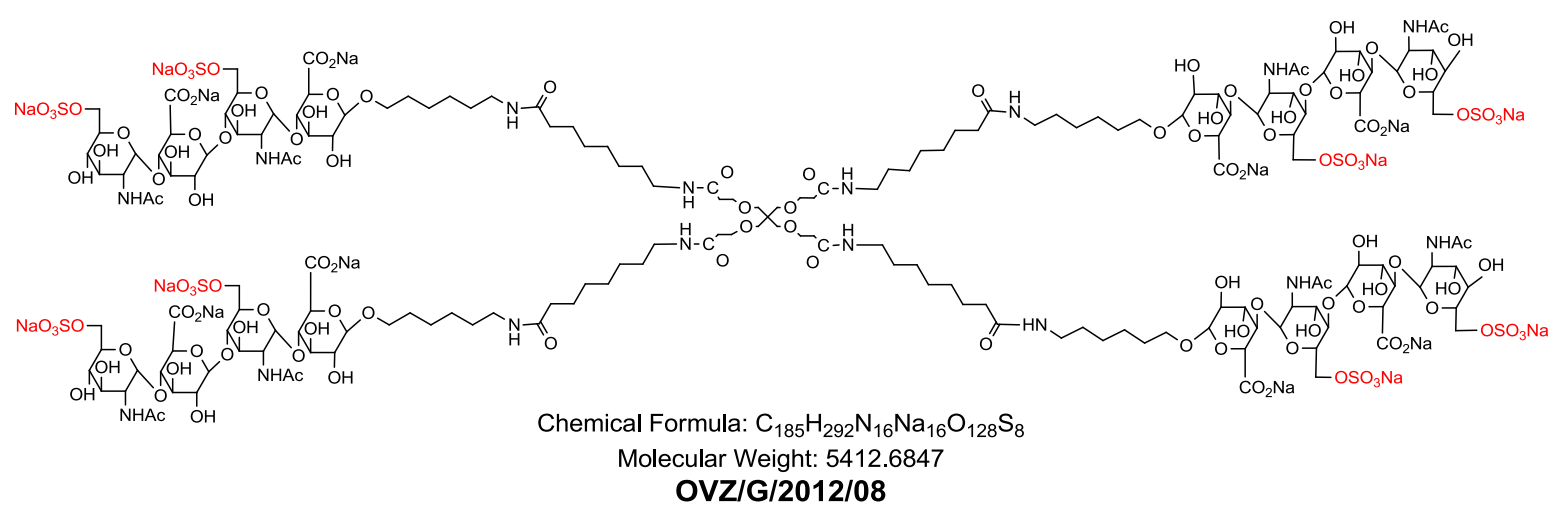




\section{HS09 Tetramer with tetrasaccharides attached, hexadeca-sulfated}

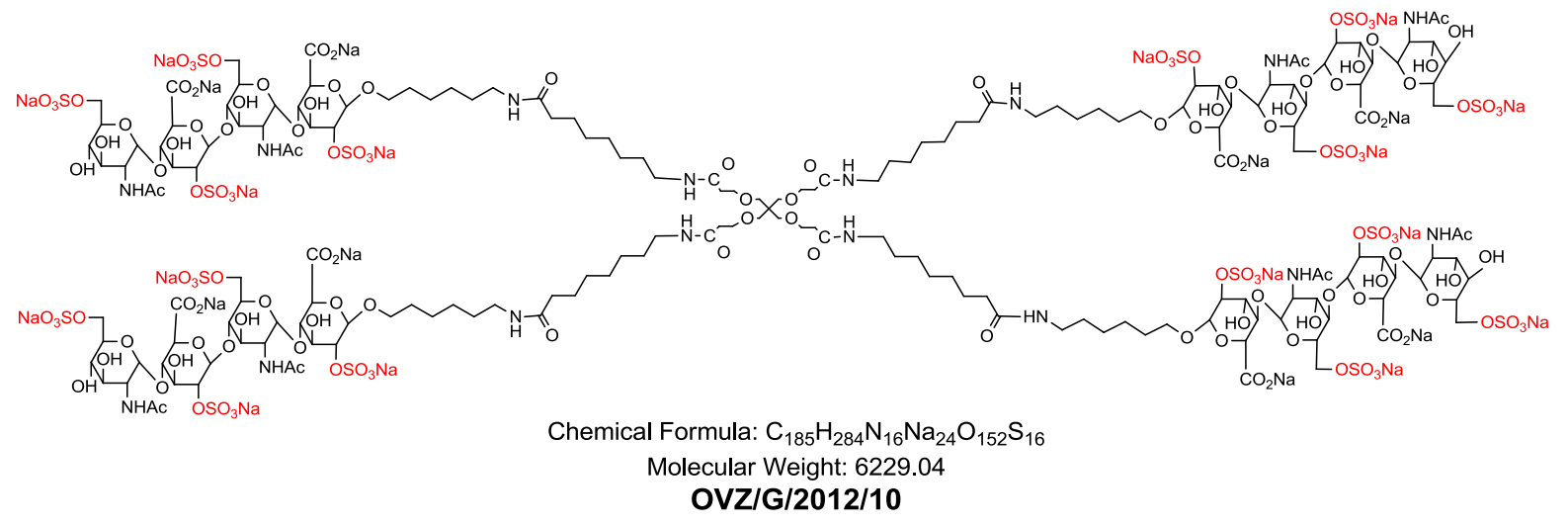

HS10 Tetramer with tetrasaccharides attached, hexadeca-O-sulfated, octa-Nsulfated

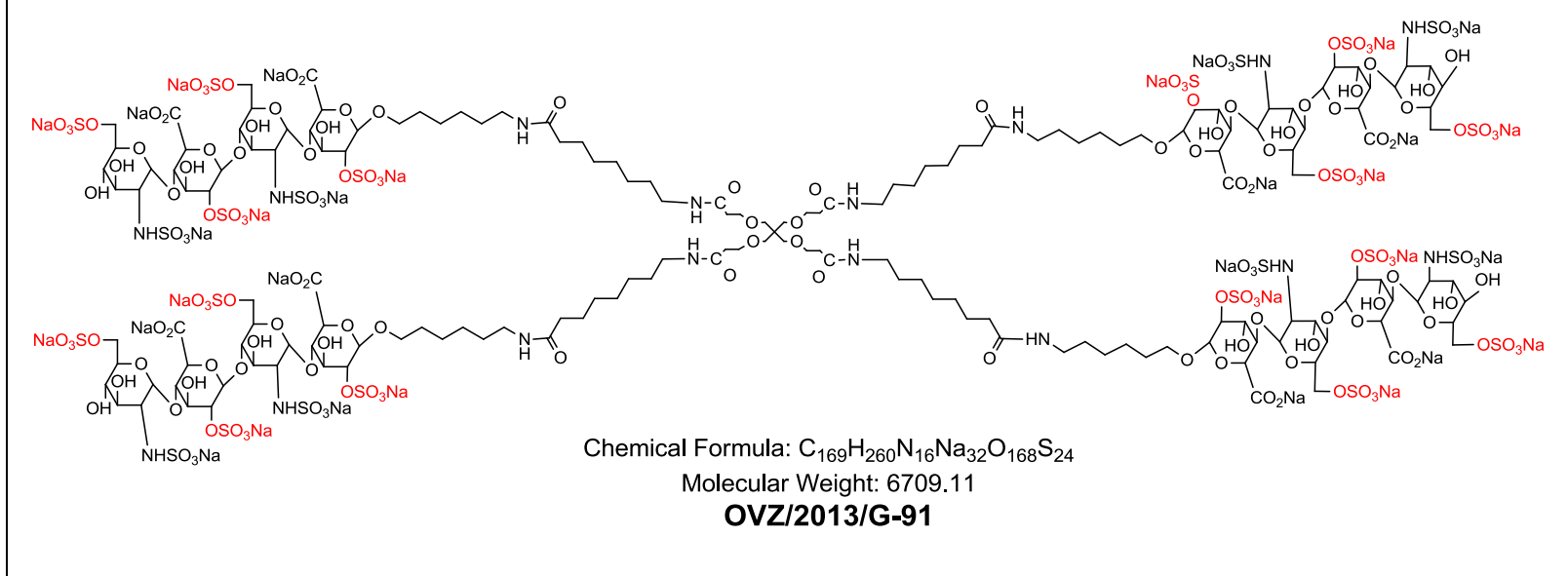

Figure 2.1 Novel heparan sulphate compounds used in this study. Compounds were obtained from Dr Olga Zubkova, The Ferrier Research Institute of Victoria University of Wellington. The structures for HS11 (a PET-PEG Tetramer) and HS12 (a PET Tetramer) are not presented as they are not yet patented.

\subsubsection{Cell lines and cell culture methods}

Skin fibroblast cell lines derived from Alzheimer and Niemann-Pick Type C (NPC) patients and healthy controls were obtained from the Corriell Institute for Medical Research (Camden, New Jersey, USA). The NPC fibroblast cell line is an established model for the 
disease as the biology in relation to intacellular cholesterol accumulation is the same as the brain and liver of NPC patients. Cell line GM03123 was derived from a 9 year old NPC patient with two heterozygous mutations in the NPC1 gene. Cell line GM09503 was used as a healthy control for the NPC cell line and was derived from a healthy 10 year old. Cell line ND41001 was derived from a 47 year old patient carrying a Presenilin 1 mutation with familial (early onset) Alzheimer's disease (AD). Cell line ND38530 from a 55 year old was used as a healthy control for the AD cell line. Further details of the cell lines are available at the Corriell Cell Repository website (https://catalog.coriell.org/). The neuroblastoma cell line SH-SY5YswAPP was obtained from Jerry Turnbull, University of Liverpool, United Kingdom. The cell line was not the identical SH-SY5YswAPP cell line used in his 2003 publication.

Cell culture work was carried out in sterile conditions in an Email Air Handling Class II Biological Safety Cabinet (AES Environmental Pty LTD, Australia). Fibroblast cell lines were cultured in DMEM (10313-021, Life Technologies) supplemented with 10\% fetal calf serum (Thermo Fisher Scientific), 1 x GlutaMAX ${ }^{\mathrm{TM}}$ Supplement (stabilised L-glutamine, Gibco Life Technologies), 100 units/mL penicillin and 100 units/mL streptomycin (Life Technologies). SH-SY5YswAPP cells were cultured in RPMI media (11875-093, Life Technologies) supplemented with $10 \%$ fetal calf serum (FCS) (Thermo Fisher Scientific), 100 units/mL penicillin and 100 units/mL streptomycin (Life Technologies).

Cell lines were maintained in 25 or $75 \mathrm{~cm}^{2}$ flasks (Corning, Invitro Technologies) in a humidified incubator (Sanyo Electric Co. Ltd) at $37^{\circ} \mathrm{C}$ and $5 \% \mathrm{CO}_{2}$. Cells were passaged twice a week. Cells were removed from the flask surface by treating with trypsin $(0.05 \%)$ ethylene-diamine tetraacetic acid (EDTA, $0.53 \mathrm{mM}$ ) (Gibco-BRL, Life Technologies) for 3 min at $37^{\circ} \mathrm{C}$. The trypsin was inactivated with growth media and the cells were spun at $300 \mathrm{~g}$ for five minutes. Cells were then resuspended in fresh media for growth in a new flask. Stock cultures were stored in liquid nitrogen in 90\% FCS/10\% dimethyl sulfoxide (DMSO). Experimental cultures were carried out in the growth media omitting the antibiotics to avoid any potential interaction with the compound being tested or other metabolic effects.

For unesterifed free cholesterol quantitation experiments, fibroblast cells were seeded at a density of $1.25 \times 10^{4}$ cells $/ \mathrm{mL}$ in black, 96 well plates (Cell-carrier, Perkin Elmer) in a volume of $100 \mu \mathrm{L}$ media and grown for 24 hours before treating. The media was then replaced with fresh media supplemented with the required treatment. Cell lines GM03123 
and ND41001 were either left untreated, or treated with either $10 \mathrm{mM}$ or $100 \mathrm{mM}$ of the heparan sulphate compound dissolved in sterile deionised water $\left(\mathrm{dH}_{2} 0\right), 10 \mathrm{mM}$ suberoylanilide hydroxamic acid (SAHA) dissolved in DMSO, or 0.1\% DMSO (as a carrier control for SAHA treatment). The healthy control cell lines GM09503 and ND38530 were left untreated or treated with U18666A dissolved in sterile $\mathrm{dH}_{2} \mathrm{O}$ at a final concentration of $1 \mu \mathrm{g} / \mathrm{mL}$. SAHA (LC Laboratories) is a global histone deacetylase inhibitor which is able to significantly reduce the accumulation of cholesterol in lysosomes of NPC fibroblasts (Munkacsi et al. 2011). U18666A (Sigma Aldrich) is an amphiphathic steroid which can inhibit cholesterol trafficking in the cell and therefore mimic the NPC phenotype of cholesterol build up in lysosomes (Cenedella 2009). Cells were then grown for 48 hours.

For amyloid beta ELISA and APP western blot experiments, SH-SY5YswAPP cells were grown in either 6 well or 96 well plates. Cells were seeded at $2 \times 10^{6}$ cells per well in a 6 well plate or $0.3 \times 10^{6}$ cells per well in a 96 well plate and then grown for 2 days or (approximately 50\% confluency) before treatments. Then the media was replaced with media containing the compound of interest and grown for the required length of time before media was removed for measurement of amyloid beta levels. Media samples were frozen at $-80^{\circ} \mathrm{C}$ with added 1 x HALT protease inhibitor (Thermo Fisher Scientific) to prevent protein degradation. Cell lysate preparation is detailed below (Section 2.2.6 below).

Heparin is a highly sulphated analogue of heparan sulphate and is used as an injectable anti-coagulant in vivo and in vitro (Lever and Page 2002). Heparin has been shown to be a direct inhibitor of BACE1 (Scholefield, Yates et al. 2003) and is therefore used as positive control for BACE1 inhibition in this study. I used heparin sodium salt from bovine intestinal mucosa (Sigma Aldrich, catalog no. H0777) and heparin sodium salt from porcine intestinal mucosa (Sigma Aldrich, catalog no. H3393).

\subsubsection{Filipin staining of free cholesterol in fixed cells}

Filipin stock solutions (Sigma Aldrich, cat no. F9765) were prepared in DMSO at a concentration of $25 \mathrm{mg} / \mathrm{mL}$ and stored at $-20^{\circ} \mathrm{C}$ in $20 \mathrm{uL}$ aliquots in black, light resistant tubes. Aliquots were thawed once and used or discarded. Fluorescence of filipin was observed in UV light at an excitation of $360 \mathrm{~nm}$ and emission of $480 \mathrm{~nm}$. The cells were grown in 96 well plates as described above. Before fixing, the cells were washed three times with $1 \mathrm{x}$ phosphate buffered saline (PBS). From this point all treatments and washes were 
undertaken on a rotating table at 45 revs per minute. Cells were fixed with $1.5 \%$ paraformaldehyde in 1x PBS (Thermo Fisher Scientific New Zealand) for 20 minutes. Cells were then washed with 1x PBS for four minutes. This was repeated twice. The cells were then stained for 2 hours with $50 \mu \mathrm{g} / \mathrm{mL}$ filipin dye protected from the light. With minimal light exposure, the cells were washed with 1x PBS for four minutes and this was repeated twice. Cells were left in 1x PBS for immediate visualization using confocal microscopy. Filipin stained cells were imaged using a Perkin Elmer Opera ${ }^{\mathrm{TM}}$ high-throughput spinning disk confocal microscope using $405 \mathrm{~nm}$ laser and 20X water immersion objective with 5 second exposures.

\subsubsection{Relative quantitation of free cholesterol in cultured cells using confocal microscopy}

Filipin fluorescnce was quantified using Perkin Elmer Acapella ${ }^{\mathrm{TM}}$ software. In NPC cells, cholesterol accumulates in organelles with the characteristics of late endosomes or early lysosomes. These can be described as lysosome-like storage organelles (LSO). Analysis of free cholesterol levels in the cells was carried out using a method designed for high throughput confocal images described by Pipalia et al (Pipalia et al. 2006). A low fluorescence threshold was chosen which identified the total area occupied by cells and another higher threshold was chosen to determine the areas of bright filipin staining of cholesterol within an untreated cell. These regions were generally perinuclear.

The lysosome-like storage organelle (LSO) ratio was defined as:

LSO ratio $=$ total intensity above high threshold / number of pixels above low threshold

Percent LSO (\%LSO) values were defined as:

\section{LSO ratio (treated)/ LSO ratio (untreated) X 100}

Two wells in a 96 well plate were used for each treatment. Ten different microscope views from each well were imaged. The LSO ratio for each image was determined using a script written by Dr Peter Bircham using Perkin Elmer Acapella ${ }^{\mathrm{TM}}$ software (Appendix A). The average LSO ratio and standard error of 20 views was determined for each treatment. Statistical significance was determined by comparing LSO data for each treatment $(n=20)$ 
compared to untreated $(\mathrm{n}=20)$ using a two-tailed student's T-test. A p-value $\leq 0.05$ was considered statistically significant.

\subsubsection{Enzyme-linked immunosorbent assay (ELISA) for A $\beta 40$ and $A \beta 42$}

A solid phase sandwich ELISA method was used to determine the levels of A $\beta 40$ and $A \beta 42$ in cell culture media (Human $A \beta 40$ and $A \beta 42$ ELISA kits, Invitrogen). The assay was carried out following the manufacturer's protocol and is described briefly here. The kit utilises a monoclonal antibody specific to the $\mathrm{NH}_{2}$ terminus of human $\mathrm{A} \beta$ molecule which is coated to the wells of microtitre strips. Media samples, standards of known concentration and controls were incubated in the plate with a rabbit antibody specific to the $\mathrm{COOH}$ terminus of $\mathrm{A} \beta 40$ or $\mathrm{A} \beta 42$. After an overnight, $4^{\circ} \mathrm{C}$ incubation and washes, the bound rabbit antibody was detected by an anti-rabbit, horse radish peroxidase (HRP) labelled antibody. After an additional incubation and washes to remove unbound HRP, a stabilized chromogen which is a substrate for the HRP was added. The bound enzyme acts on the chromogen to produce a blue colour which is directly proportional to the amount of the specific A $\beta$ present. A stop solution was added to stop the enzymatic reaction causing a colour change from blue to yellow. The absorbance was measured at 450nm on a Perkin Elmer Enspire 2300 Multi Label plate reader (Perkin Elmer) and sample concentrations were determined from a standard curve. $\mathrm{A} \beta$ levels were normalised to total protein in the media measured by a BCA (bicinchoninic acid) assay using a Pierce ${ }^{\mathrm{TM}}$ BCA Protein Assay Kit (Thermo Fisher Scientific) following the manufacturer's instructions. Normalised $A \beta$ levels were represented relative to $A \beta$ levels in untreated cells.

\subsubsection{Western blot analysis of amyloid precursor protein (APP)}

Cell lysates were prepared by first washing cells with cold $1 \mathrm{x}$ PBS and then incubating with cold RIPA buffer (Sigma Aldrich, cat no. R0278) with protease inhibitors (Roche Complete ULTRA Tablets, product number 05892791001) on ice for five minutes. Cells were removed from the plate surface with a cell scraper and transferred to a $1.5 \mathrm{~mL}$ tube on ice. After 30 minutes on ice, with brief vortexing at 5 minute intervals, the lysate was centrifuged for 30 minutes at $16000 \times g$ at $4{ }^{\circ} \mathrm{C}$. The cell lysate (supernatant) was collected to a fresh tube and stored at $-20^{\circ} \mathrm{C}$. Total protein concentration was determined using a Pierce ${ }^{\mathrm{TM}}$ BCA (bicinchoninic acid) protein assay kit (Thermo Scientific 23225/23227) using the manufacturer's protocol. 
Cell lysates were prepared for western blot analysis by dilution with RIPA buffer at a final concentration of $10 \% \beta$-mercaptoethanol and 1x SDS loading buffer. After incubation at $37^{\circ} \mathrm{C}$ for 10 minutes, samples were loaded on a $10 \%$ denaturing polyacrylamide gel in $1 \mathrm{x}$ SDS running buffer using the Bio-Rad Mini Trans-Blot system. Proteins standards were also loaded (Precision plus protein dual colour standards, Bio-Rad \#161-0374). Proteins were transferred at room temperature to a PVDF (Polyvinylidene difluoride) membrane with a pore size of $0.2 \mu \mathrm{m}$ (Bio-Rad, cat no. 162-0177) at $40 \mathrm{~V}$ for 2 hours and 15 minutes using $1 \mathrm{x}$ transfer buffer and an ice block in the transfer tank. All remaining steps were carried out at $4^{\circ} \mathrm{C}$. The membrane was blocked with $3 \%$ BSA (bovine serum albumin) in PBST (Phosphate buffered saline, $0.1 \%$ Tween 20) for 1 hour, followed by incubation overnight with an APP antibody (1:1000, Rabbit anti- $\beta$-amyloid precursor protein, Invitrogen) in 3\% BSA in PBST. The membrane was then washed five times with PBST (five minutes each) and incubated with a secondary Cy5 dye labelled anti-rabbit antibody (1:1000, ECL Plex goat-anti-rabbit IgG, Cy5 PA 45012, GE Healthcare) for 1.5 hours in 1\% BSA in PBST, followed by three PBST washes and three PBS washes (five minutes each). The membrane was then probed with a mouse antibody for $\beta$-actin (1:1000, A2228-Sigma) in PBST 1\% BSA for 1.5 hours, and washed three times in PBST. The membrane was finally probed with a secondary Cy5 dye labelled anti-mouse antibody (1:1000, ECL Plex goat-anti-rabbit IgG, Cy5 PA 45012, GE Healthcare) followed by two PBST washes and one PBS wash (ten minutes each). The membranes were scanned using a Fujifilm FLA-5100 imaging system to detect fluorescent bands. Band densities were quantified using ImageJ software (NIH). APP bands were normalised to $\beta$-actin. Details of solution preparation are in Appendix B.

\subsection{Results}

\subsubsection{Novel heparan sulphate compounds reduce cholesterol levels in cells derived from patients with Niemann-Pick type $\mathrm{C}$ disease and Alzheimer's disease}

The clinical diagnosis of NPC disease includes the use of filipin, a fluorescent stain that binds free unesterified cholesterol. It is used clinically to demonstrate the lysosomal accumulation of unesterified cholesterol in fibroblasts cultured from patient skin biopsies (Patterson et al. 2012). Elevated levels of cholesterol ester have also been demonstrated by filipin staining in cultured fibroblasts from AD patients (Pani et al. 2009). My lab had previously used filipin to stain ergosterol in yeast cell membranes and the useful storage life 
of filipin solutions was established as 1-2 months for effective fluorescence. However, I determined that that the useful storage life of filipin in solution for staining of mammalian cells was only two weeks.

Initial attempts at imaging filipin stained cells in this study were carried out on a standard inverted fluorescence microscope. The degree of photo-bleaching that occurs with UV light exposure was a significant problem. Without a neutral density filter to attenuate the incidental light, it was very difficult to obtain good quality images with consistently high levels of fluorescence. This prevented any accurate quantitative assessment of cholesterol staining. For this reason, my presented results were obtained used a spinning disk confocal microscope which minimises photo-bleaching and allows acquisition of multiple images for quantitation.

To determine the effects of novel heparan sulphate compounds on the accumulation of unesterified cholesterol in NPC and AD model cell lines, patient derived fibroblast cells were grown for 24 hours and then treated for 48 hours with ten HS compounds (HS03-HS12) at two concentrations $(10 \mu \mathrm{M}$ and $100 \mu \mathrm{M})$ before fixing and staining with filipin. HS01 and HS02 were not available at this stage of the study. The cell lines were GM03123 (NPC) and GM09503 (NPC control), and ND41001 (AD) and ND38530 (AD control). By visual inspection, none of the compounds had any toxic or growth inhibitory effects at $10 \mu \mathrm{M}$ or $100 \mu \mathrm{M}$. Confocal microscopy images of untreated NPC (GM03123) and AD (ND41001) fibroblasts showed a distinctive perinuclear pattern of cholesterol staining (Figure 2.2, Figure 2.6). The perinuclear cholesterol staining was also present in untreated healthy control cells but at a much lower intensity and with a more diffuse pattern (Figure 2.2, Figure 2.6).

In NPC patients, cholesterol accumulates in organelles with the characteristics of late endosomes or early lysosomes, and these can be described as lysosome-like storage organelles (LSO) (Pipalia, Huang et al. 2006). Here I analysed NPC and AD cells for free cholesterol levels using an automated image analysis designed for high throughput confocal images (Pipalia, Huang et al. 2006). A low fluorescence threshold was chosen which identified the total area occupied by cells and another higher threshold was chosen to determine the areas of bright filipin staining of cholesterol within an untreated cell. The LSO ratio was calculated as the total fluorescent intensity of all pixels above the high threshold relative to the total number of pixels above the low threshold. 
As would be expected due to the severity of cholesterol accumulation in NPC disease, the staining was more intense in NPC cells where the average LSO ratio was 58.1 compared to 32.3 for AD cells. In comparison, the average LSO ratios for the untreated control cell lines were 11.7 (GM09503) and 19.2 (ND38530) (Figure 2.2, Figure 2.6). This was in contrast to control cells treated with $1 \mu \mathrm{g} / \mathrm{mL} \mathrm{U18666A}$, an inhibitor of cholesterol transport that mimics NPC disease (Cenedella 2009), and thus a positive control for filipin staining. Images of U18666A treated cells showed more intense staining than the NPC cell lines (Figure 2.3,

Figure 2.7). The average LSO ratio for U18666A treated cells was 76.8 (GM09503) and 176 (ND38530) (data not shown in Figure 2.2 and Figure 2.6). As an indicator of therapeutic potential, cells were also treated with SAHA (suberoylanilide hydroxamic acid), a global histone deacetylase inhibitor that dramatically reduces the levels of lysosomal cholesterol in NPC fibroblast cell lines (Munkacsi, Chen et al. 2011). The percent LSO value after treatment with $10 \mu \mathrm{M}$ SAHA was $43 \%$ and $42 \%$ in NPC and AD fibroblasts, respectively.

In the NPC cell line GM03123, seven of the ten heparan sulphate compounds tested decreased the accumulation of unesterifed cholesterol with statistical significance $(\mathrm{P} \leqslant 0.05)$ at either $10 \mu \mathrm{M}, 100 \mu \mathrm{M}$ or both concentrations. These compounds were HS06, HS07, HS08, HS09, HS10, HS11 and HS12. Cholesterol levels relative to the untreated control (LSO \%) for these seven compounds range from 56.6 to 82.8 (Figure 2.2). Representative images of all treatments of the NPC cell line and control are shown in Figure 2.3, Figure 2.4 and Figure 2.5. The compounds HS06, HS11 and HS12 reduced cholesterol levels at two concentrations, $10 \mu \mathrm{M}$ and $100 \mu \mathrm{M}$. For HS11 and HS12, cholesterol was reduced further with the higher $100 \mu \mathrm{M}$ treatment. In contrast, compound HS09 reduced cholesterol the most of all ten compounds (LSO \% 57.4, p-value $=0.0001$ ) at a concentration of $10 \mu \mathrm{M}$ but at a higher concentration, $100 \mu \mathrm{M}$ had no effect (LSO \% 100). Overall, reductions in cholesterol accumulation by $17-43 \%$ indicate that the HS compounds regulate, to varying degrees, the intracellular cholesterol transport in NPC disease.

In the fibroblasts derived from a patient with Alzheimer's disease (ND41001), seven of the ten heparan sulphate compounds tested were shown to decrease the accumulation of unesterifed cholesterol with statistical significance at either $10 \mu \mathrm{M}, 100 \mu \mathrm{M}$ or both concentrations (Figure 2.6). There was a distinct overlap between compounds that were 
effective in both the NPC and the Alzheimer cell lines. Compounds HS06, HS08, HS09, HS10, HS11 and HS12 were effective in one or both concentrations in both the AD and NPC cells. In addition, HS03 was effective at $10 \mu \mathrm{M}$ but not $100 \mu \mathrm{M}$. Cholesterol levels relative to the untreated control (LSO \%) for these seven compounds range from 55.3 to 78.0. Representative images of the treated Alzheimer cell line and control are shown in

Figure 2.7, Figure 2.8 and Figure 2.9. Overall, reductions in cholesterol accumulation by $22-47 \%$ indicate that the HS compounds regulate, to varying degrees, the intracellular cholesterol transport in AD.

Intriguingly, compounds HS06, HS08, HS09, HS10, HS11 and HS12 were effective in reducing cholesterol in both AD and NPC cell lines. They share a tetramer structure with more highly sulphated sugar residues than the other compounds tested. HS08 contains eight sulphated residues, HS09 and HS10 contain 16 sulphated residues. Further details of HS11 and HS12 cannot be presented as they are not yet patented. HS06, which is also effective in both cell lines, is a simpler dimer structure with only four sulphate residues but also two carboxyl groups. These results suggest that compounds with higher molecular weights and higher degrees of negatively charged side groups may in general be more able to mimic biological HS. 


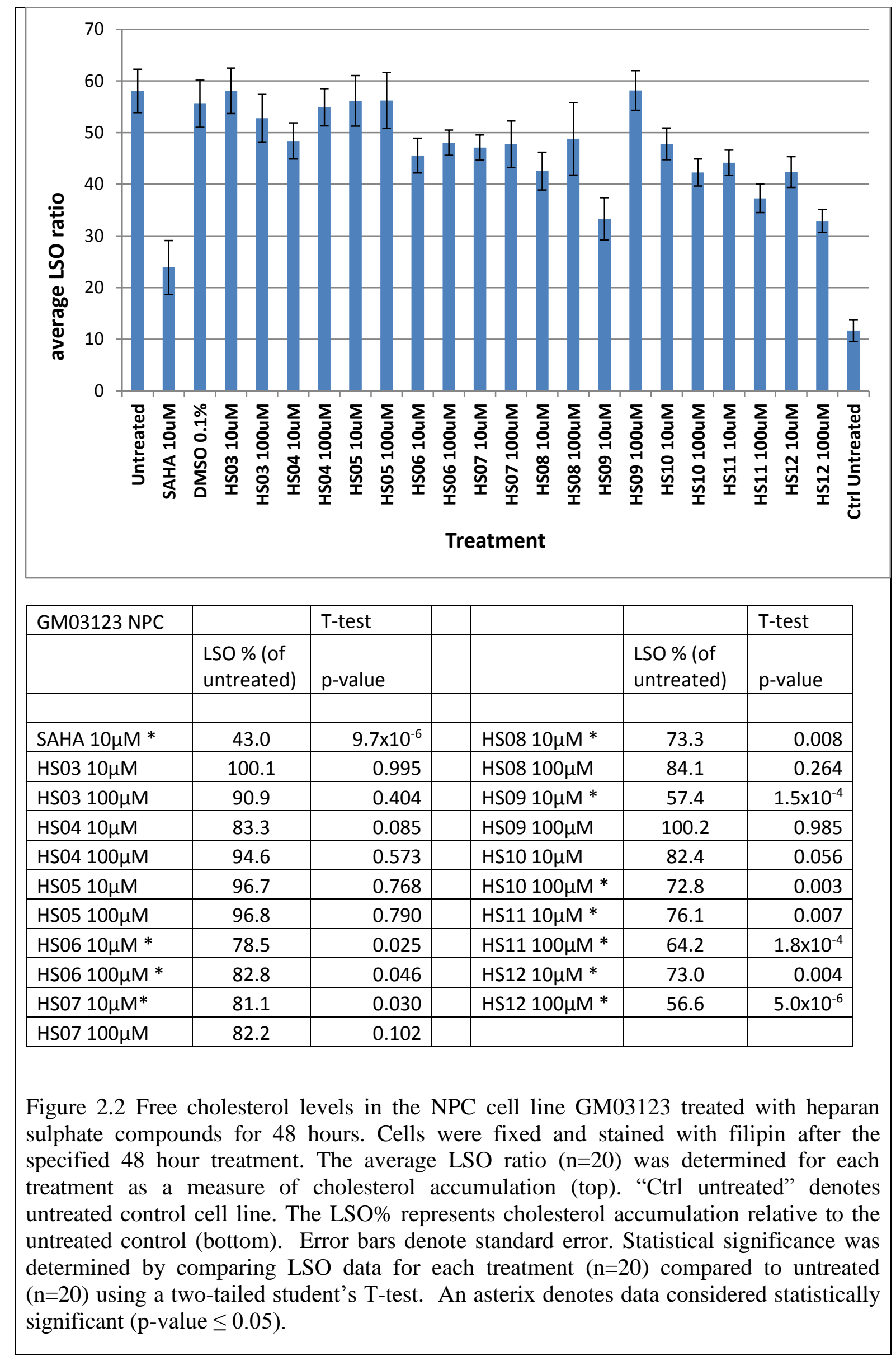



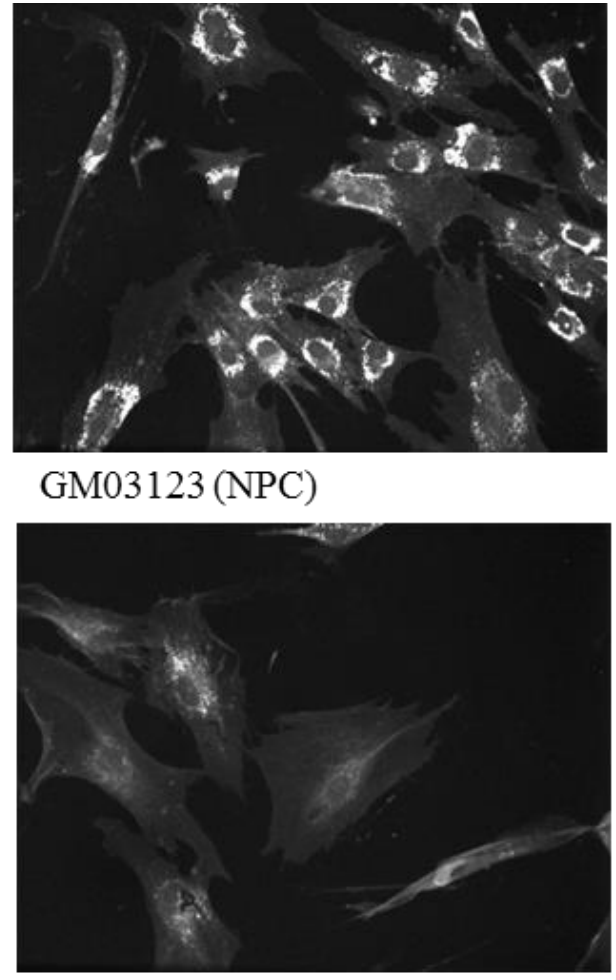

GM03123 SAHA $10 \mu \mathrm{M}$

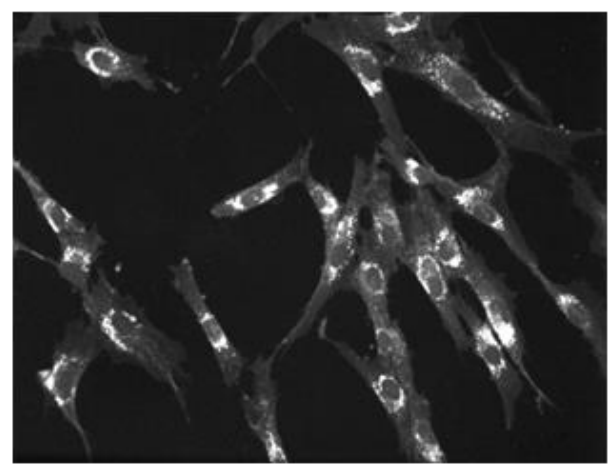

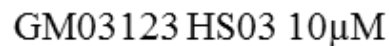

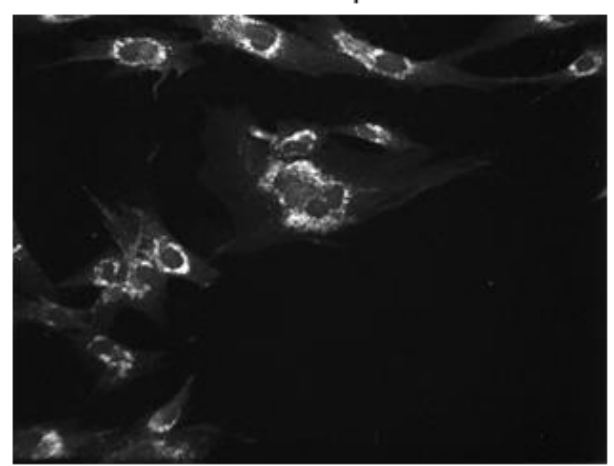

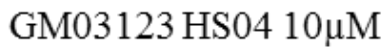

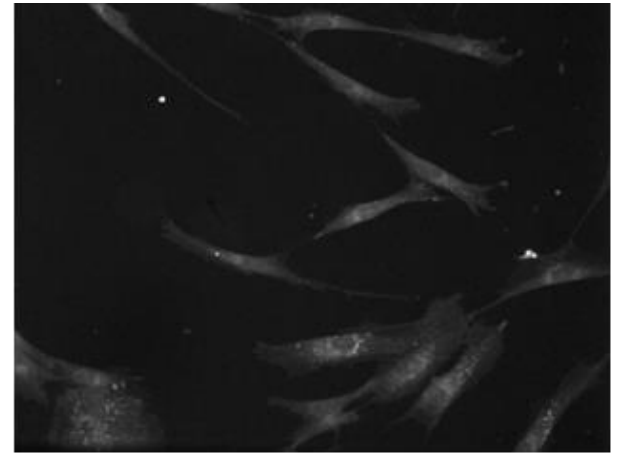

GM09503 (Control)

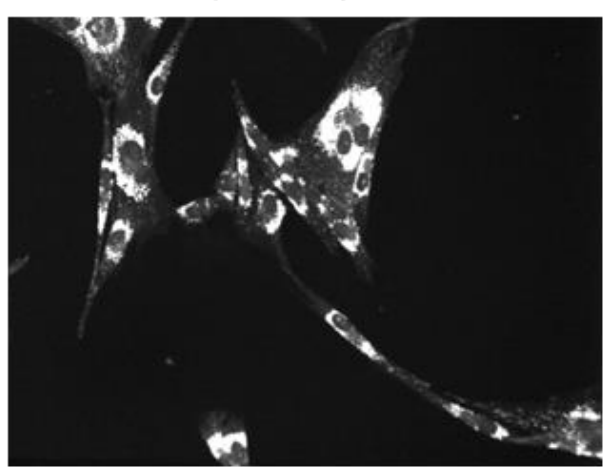

GM09503 U18666A $1 \mu \mathrm{g} / \mathrm{mL}$

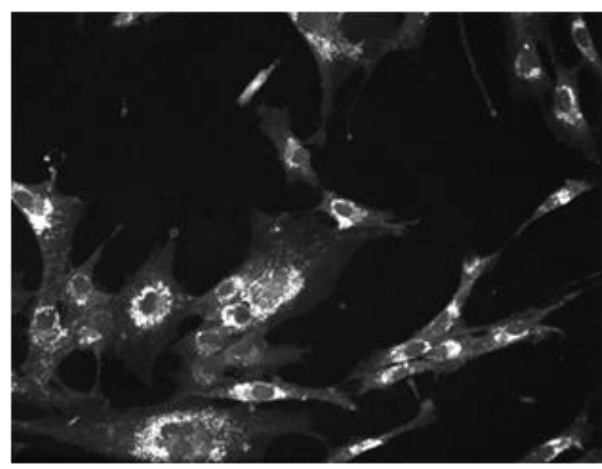

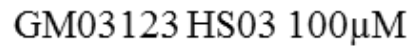

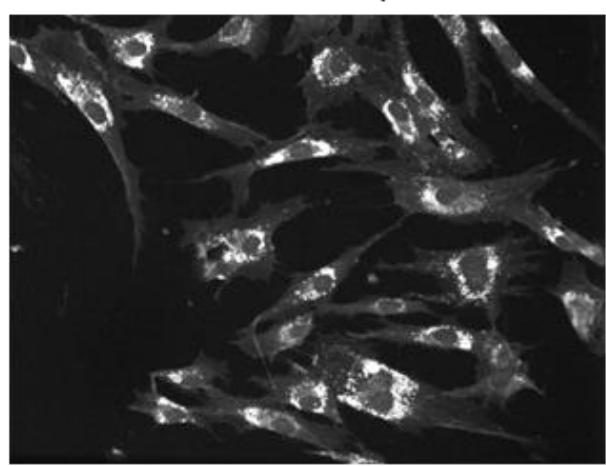

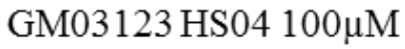

Figure 2.3 Confocal microscopy images of filipin stained free cholesterol in NPC (GM03123) and control (GM09503) patient derived fibroblast cell lines. Cells were treated for 48 hours as indicated, before fixing and staining for quantitation of relative cholesterol levels. 


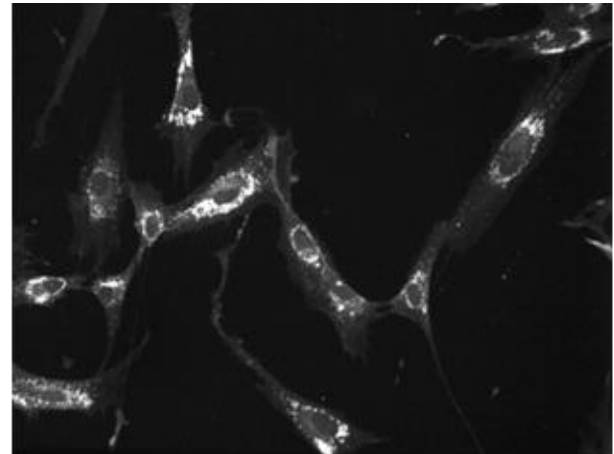

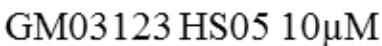

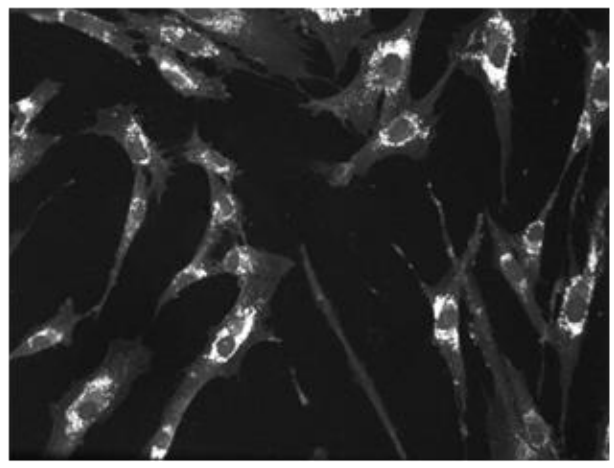

GM03123 HS06 10 $\mu \mathrm{M}$

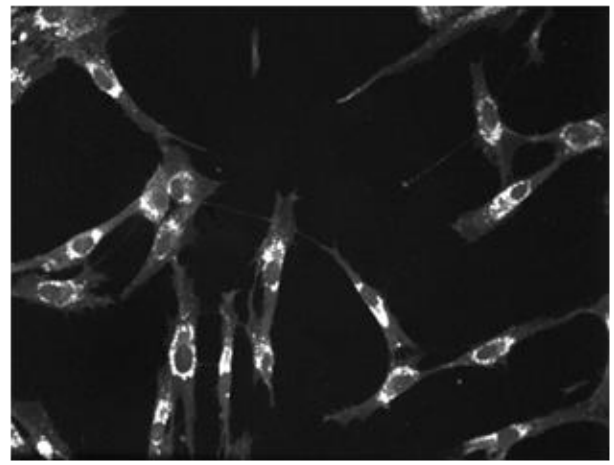

GM03123 HS07 10 $\mu \mathrm{M}$

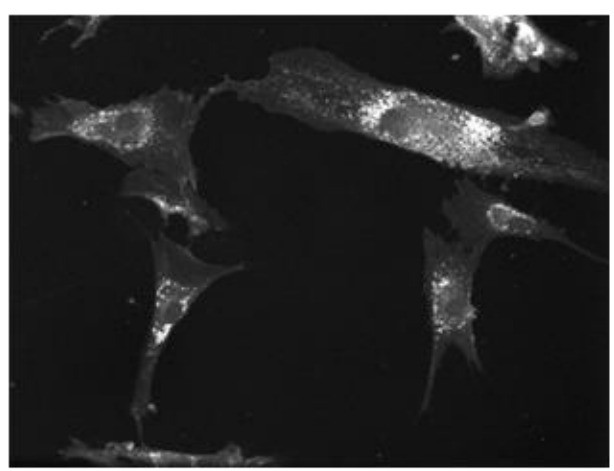

GM03123 HS08 10 $\mu \mathrm{M}$

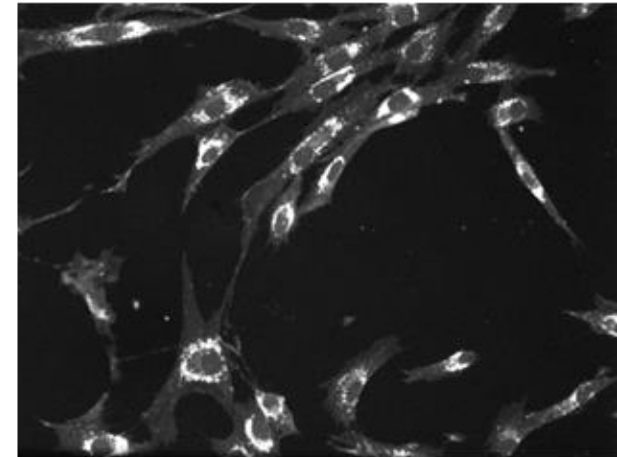

GM03123 HS05 $100 \mu \mathrm{M}$

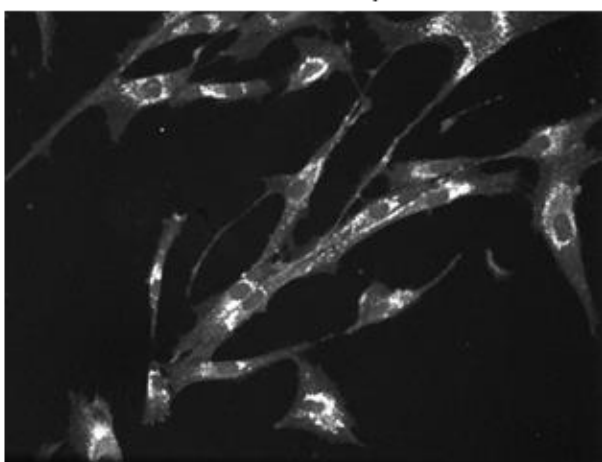

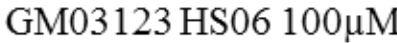

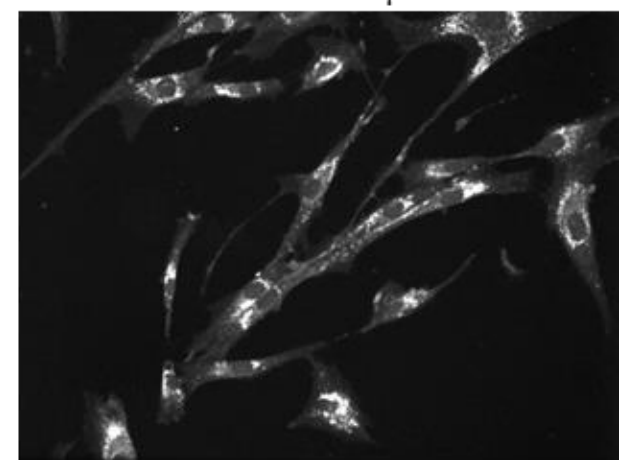

GM03123 HS07 100 $\mu \mathrm{M}$

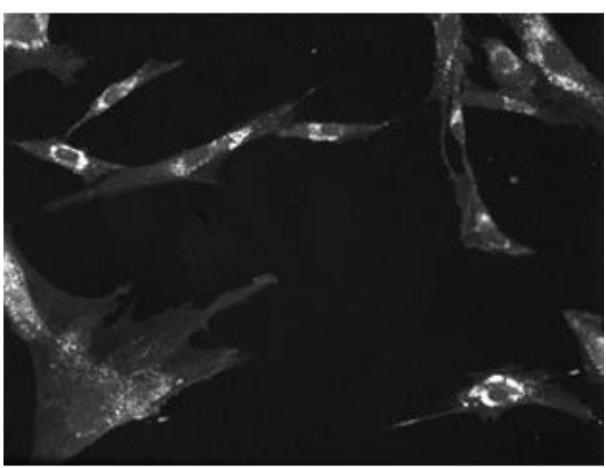

GM03123 HS08 100 $\mu \mathrm{M}$

Figure 2.4 Confocal microscopy images of filipin stained free cholesterol in NPC (GM03123) patient derived fibroblast cell lines. Cells were treated for 48 hours as indicated, before fixing and staining for quantitation of relative cholesterol levels. 


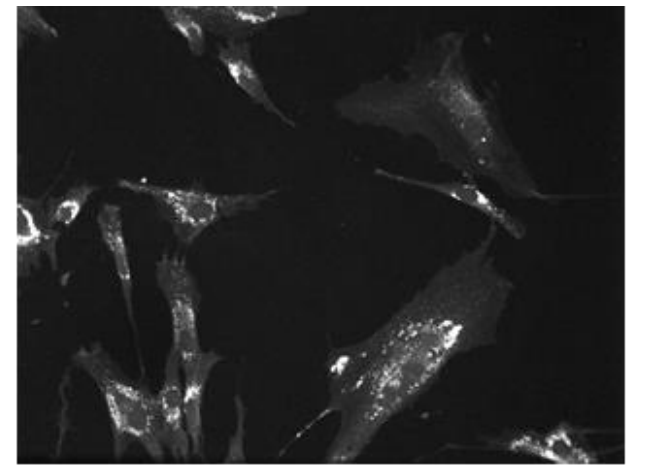

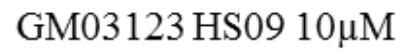

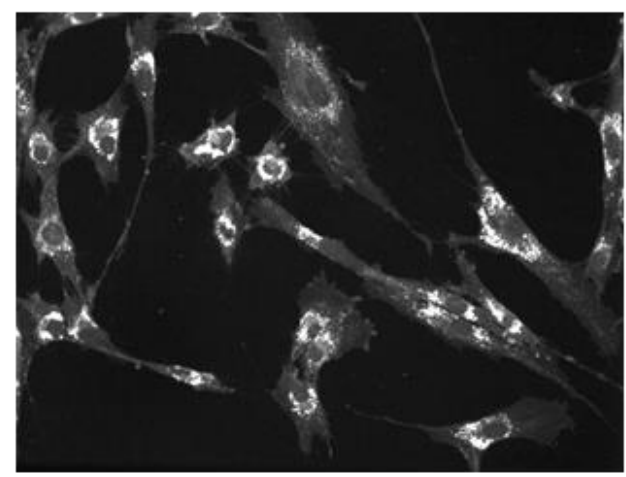

GM03123 HS10 10 $\mu \mathrm{M}$

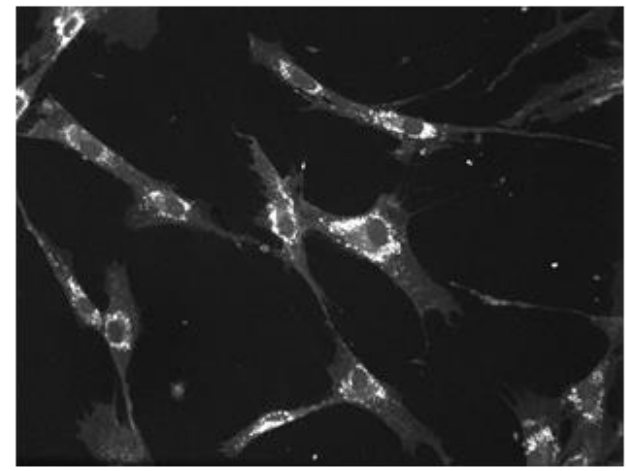

GM03123 HS11 10 $\mu \mathrm{M}$

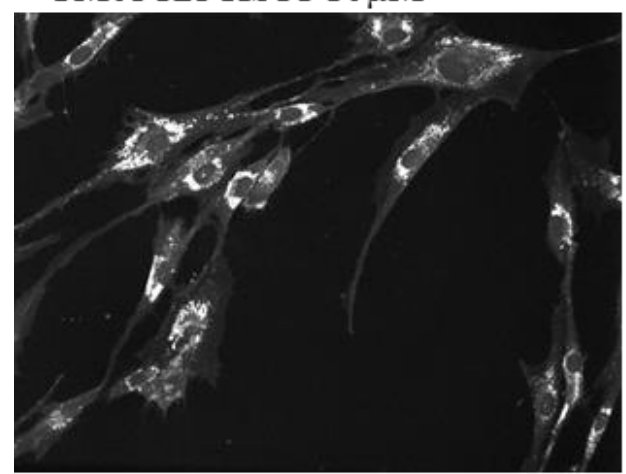

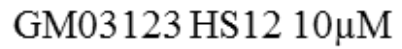

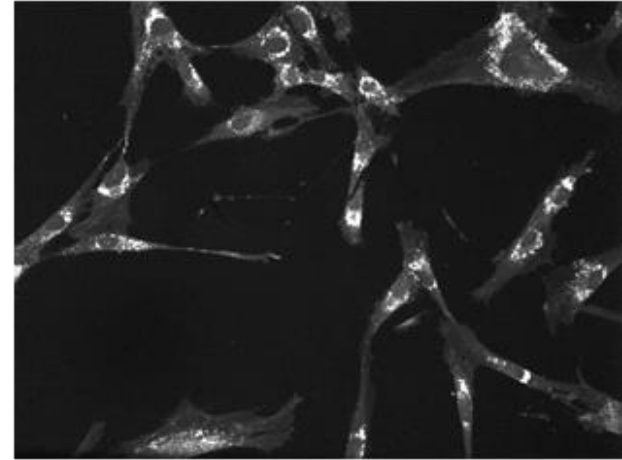

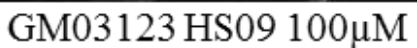

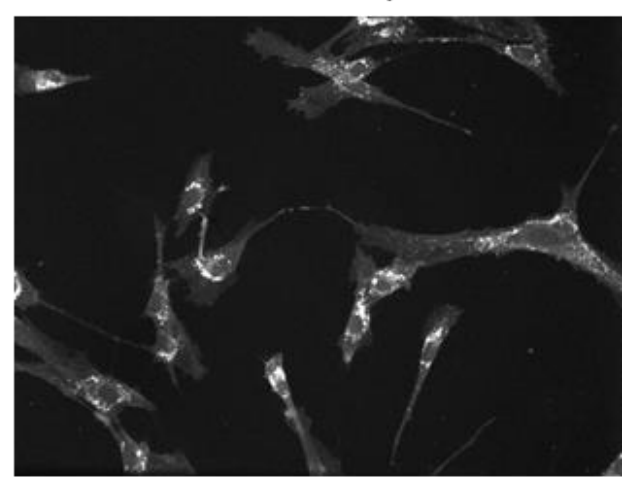

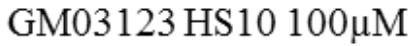

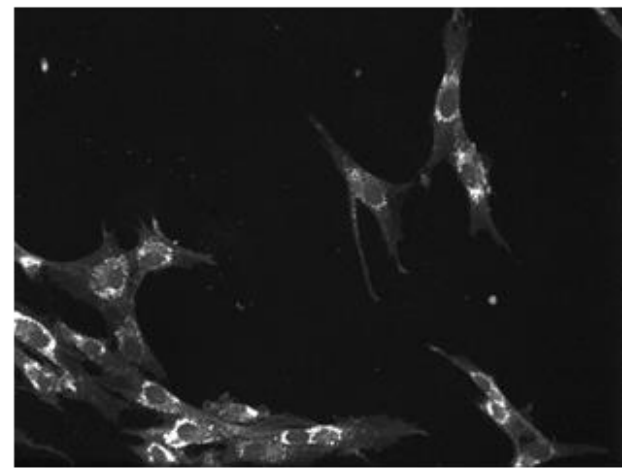

GM03123 HS11 100 $\mu \mathrm{M}$

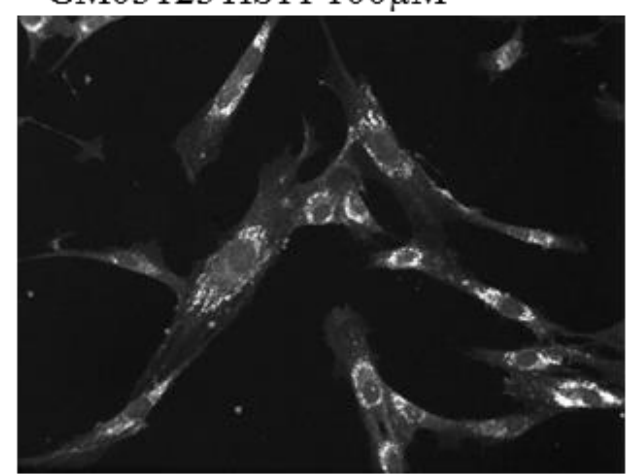

GM03123 HS12 100 $\mu \mathrm{M}$

Figure 2.5 Confocal microscopy images of filipin stained free cholesterol in NPC (GM03123) patient derived fibroblast cell lines. Cells were treated for 48 hours as indicated, before fixing and staining for quantitation of relative cholesterol levels. 


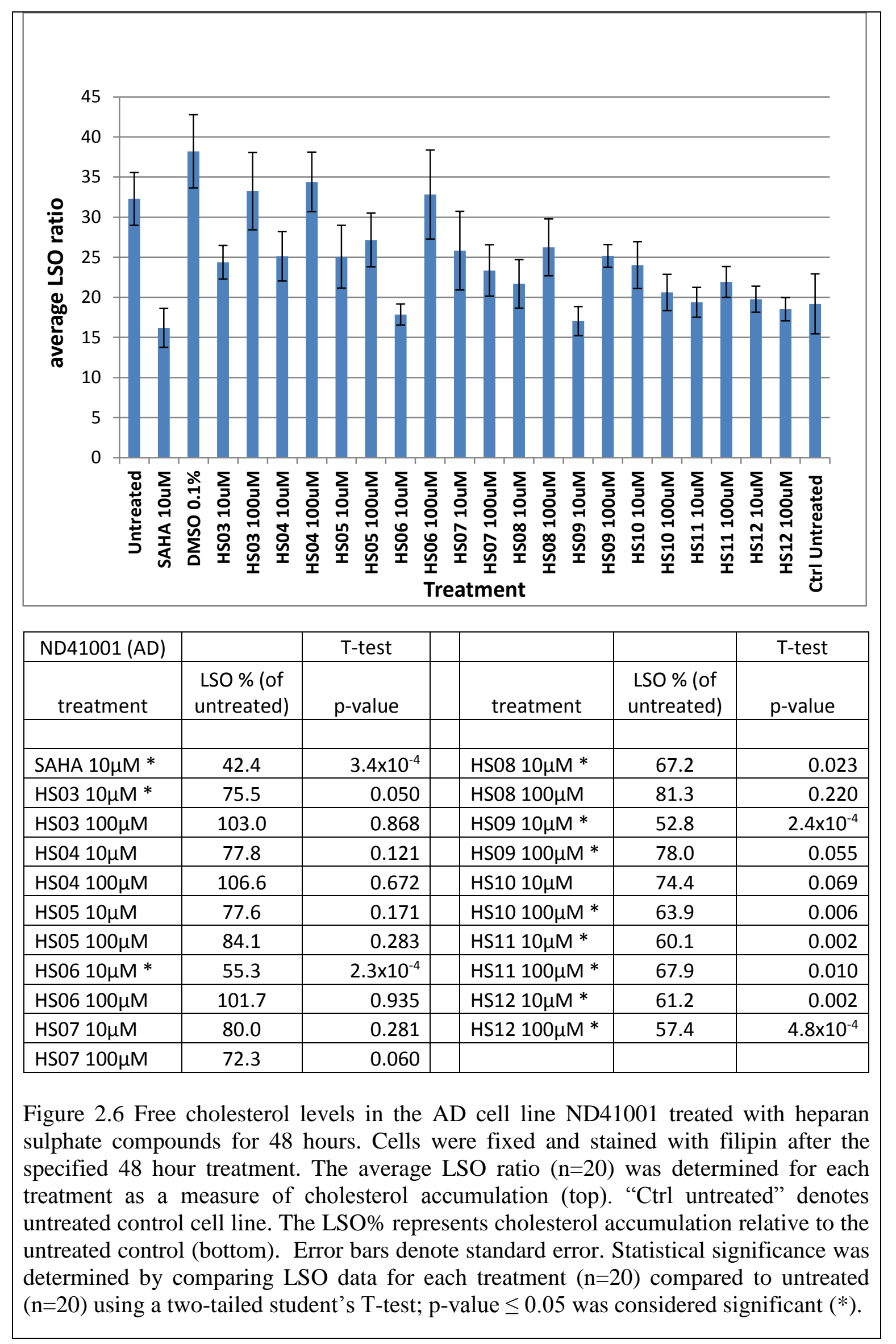




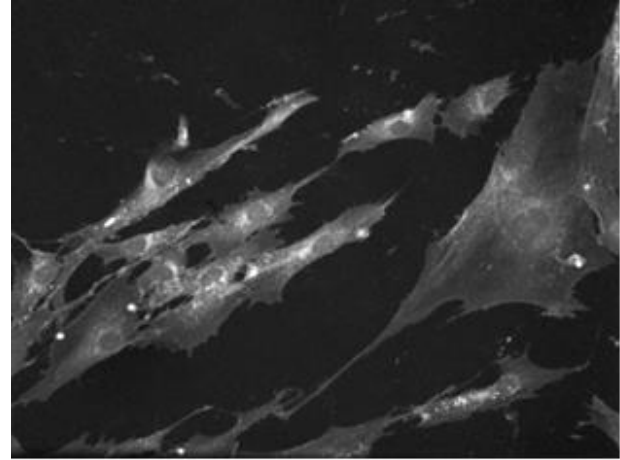

ND41001 (AD)

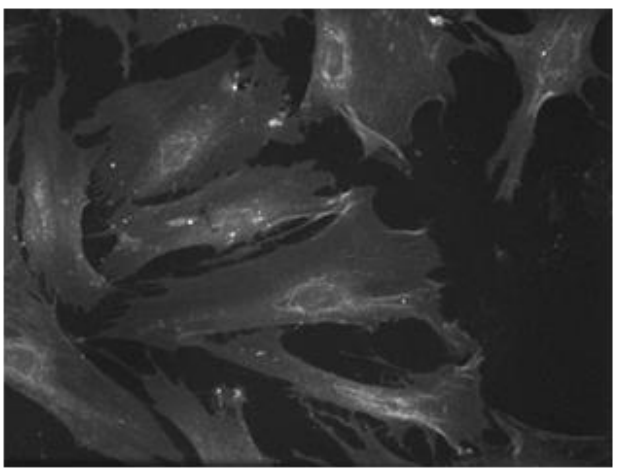

ND41001 SAHA $10 \mu \mathrm{M}$

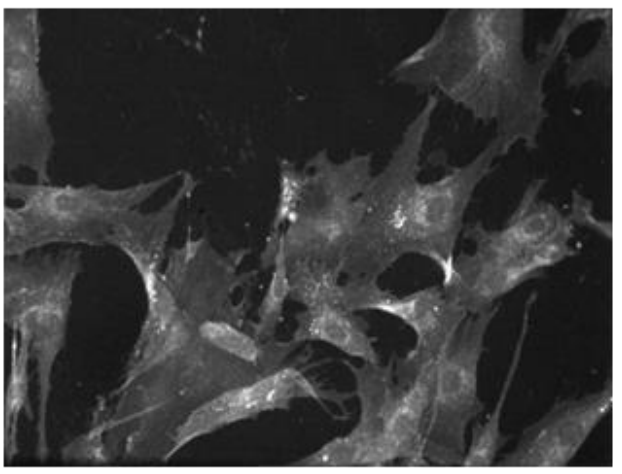

ND41001 HS03 $10 \mu \mathrm{M}$

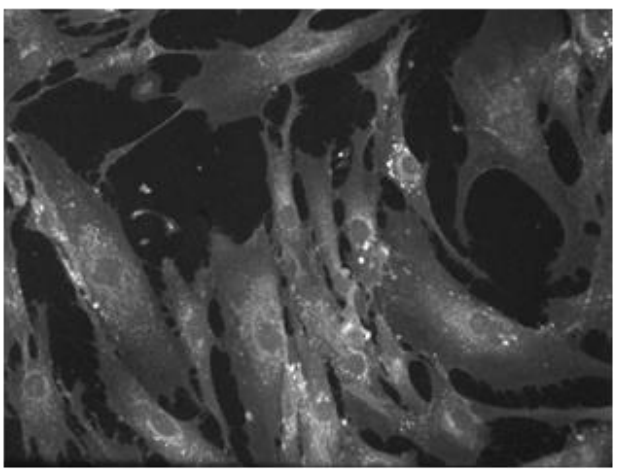

ND41001 HS04 10 $\mu \mathrm{M}$

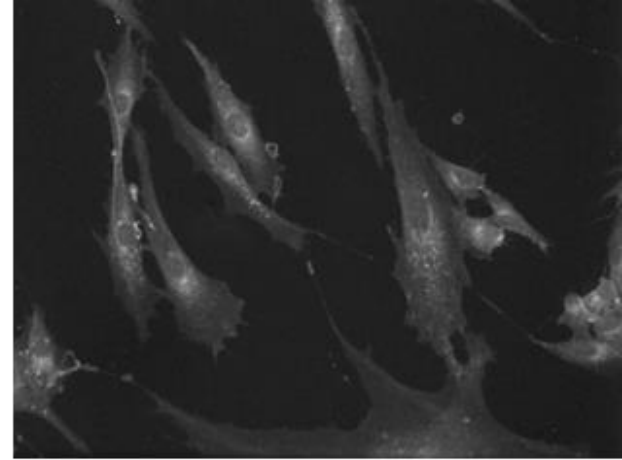

ND38530 (Control)

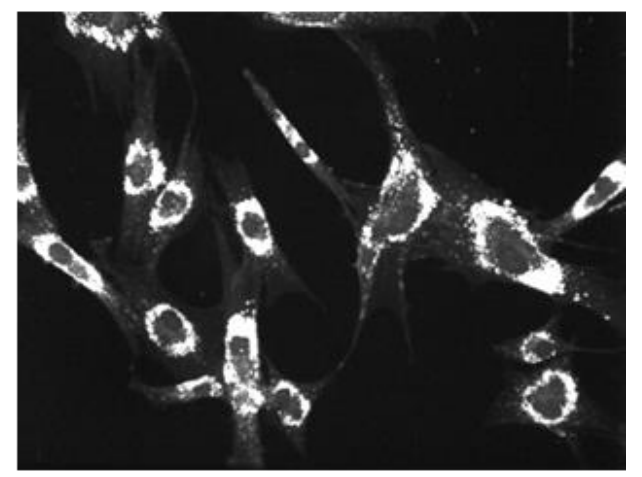

ND38530 U18666A $1 \mu \mathrm{g} / \mathrm{mL}$

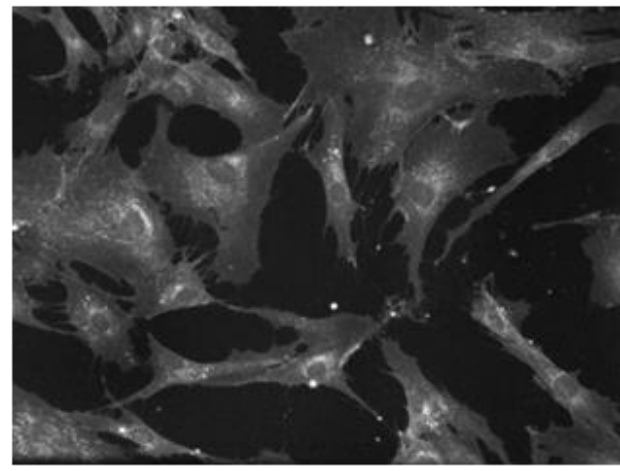

ND41001 HS03 100 $\mu \mathrm{M}$

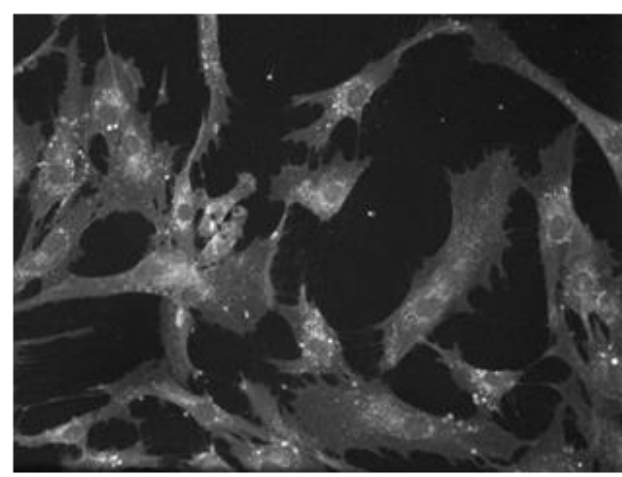

ND41001 HS04 100 $\mu \mathrm{M}$

Figure 2.7 Confocal microscopy images of filipin stained free cholesterol in Alzheimer's (ND41001) and control (ND38530) patient derived fibroblast cell lines. Cells were treated for 48 hours as indicated, before fixing and staining for quantitation of relative cholesterol levels. 


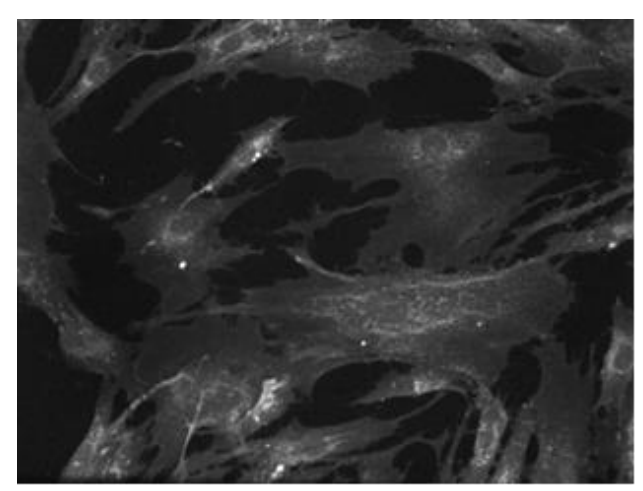

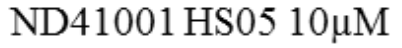

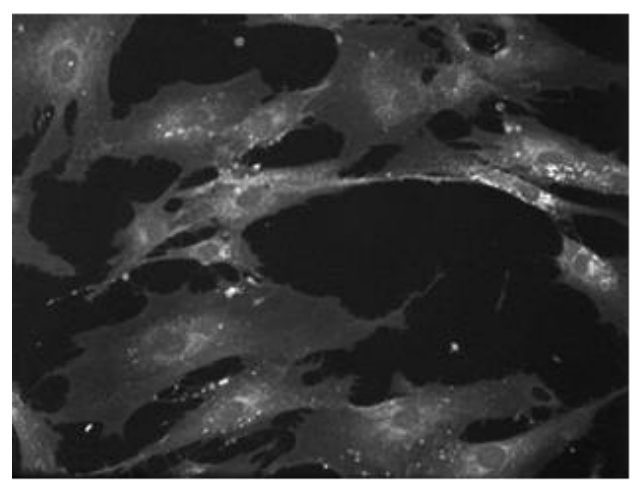

ND41001 HS06 10 $\mu \mathrm{M}$

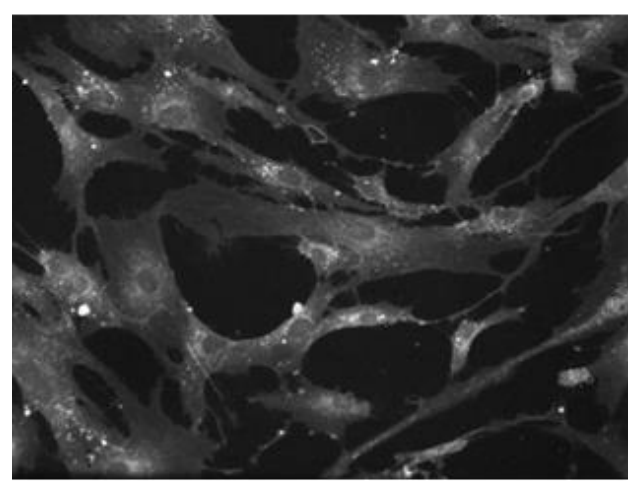

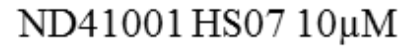

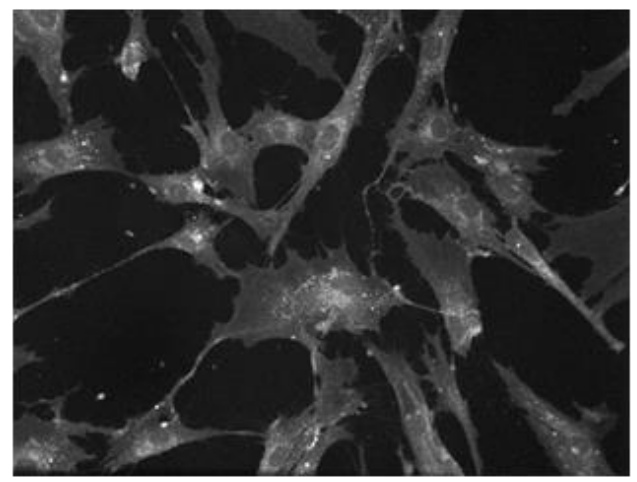

ND41001 HS08 10 $\mu \mathrm{M}$

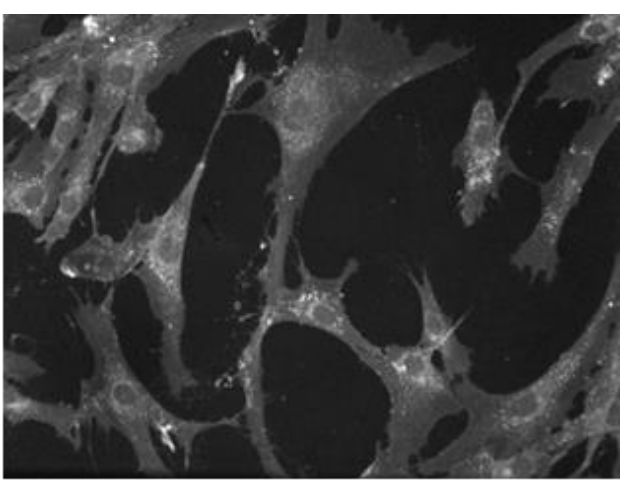

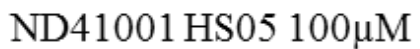

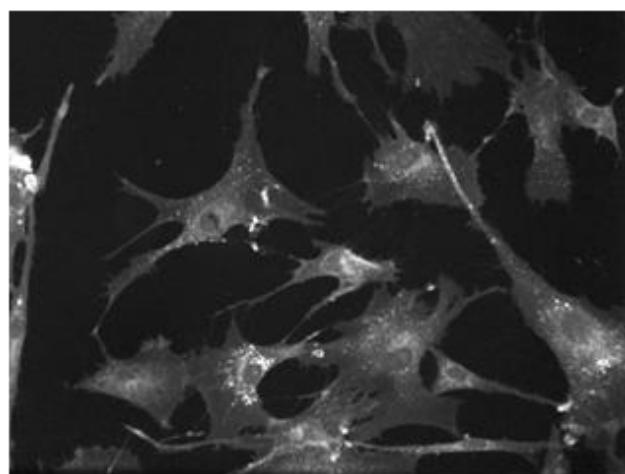

ND41001 HS06 100 $\mu \mathrm{M}$

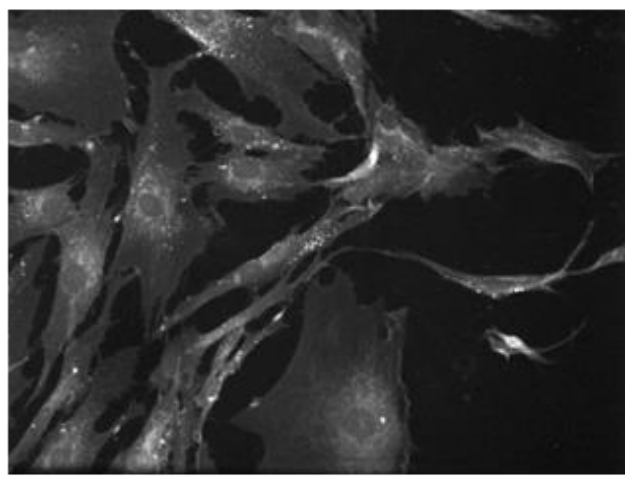

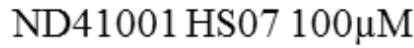

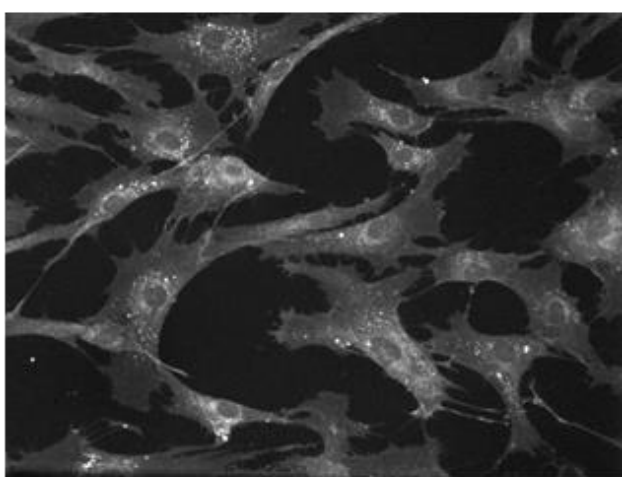

ND41001 HS08 100 $\mu \mathrm{M}$

Figure 2.8 Confocal microscopy images of filipin stained free cholesterol in Alzheimer's (ND41001) patient derived fibroblast cell lines. Cells were treated for 48 hours before fixing and staining for quantitation of relative cholesterol levels. 


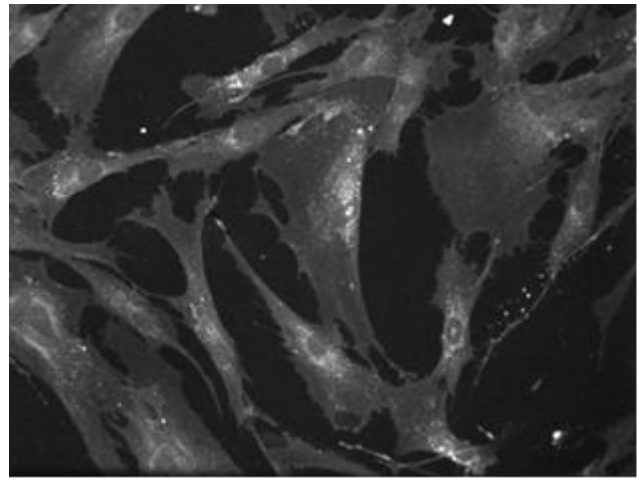

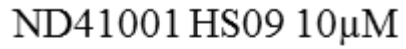

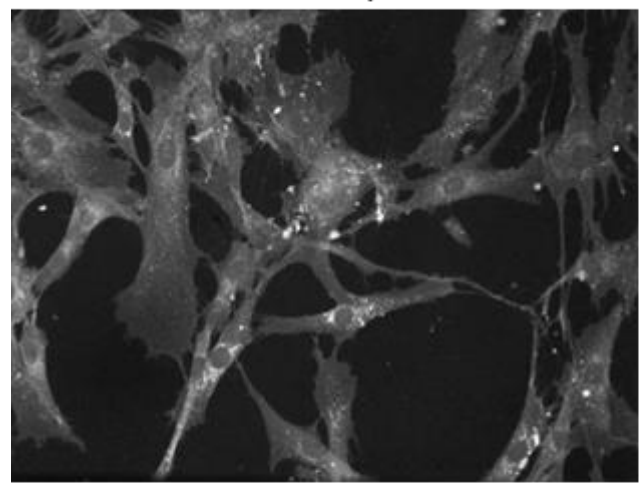

ND41001 HS10 10 $\mu \mathrm{M}$

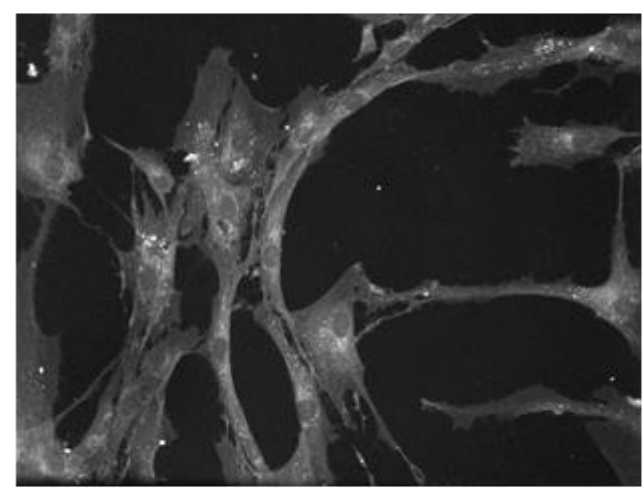

ND41001 HS11 10 $\mu \mathrm{M}$

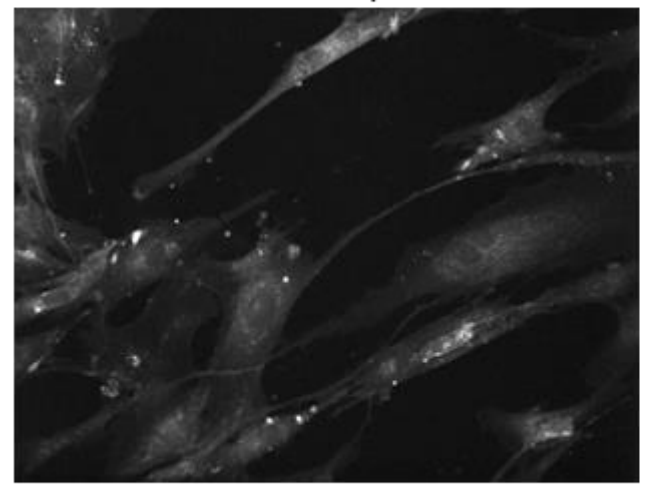

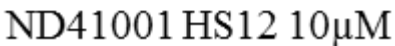

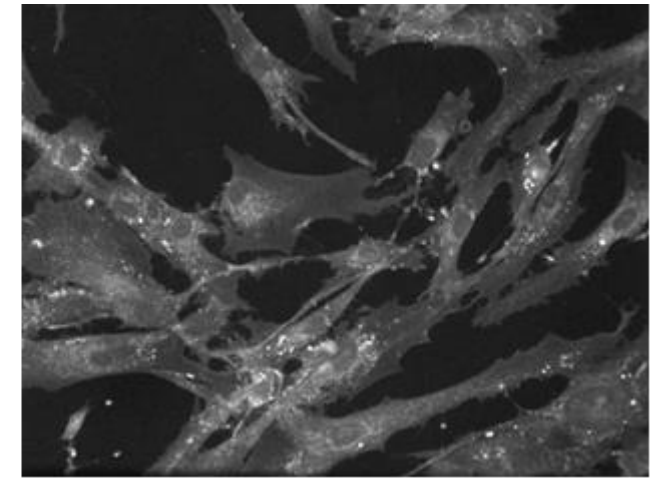

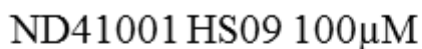

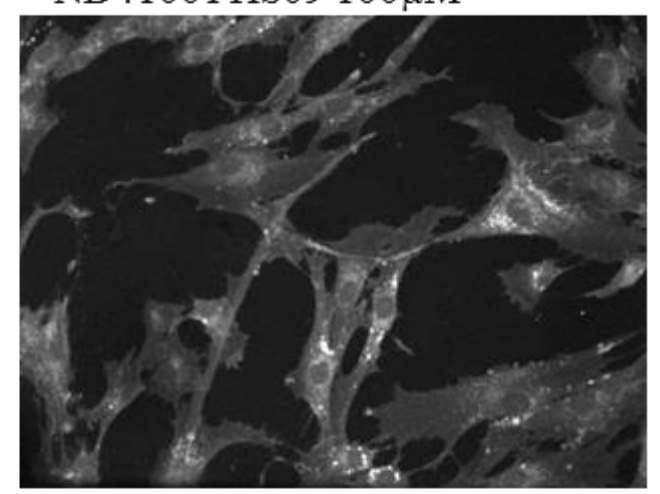

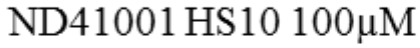

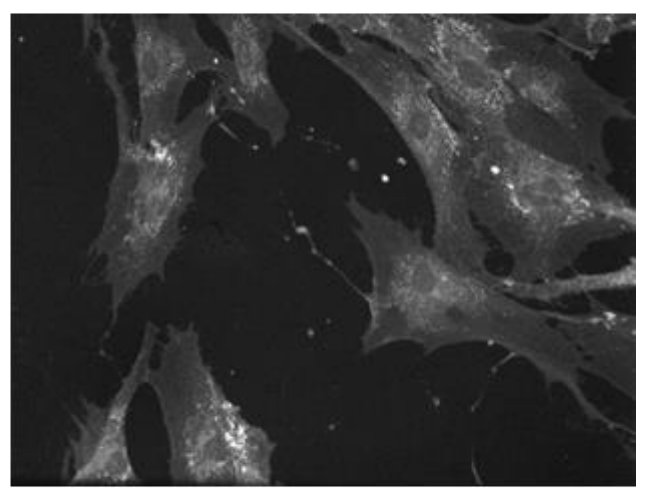

ND41001 HS11 $100 \mu \mathrm{M}$

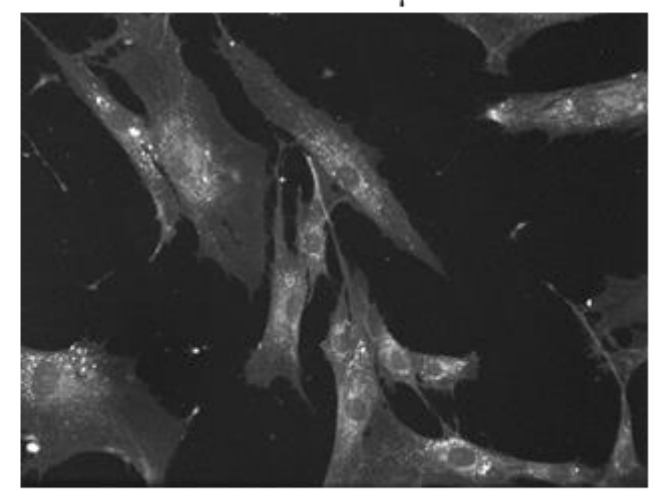

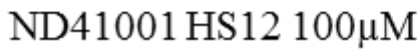

Figure 2.9 Confocal microscopy images of filipin stained free cholesterol in Alzheimer's (ND41001) patient derived fibroblast cell lines. Cells were treated for 48 hours before fixing and staining for quantitation of relative cholesterol levels. 


\subsubsection{Amyloid beta levels are not affected by heparan sulphate compounds in the SH-SY5Y swAPP cell model of Alzheimer's disease}

To determine whether heparan sulphate compounds can affect amyloid beta metabolism, levels of A $\beta 42$ were measured by ELISA in SH-SY5Y cells stably expressing a Swedish mutation in APP (SH-SY5Y swAPP) after treatment with compounds HS01, HS02, HS06, HS07 and HS09. These compounds were chosen for these experiments because they were shown to inhibit BACE1 significantly using biochemical and ex vivo techniques by our collaborator (personal communication from Prof. Jeremy Turnbull, Liverpool University, United Kingdom), (Patent WO2014084744 A1 (Tyler et al. 2014)). The biochemical methods include FRET assays (fluorescence resonance energy transfer), which involves the use of a weakly fluorescent peptide substrate which become highly fluorescent upon enzymatic cleavage allowing measurement of BACE1 activity. The ex vivo methods include the detection of amyloid $\beta$ levels secreted from brain tissue slices from mice expressing APP carrying the Swedish mutation of APP.

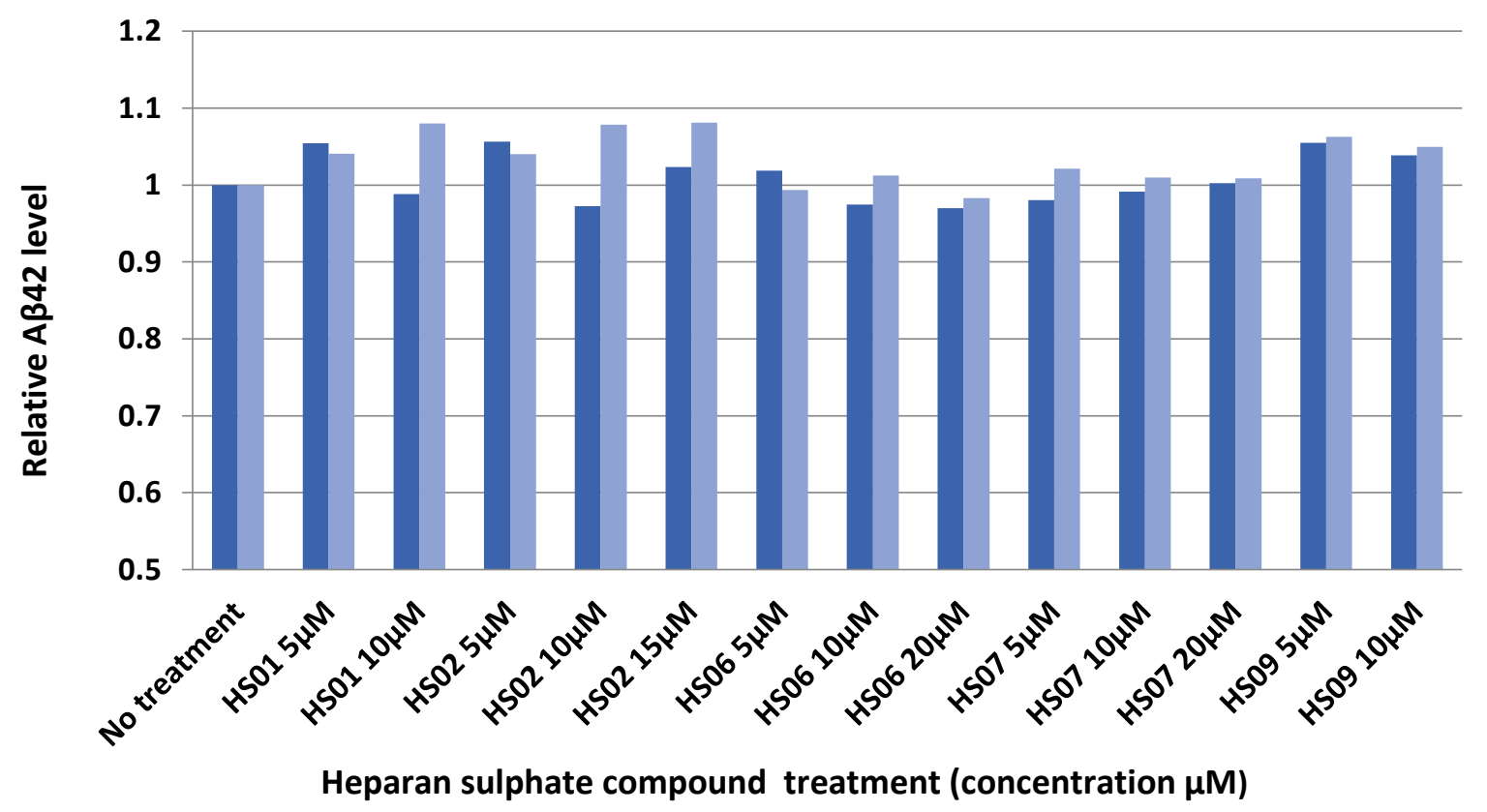

Figure 2.10 Relative quantitation of A $\beta 42$ levels in media from SH-SY5Y swAPP cells after 24 hour heparan sulphate compound treatment $(n=2)$. Cells were treated for 24 hours and A $\beta 42$ levels measured by ELISA. There was very little change in A $\beta 42$ levels produced by SHSY-5Y swAPP cells treated with five HS compound at several concentrations. Cells were treated for 24 hours and A $\beta 42$ levels measured by ELISA. 
First, SH-SY5Y swAPP cells were grown as described above in 6 well plates for two days and treated for 24 hours before media was removed for assays. Two biological replicates were performed (two wells) for each treatment. A larger number of replicates was not possible due to the cost of ELISA kits. Concentrations used for treatments for different compounds ranged between 5-20 $\mu \mathrm{M}$ depending on the amount of compound available. Unexpectedly, the relative levels of $A \beta 42$ did not change with any of the treatments (Figure 2.10).

Based on the results that the HS compounds did not affect A $\beta 42$ levels, I next sought to measure A $\beta 42$ levels in the growth media of SH-SY5Y swAPP cells treated for 24 hours with heparin (heparin sodium salt from bovine intestinal mucosa) using a concentration range of 1.25 to $1000 \mu \mathrm{g} / \mathrm{mL}$. A heparin concentration of $12 \mu \mathrm{g} / \mathrm{mL}$ had previously been reported to inhibit A $\beta 42$ production by $50 \%$ in cells carrying the Swedish mutation (Scholefield, Yates et al. 2003). Surprisingly there was also no decrease in A $\beta 42$ levels with heparin treatment at any concentration (Figure 2.11).

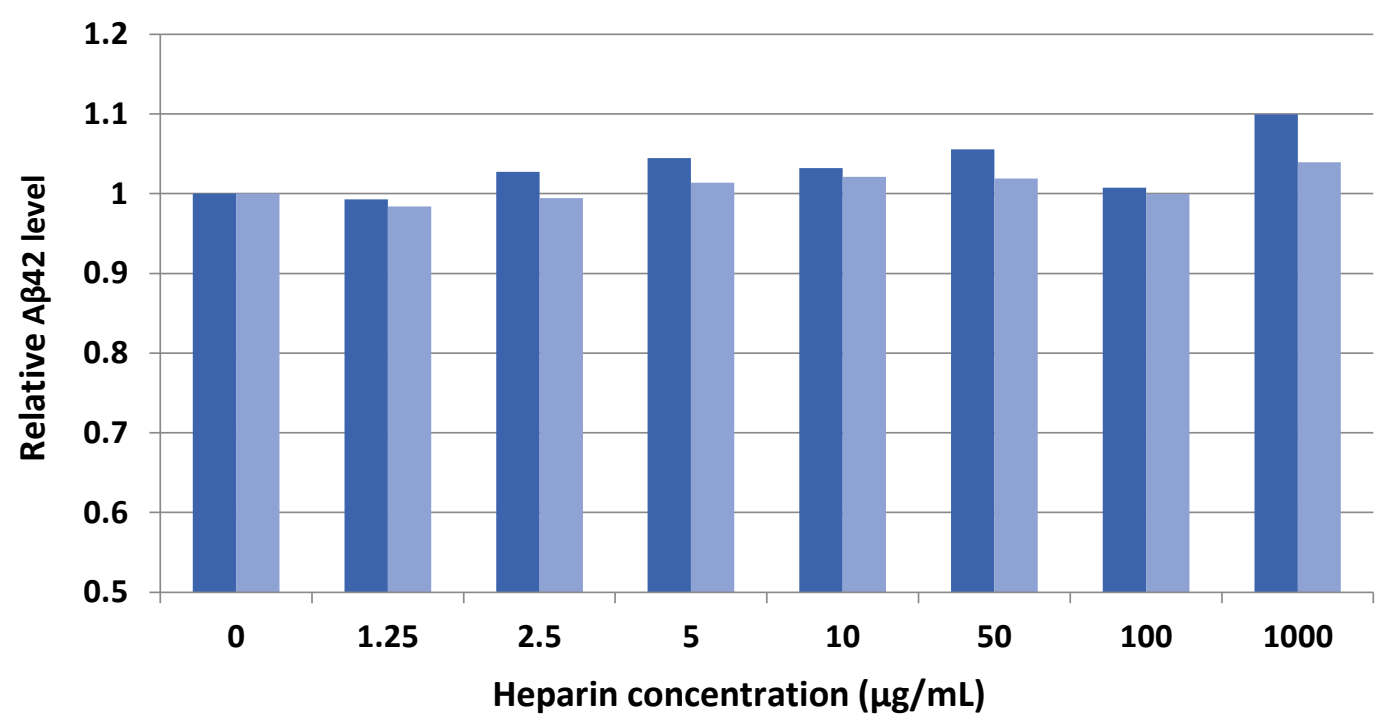

Figure 2.11 Relative quantitation of A $\beta 42$ levels in media from SH-SY5Y swAPP cells after 24 hour heparin treatment $(n=2)$ Heparin treatment for 24 hours had little effect on A 342 production in SH-SY5Y swAPP cells. Instead of the expected decrease, there was a slight increase in $A \beta 42$ concentrations measured by ELISA at the highest concentration. Concentrations of $12 \mu \mathrm{g} / \mathrm{mL}$ have been reported as reducing $A \beta 42$ production by $50 \%$ in other cell lines expressing APP with the Swedish mutation (Scholefield, Yates et al. 2003). 
In the above experiments, secreted $A \beta 42$ levels were measured after a 24 hour treatment. If the BACE1 inhibiting effects of the heparin do not occur until later in that 24 hours, the reduction in $A \beta 42$ may not yet be sufficient to be measured. To test this hypothesis, cells were treated for 10 hours with heparin (1st treatment) and then growth media was removed. Then fresh media with heparin was added for a further 12 hours (2nd treatment) before being removed. A $\beta 42$ levels were measured in media from the 1st treatment and the 2nd treatment to determine whether the BACE1 inhibition was occurring later in the treatment timespan. This experiment was carried out with porcine intestinal mucosa heparin, which is the type of heparin that showed BACE1 inhibitor activity in cell culture experiments by our collaborator (J. Turnbull, University of Liverpool, United Kingdom). After the first treatment, relative A $\beta 42$ levels did not exhibit a dose-dependent pattern nor follow a pattern that would be expected if the heparin was acting as a BACE1 inhibitor. After the second treatment, there appears to be a slight increase in A $\beta 42$ at the lowest heparin concentration $(0.039 \mu \mathrm{g} / \mathrm{mL})$ and then levels decrease slightly before increasing at the highest concentrations (10 or $50 \mu \mathrm{g} / \mathrm{mL})$ to the level of untreated cells or above in the $100 \mu \mathrm{g} / \mathrm{mL}$ treatment (Figure 2.12). To further understand $\mathrm{A} \beta$ metabolism, I measured $A \beta 40$ levels. $A \beta 40$ levels showed a slight decrease in all heparin concentrations to approximately $0.7-0.8$ of untreated, however they did not show the expected dose dependent decrease (Figure 2.13). Together, these results indicate that neither heparin nor any of the heparan sulphate compounds tested inhibits BACE1 activity in this SH-SY5Y swAPP Alzheimer's cell line model. 


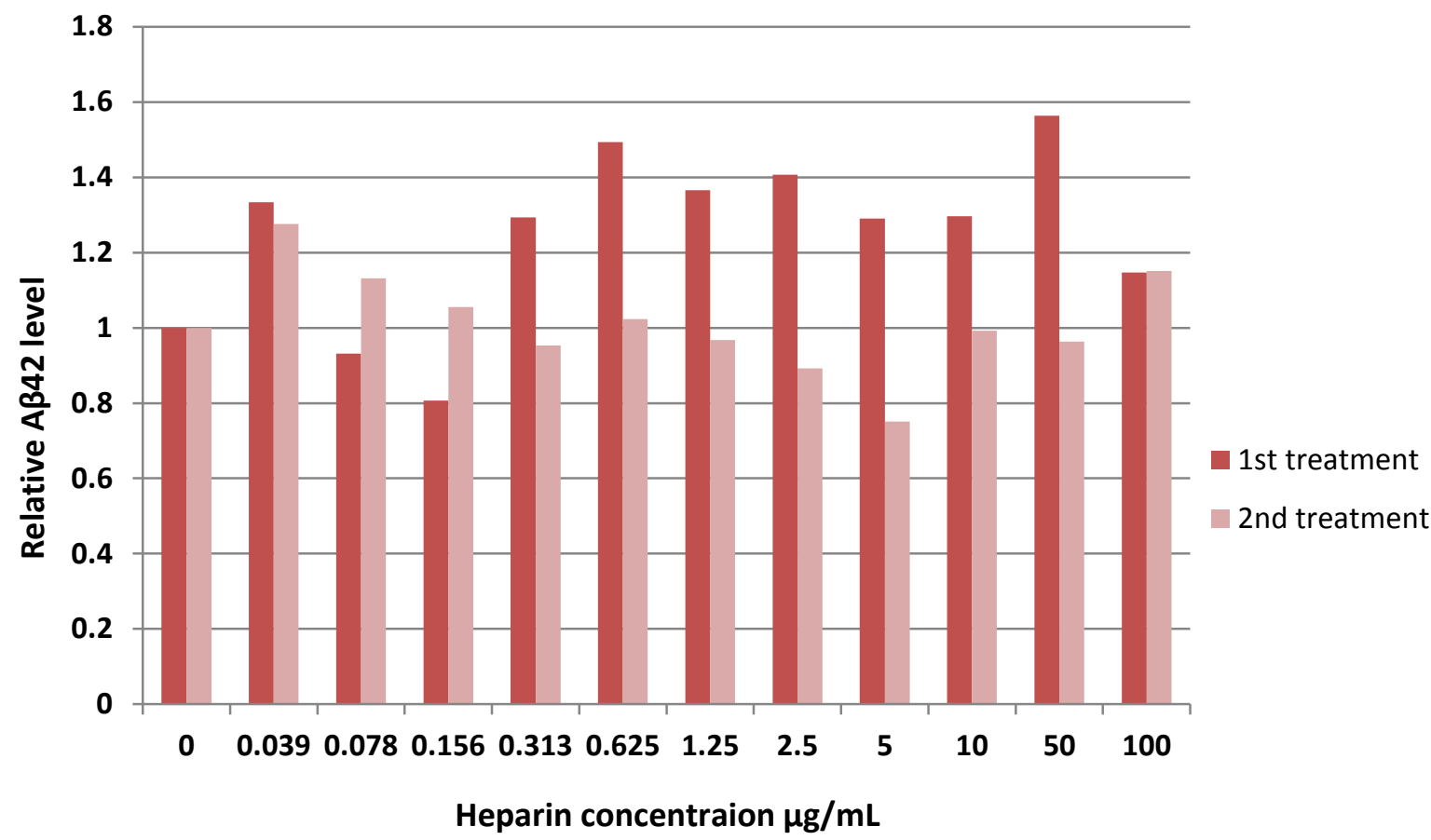

Figure 2.12 Relative quantitation of A $\beta 42$ levels in media from SHSY5Y swAPP cells after 10 hour $\left(1^{\text {st }}\right.$ treatment $)$ and consecutive 12 hour $\left(2^{\text {nd }}\right)$ heparin treatments $(n=1)$

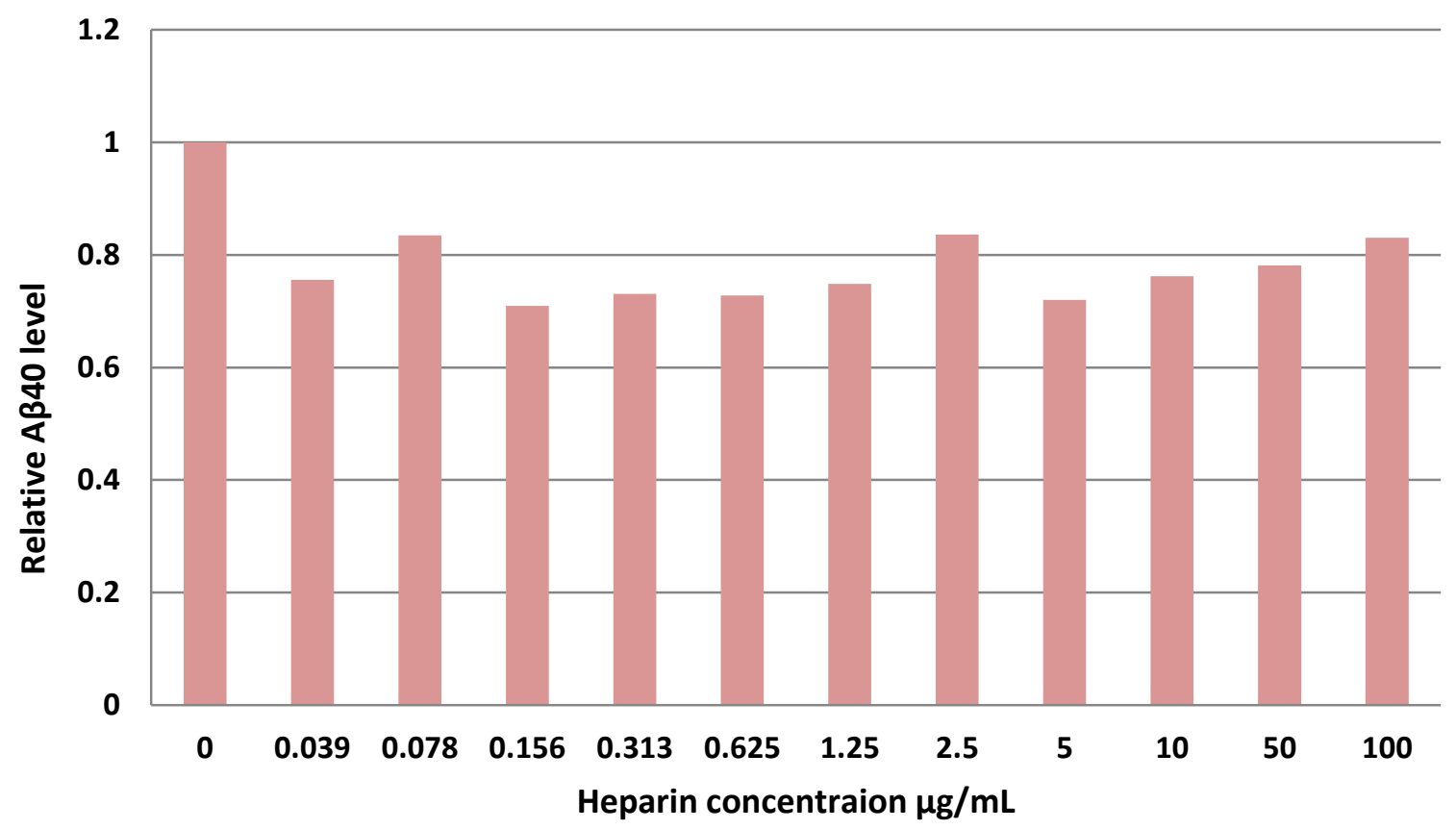

Figure 2.13 Relative quantitation of A $\beta 40$ levels in media from SH-SY5Y swAPP cells after 2 nd consecutive heparin treatment $(n=1)$ 


\subsubsection{Amyloid precursor protein (APP) levels in SH-SY5Y swAPP cells are not affected with heparin treatment but are affected with SAHA treatment}

As heparin did not have the expected effects on the levels of amyloid beta in the SHSY5Y swAPP Alzheimer model cell line, I then determined if heparin altered the levels of the amyloid precursor protein (APP). I treated the SH-SY5Y swAPP cells with $0-1000 \mu \mathrm{g} / \mathrm{mL}$ heparin, and for comparison, cells were also treated with the histone deacetylase inhibitor suberanilohydroxamic acid (SAHA) that was previously used a control in quantification of intracellular homeostasis (Figure 2.6). Histone deacetylases play an important role in regulating transcription in all cells by increasing the binding between DNA and histones and reducing the availability of DNA for transcription. Deregulation of histone acetylation has been associated with age-related memory loss in mice (Peleg et al. 2010) and histone deacetylase (HDAC) inhibitors have been shown to improve the age-related memory loss in AD mouse models although the mechanism is unclear. HDAC inhibitors therefore have exciting therapeutic potential and are being tested in a variety of neurodegenerative disorders including AD (Graff and Tsai 2013).

There was a 1.5-2-fold increase in APP levels after heparin treatment in the SH-SY5Y swAPP cells however this was not dose-dependent (Figure 2.14). Treatment with $5 \mu \mathrm{M}$ and $10 \mu \mathrm{M}$ SAHA increased full length APP levels by 8 -fold ( $\mathrm{p}$-value $=5.8 \times 10^{-7}$ ) and 7-fold (pvalue $=0.00021$ ), respectively (Figure 2.15), a result that is consistent, albeit not linear, with my finding that SAHA treatment increased $\mathrm{A} \beta 42$ levels by $<10 \%$ compared to untreated (Figure 2.16). These results indicate that heparin does not regulate full length APP levels in the SH-SY5Y swAPP cell model of AD. In addition, these results indicate that SAHA regulates APP levels dramatically more so than A $\beta 42$ levels, suggesting further investigation of APP regulation by SAHA and other HDAC inhibitors. 


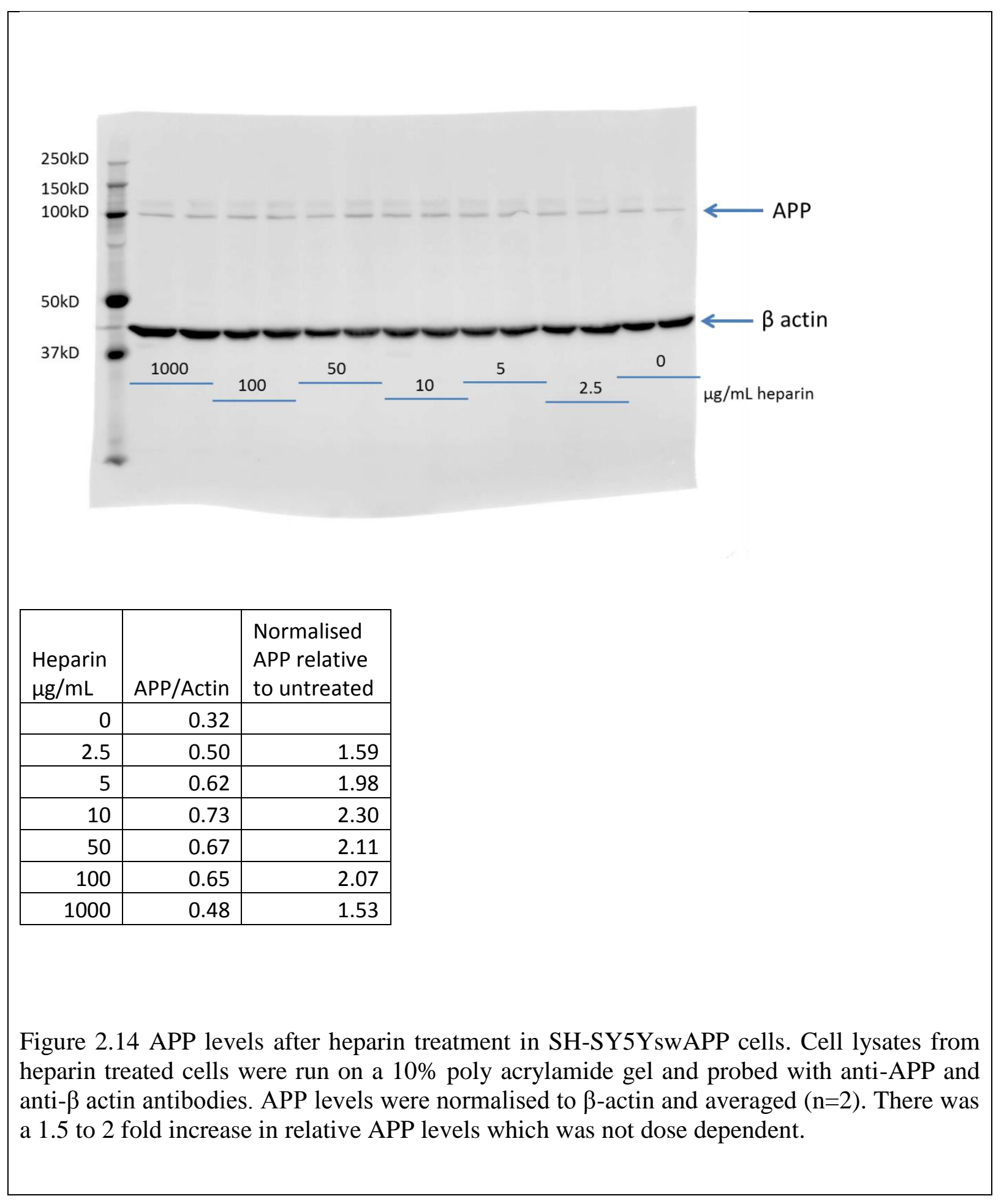




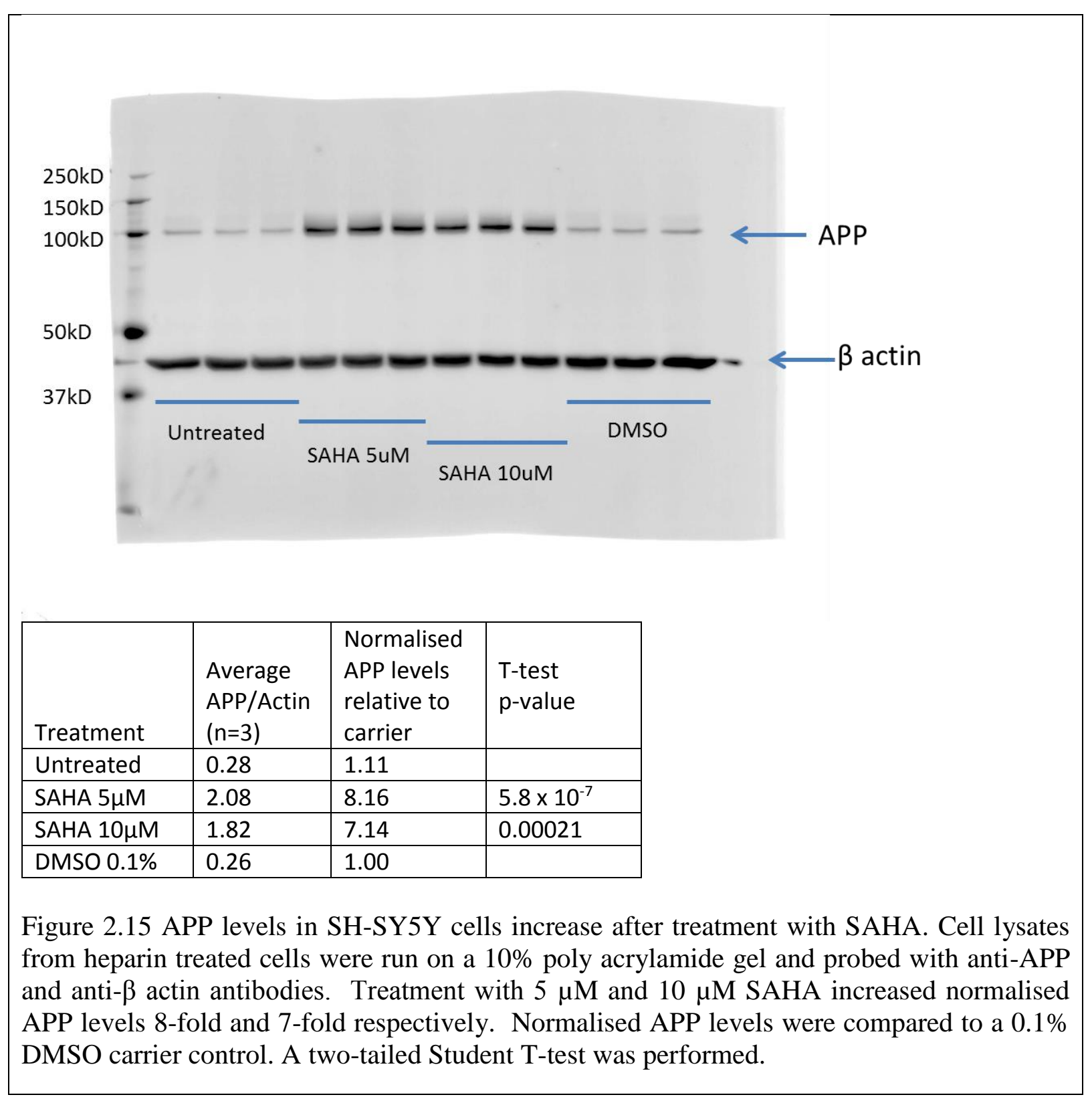




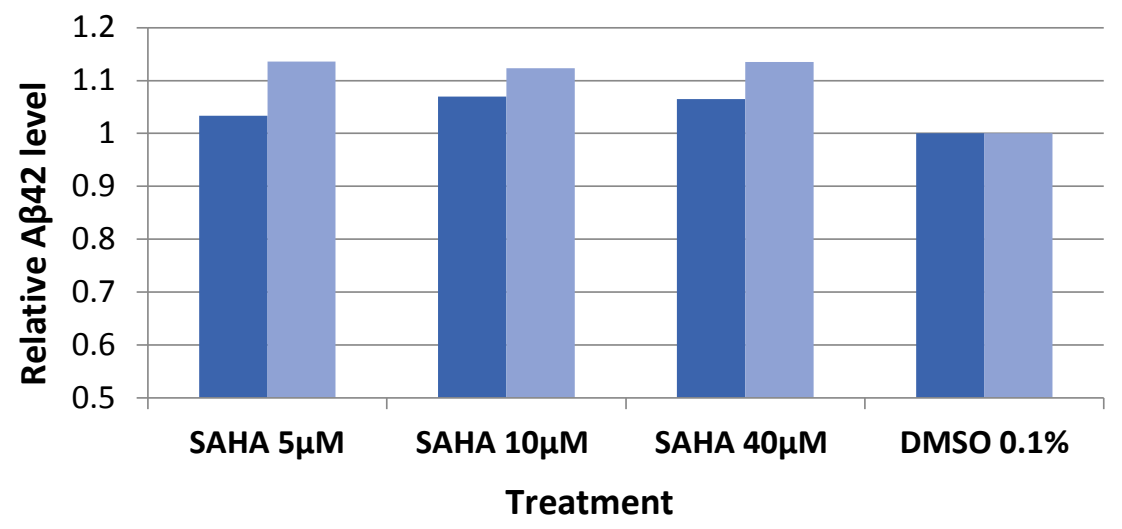

Figure 2.16 Relative quantitation of A $\beta 42$ levels in media from SH-SY5Y swAPP cells after 24 hour SAHA treatment $(n=2)$. SAHA treatment caused a slight increase in relative A 342 production which was not dose dependent. SAHA is compared to a carrier control of $0.1 \%$ DMSO. 


\subsection{Discussion}

\subsubsection{Novel heparan sulphate compound effects on cholesterol metabolism}

The structural diversity of heparan sulphate side chains of proteoglycans confers their wide range of regulatory functions in the cell. In this study a subset of novel heparan sulphate compounds were investigated for their ability to influence cholesterol metabolism in cell models of neurodegenerative disease. Inhibitory activity appeared to be related to the structure and degree of sulphation of the heparan sulphate compound. Of the ten compounds tested those with dendritic tetramer structures with a higher number of more highly sulphated sugar residues were more effective. The negatively charged sulphate and carboxylate side chains in natural heparan sulphate confer an ability to interact with a large number of ligands in the cell. This may be more effectively mimicked by a tetramer structure presenting a larger number of negatively charged sugar residues. The nature and conformation of the charged groups may also affect the specificity of the interaction of HS which results in cholesterol reduction. In naturally occurring HS chains the huge structural diversity is due to the action of many different isoforms of modifying enzymes such as $N$-deacetylase $/ N$-sulfotransferases, 6- $O$-sulfotransferases and 3-O-sulfotransferases (Aikawa and Esko 1999; Habuchi et al. 2000). These result in additions of sulphate groups and also epimerization of $D$-glucuronic acid to $L$-iduronic acid which can also be further sulphated. Highly modified regions are interspersed with linker regions of essentially unmodified $D$-glucuronic acid- $N$-acetylglucosamine disaccharides. Differences in structure occur between cell and tissue type, and cells can alter HS structures in response to signals such as growth factors. (Kato et al. 1994; Schmidt et al. 1995). Recently sequencing and computational methods have been developed to understand the complex structure to function relationships of heparan sulphate proteoglycans (Spencer et al. 2010).

The degree of significant cholesterol reduction in treated cells for different compounds ranged from $20 \%$ to $47 \%$. Significantly there was an overlap between the compounds effective in both AD and NPC cell lines. As the same HS compound structure was effective in both models this would imply similar mechanisms are being affected in both models. Further experiments in other cell line models of both diseases would be necessary to validate these results. 
A decrease in uptake or increases in efflux are two possible mechanisms for the change in cholesterol levels in the cell after HS treatment. Heparan sulphate proteoglycans are involved in the endocytosis of cholesterol laden LDL by LRP1 and LDLR and can also act as receptors alone (Bishop, Schuksz et al. 2007). Endocytosed cholesterol is hydrolysed by lysosomal acid lipase to free cholesterol. Heparan sulphate compounds may be able to bind cholesterol/LDL in competition with HSPG associated endocytic binding, reducing endocytic entry into the cell. Therefore less endocytosed cholesterol may reduce the accumulation of endosomal/lysosomal free cholesterol in NPC or AD cells. It would also be useful to examine mRNA expression levels and protein expression levels of genes involved in cholesterol uptake (LDLR and LRP1), efflux (ATP binding cassette transporter A1, ABCA1) and lysosomal degradation such as lysosomal lipase.

Interestingly HSPG and LRP1 also work together in the uptake of amyloid $\beta$ into neuronal cells and in healthy cells this is the first step towards degradation in the lysosome and prevention of $A \beta$ accumulation (Kanekiyo, Zhang et al. 2011). In unhealthy cells such as in $\mathrm{AD}$, where there is an accumulation of $\mathrm{A} \beta$, the endocytic clearance pathway may become overwhelmed resulting in excessive uptake without degradation and toxic $A \beta$ accumulation in the cell. In this situation Kanekiyo et al suggested that heparin like compounds may be useful therapeutically by competing with HSPG and reducing further A $\beta$ uptake. It would be useful to test the compounds in this study for their effects on $A \beta$ uptake and degradation in a neuronal AD model cell line.

A decrease in cholesterol synthesis or increases in esterification are also possible mechanisms resulting in free cholesterol reduction in the cell. Therefore other proteins that could be examined are those involved in cholesterol synthesis such as the rate limiting enzyme and target of statin drugs, HMG-CoA reductase (3-hydroxy-3-methyl-glutaryl-CoA reductase) and also ACAT (acyl CoA:cholesterol acyltransferase 1) which catalyses the conversion of cholesterol to cholesterol ester.

\subsubsection{Lack of BACE1 inhibition in an SH-SY5Y cell line carrying the Swedish APP mutation}

Significant BACE1 inhibition by heparin and heparan sulphate has been observed in other studies in SH-SY5Y and HEK293T (human embryonic kidney 293T) cells carrying the Swedish APP (swAPP) mutation (Scholefield, Yates et al. 2003). In the Scholefield study 
inhibition of up to $90 \%$ was achieved with heparin concentrations below $20 \mu \mathrm{g} / \mathrm{mL}$. The particular SH-SY5Y-swAPP cell line used in our study did not exhibit significant reduction in $A \beta$ secretion after treatment with either bovine or porcine intestinal mucosa heparin at concentration ranges up to $1000 \mu \mathrm{g} / \mathrm{mL}$ or with any of the novel heparan sulphate compounds tested. As well as testing media after 24 hours of treatment, I also assayed for A $\beta$ levels after two successive 12 hour treatments where fresh media was given to the cells after the first 12 hours. $A \beta$ assays after the second treatment would therefore not be affected by accumulated $A \beta$ in the first 12 hours. Neither method showed any significant decrease in $A \beta$.

It is difficult to explain the reasons for this. Cell lines from different sources can have significantly different characteristics. For instance if a cell line has been passaged a large number of times, stored and then regrown for a further length of time, unknown mutations that affect the functional characteristics of the cell may eventuate altering the phenotype of interest. For examples mutations at the BACE1 active site may affect HSPG binding preventing inhibitory activity. Unfortunately due to time constraints and the availability of cell lines I was not able to test other cell lines with mutant APP for BACE1 inhibition by heparin and our HS compounds.

\subsubsection{Amyloid precursor protein levels in an SH-SY5Y cell line carrying the Swedish APP mutation after heparin and SAHA treatment}

Amyloid precursor protein (APP) levels also do not appear to be significantly affected by heparin in the SH-SY5Y swAPP cell line. However the histone deacetylase inhibitor SAHA did increase levels of full length APP in the cell significantly (7-8 fold). SAHA is a global inhibitor of histone deacetylases. Histone deacetylase inhibitors promote transcription by disrupting interaction between DNA and histone proteins. A global inhibitor will affect the expression of multiple protein targets which could potentially result in changes to the expression or metabolism of APP. SAHA may affect APP expression directly or SAHA may increase the expression of some of the enzymes involved in APP metabolism such as BACE1, $\alpha$-secretase or the catalytic components of the $\gamma$-secretase complex (presenilin 1 and 2). We observed a $10 \%$ increase in A $\beta 42$ levels after SAHA treatment which could be due to changes in BACE1 or $\gamma$-secretase activity. If genes involved in the amyloidogenic pathway were upregulated, promoting an increase in metabolism of APP to amyloid $\beta$, this may result in a feedback mechanism resulting in higher APP expression. 
The memory and learning deficits characteristic of neurodegenerative diseases have been linked to chromatin remodelling processes such as histone acetylation (Peleg, Sananbenesi et al. 2010; Graff and Tsai 2013) implying HDAC inhibitors may be useful as a therapy for $\mathrm{AD}$. In mouse models of neuronal loss, memory and learning were improved by treatment with HDAC inhibitors which increase acetylation levels (Fischer et al. 2007; Guan et al. 2009). HDAC inhibitors have been shown to improve age-related memory loss in AD mouse models (Francis et al. 2009; Peleg, Sananbenesi et al. 2010). In contrast to my results, a number of studies have shown HDAC inhibitors decreasing A $\beta$ levels and APP. In AD mouse models treatment with HDAC inhibitors decreased $\mathrm{A} \beta$ levels and reduced memory impairments (Ricobaraza et al. 2011; Sung et al. 2013). The HDAC inhibitor valproic acid was shown to down regulate APP in pancreatic and colon cancer (Venkataramani et al. 2010). Given these conflicting results with a range of different HDAC inhibitors further investigation of the effects of SAHA specifically on APP metabolism would be valuable.

In this thesis, using fluorescent confocal microscopy, I have shown that novel heparan sulphate compounds can inhibit the accumulation of cholesterol in the lysosomal storage organelles of established cell line models of NPC and AD. Synthesised compounds with dendritic structures and higher levels of sulphation had greater inhibitory effect. Unexpectedly A $\beta$ and APP protein levels were unaffected by these compounds in a neuronal cell line model of AD suggesting further work in other in vitro AD models would be useful. The mechanism of inhibition remains unclear but may be related to HSPG-associated endocytosis of LDL/cholesterol. 


\section{Future Directions}

In this study I have shown that several novel heparan sulphate compounds can reduce the accumulation of unesterified cholesterol in fibroblast cell lines derived from AD and NPC patients. It would be useful to confirm these results in additional cell lines from patients with these diseases carrying different disease related mutations. Further investigations following on from this study would include cellular lipid analysis by alternative methods to analyse cholesterol and sphingolipid regulation, analysis of LDL uptake and cholesterol recycling, analysis of nitric oxide dependent cleavage of heparan sulphate, analysis of changes in autophagy, and exploring the effects of SAHA on APP metabolism.

To further investigate cholesterol synthesis and transport, I would like to measure the ratio of total cholesterol and esterified cholesterol in cells treated with HS compounds. I would measure cholesterol levels using MALDI-TOF (Matrix Assisted Laser Desorption Ionization - Time Of Flight) mass spectrometry (Hidaka et al. 2007). Lipids would be extracted using a modified Bligh and Dyer method (Bligh and Dyer 1959). Total lipid extracts from cells can be analysed and normalised to total lipid content. Peak mass/charge ratios would be normalised using lipid standards and identified using the online databases LIPID MAPS (http://www.lipidmaps.org/). An alternative method for lipid analysis would be Electrospray Ionization Mass Spectrometry (Brugger 2014). By delivering the sample in a solvent this method avoids the use of a solid matrix which can produce peaks which interfere with identification of lipids at the lower molecular weight such as cholesterol. Both of these methods would also allow for the quantification of sphingolipids that also accumulate in NPC and AD (Rodriguez-Lafrasse et al. 1994; Fan et al. 2013), which would be interesting considering the crosstalk between cholesterol and sphingolipids (Walkley and Vanier 2009).

To determine whether a decrease in cholesterol uptake contributes to the changes to cholesterol accumulation in the lysosomal storage organelle observed with HS compounds, I would grow cells with lipid deficient media and then add media containing LDL labelled with Dil (1,1'-dioctadecyl-3,3,3,3-tetramethylindocarbocyanine perchlorate), a fluorescent lipophilic dye. Levels of LDL uptake could be quantitated with respect to HS treatment and cholesterol accumulation. HS compounds may bind to LDL/cholesterol complexes in competition with binding to extracellular membrane associated HSPG and so prevent HSPG associated endocytosis. 
To determine if reduction in cholesterol levels in the late endosome/lysosome (lysosomal storage organelle) in NPC cells is due to an increase in recycling of cholesterol to the ER, I would measure expression of genes and proteins involved in cholesterol metabolism. Sterol-responsive element binding protein-2 (SREBP2) is a transcription factor which regulates LDLR expression and genes involved in cholesterol synthesis. It is cleaved to its active form when cholesterol levels are low in the ER, resulting in higher LDLR expression and an increase in cholesterol uptake (Horton et al. 1998). Therefore, analysis of the relative levels of inactive and cleaved active forms of SREBP2 transcription factor by western blotting may give some insight to changes in levels of cholesterol in the ER after HS treatments. HMG CoA reductase and HMG CoA synthase, two proteins in the cholesterol synthesis pathway, are both targets of SREBP2 and so analysis by real-time quantitative reverse transcription PCR (qRT-PCR) of these proteins would be informative in relation to levels of cholesterol synthesis in the cell, and could also be related back to changes in the levels of cholesterol in the ER. Other proteins that could be investigated for changes in expression or activity that may alter cholesterol metabolism after HS compound treatment would include ABCA1, which regulates cholesterol efflux from the cell, ACAT, which catalyses the conversion of free cholesterol to cholesterol ester, and lysosomal acid lipase, which degrades cholesterol esters to free cholesterol.

The cleavage of HS groups from membrane-associated HSPG after endocytosis occurs in the endosomes. HSPGs are recycled from the endosomes to the Golgi and after modifications back to the cell membrane. Mani et al (Mani et al. 2006) showed that in NPC fibroblasts nitric oxide (NO) dependent cleavage of HS groups from the HSPG glypican is defective, but the heparanase pathway of degradation is not. It would thus be interesting to determine whether treatment with heparan sulphate compounds affects the defective degradation pathway in NPC endosomes and explore whether this is related to the mechanism of cholesterol reduction. NO-dependent deaminative cleavage of HS residues can be followed by staining and confocal microscopy with an antibody to the specific oligosaccharide degradation products. Levels of cholesterol and degradation products could be examined in relation to HS compound treatment.

I could not confirm BACE1 inhibition in our SHSY-5Y swAPP cell line using A $\beta$ ELISAs for obscure reasons. The SHSY-5Y swAPP cell line used in this study did not respond to heparin treatments as SHSY-5Y swAPP cells did in previous studies that showed 
BACE1 inhibition by heparin and heparan sulphate (Scholefield, Yates et al. 2003). To relate cholesterol metabolism and neurodegeneration, I would explore the relationship between cholesterol reduction and secreted amyloid $\beta$ levels in swAPP cell lines where inhibition by heparin as a positive control could be demonstrated. BACE1 inhibition could be measured by western blots for $\mathrm{SAPP} \beta$, another cleavage product of BACE1 in the amyloidogenic pathway.

In this study, the treatment of the SH-SY5Y swAPP cell line with the global HDAC inhibitor SAHA resulted in an increase in APP protein expression and a smaller increase in A $\beta$ levels. SAHA may act directly on the expression of APP or change the expression of genes involved in APP metabolism to $A \beta$. An increase in $A \beta$ production may result in a feedback mechanism increasing APP expression. Real-time quantitative reverse transcription (qRT-PCR) and western blotting of genes such as BACE1, $\alpha$ and $\gamma$-secretases may give some insight into this mechanism. Alternatively, APP levels may be higher due to less degradation of the APP protein.

Given that HDAC inhibitors are therapeutic in cancer by inducing autophagy (Gammoh et al. 2012) and that HDAC inhibitors can reduce intracellular cholesterol levels (Munkacsi, Chen et al. 2011), I would like to explore autophagy as a mechanism mediating the increase of APP by SAHA as well as a mechanism mediating the reduction of intracellular cholesterol by HS compounds. Autophagy is a degradation process which clears misfolded proteins and organelles from the cell and also regulates the metabolism of cholesterol and other lipids (Singh et al. 2009). Defective autophagy has been observed in NPC patient fibroblasts and affected tissues in association with cholesterol accumulation. The fusion of autophagosomes and late endosomes is defective in NPC cells and functional NPC protein corrects this defect. Inhibiting autophagy also causes cholesterol accumulation (Sarkar et al. 2013). Does the mechanism of cholesterol reduction after HS compound treatment involve autophagy? Autophagy can be monitored by assaying the membrane bound autophagosome marker LC3-II protein in cell lysates from treated cells by western blotting. Also the autophagy substrate p62 protein can be used to follow changes in autophagic flux. The protein accumulates when autophagy is inhibited and degraded if autophagic flux increases. To assay cholesterol accumulation and autophagy changes after HS treatment, NPC fibroblasts could be stained with filipin in conjunction with fluorescently labelled p62 and visualised by fluorescent microscopy. 


\section{Appendices}

\subsection{Appendix A: Script for analysis of OPERA confocal images}

The script was written using Perkin Elmer Acapella ${ }^{\mathrm{TM}}$ software by Dr Peter Bircham. Fluorescence thresholds $\mathrm{X}$ and $\mathrm{Y}$ were set for each experiment using images of untreated cells. A low fluorescence threshold (Background_threshold, X) was chosen which identified the total area occupied by cells and another higher threshold (spot_threshold, Y) was chosen to determine the areas of bright filipin staining of cholesterol within an untreated cell.

Set(Background_threshold=X)

Set(spot_threshold=Y)

CombineStack(1, 5, ImageAddition=no, MaxProjection=no, ShowIllustrations=no)

Foreach $(1 . .5)$

Mean $($ Image=_["CombinedPack.ComImage_Focus_C1_F"\&i])

$\operatorname{Mask}($ Background_threshold, image=image | BG_mask=mask)

Mask2Stencil(Mask=BG_mask, Method="One large object" | BG_stencil=stencil)

Stencil2Objects(BG_stencil)

ThreshMask(Image=_["CombinedPack.ComImage_Focus_C1_F"\&i], Threshold=spot_threshold)

CalcIntensity (Image=_["CombinedPack.ComImage_Focus_C1_F"\&i], Total=yes)

CalcIntensity(threshmask, _["CombinedPack.ComImage_Focus_C1_F"\&i], Total=yes)

CalcArea()

CalcArea(threshmask)

Set(_["Average_filipin"\&i]=objects.intensity.mean/objects.area.mean)

Set(_["LSO_ratio"\&i]=objects.threshmask_intensity.mean/objects.area.mean)

Set(_["Area_ratio"\&i]=objects.threshmask_area.mean/objects.area.mean)

Output(_["Average_filipin"\&i], "Average_filipin"\&i)

Output(_["LSO_ratio"\&i], "LSO_ratio"\&i)

output(_["Area_ratio"\&i], "Area_ratio"\&i)

CalcBorder(threshmask) 


\subsection{Appendix B: Solutions}

$\underline{30 \% \text { Acrylamide }(100 \mathrm{~mL})}$

29 g Acrylamide

$1 \mathrm{~g} N, N$ methylene bis acrylamide

$10 \%$ separating gel for 2 gels $(20 \mathrm{~mL})$

$5 \mathrm{~mL} 1.5 \mathrm{M}$ Tris $\mathrm{pH} 6.8$

$6.6 \mathrm{~mL} \mathrm{30 \%} \mathrm{acrylamide}$

$8 \mathrm{~mL} \mathrm{ddH}_{2} \mathrm{O}$

$200 \mu \mathrm{L} 10 \%$ SDS

$100 \mu \mathrm{L} 10 \%$ ammonium persulfate (APS)

$10 \mu \mathrm{L} N, N, N^{\prime}, N^{\prime}$ - tetramethylethylenediamine (TEMED)

$4 \%$ stacking gel for 2 gels $(10 \mathrm{~mL})$

$2.5 \mathrm{~mL} 0.5 \mathrm{M}$ Tris $\mathrm{pH} 6.8$

$1.3 \mathrm{~mL} 30 \%$ acrylamide

$6.1 \mathrm{~mL} \mathrm{ddH_{2 } \mathrm { O }}$

$100 \mu \mathrm{L} 10 \%$ SDS

$50 \mu \mathrm{L} \mathrm{10 \%} \mathrm{APS}$

$10 \mu \mathrm{L}$ TEMED

10X SDS Running buffer (1 L)

$10 \mathrm{~g}$ SDS

$30.3 \mathrm{~g}$ Tris

144.1 g Glycine

Western transfer buffer $(1 \mathrm{~L})$

$3.03 \mathrm{~g}$ Tris

14.4 g Glycine

200 mL Methanol

Made up fresh and chilled to $4{ }^{\circ} \mathrm{C}$ 
$\underline{1 \mathrm{X} P B S}(1 \mathrm{~L})$

$8 \mathrm{~g} \mathrm{NaCl}(137 \mathrm{mM})$

$0.2 \mathrm{~g} \mathrm{KCL}(1.6 \mathrm{mM})$

$1.44 \mathrm{~g} \mathrm{Na}_{2} \mathrm{HPO}_{4}(10.1 \mathrm{mM}) \quad$ or $\left.3.62 \mathrm{~g} \mathrm{Na}_{2} \mathrm{HPO}_{4} .12 \mathrm{H}_{2} \mathrm{O}\right)$

$0.24 \mathrm{~g} \mathrm{KH}_{2} \mathrm{PO}_{4}(1.8 \mathrm{mM})$

$\mathrm{pH} 7.4$

5X SDS loading Buffer

250mM Tris $\mathrm{HCl}$ pH 6.8

$10 \%$ SDS

$30 \%$ Glycerol

$0.02 \%$ bromophenol blue 


\section{References}

Aikawa, J. and J. D. Esko (1999). "Molecular cloning and expression of a third member of the heparan sulfate/heparin GlcNAc N-deacetylase/ N-sulfotransferase family." J Biol Chem 274(5): 2690-2695.

Aisen, P. S., S. Gauthier, et al. (2007). "Alzhemed: a potential treatment for Alzheimer's disease." Curr Alzheimer Res 4(4): 473-478.

Alzheimer's_Association (2010). "2010 Alzheimer's disease facts and figures." $\underline{\text { Alzheimer's \& }}$ Dementia 6(2): 158-194.

Alzheimer, A., R. A. Stelzmann, et al. (1995). "An English translation of Alzheimer's 1907 paper, "Uber eine eigenartige Erkankung der Hirnrinde"." Clin Anat 8(6): 429-431.

Barash, U., V. Cohen-Kaplan, et al. (2010). "Proteoglycans in health and disease: new concepts for heparanase function in tumor progression and metastasis." FEBS J 277(19): 3890-3903.

Bhattacharyya, R. and D. M. Kovacs (2010). "ACAT inhibition and amyloid beta reduction." Biochim Biophys Acta 1801(8): 960-965.

Bishop, J. R., M. Schuksz, et al. (2007). "Heparan sulphate proteoglycans fine-tune mammalian physiology." Nature 446(7139): 1030-1037.

Bligh, E. G. and W. J. Dyer (1959). "A rapid method of total lipid extraction and purification." Can J Biochem Physiol 37(8): 911-917.

Bode, L., C. Salvestrini, et al. (2008). "Heparan sulfate and syndecan-1 are essential in maintaining murine and human intestinal epithelial barrier function." J Clin Invest 118(1): 229-238.

Brugger, B. (2014). "Lipidomics: analysis of the lipid composition of cells and subcellular organelles by electrospray ionization mass spectrometry." Annu Rev Biochem 83: 79 98.

Castillo, G. M., C. Ngo, et al. (1997). "Perlecan binds to the beta-amyloid proteins (A beta) of Alzheimer's disease, accelerates A beta fibril formation, and maintains A beta fibril stability." J Neurochem 69(6): 2452-2465.

Cenedella, R. J. (2009). "Cholesterol synthesis inhibitor U18666A and the role of sterol metabolism and trafficking in numerous pathophysiological processes." Lipids 44(6): 477-487.

Christianson, H. C. and M. Belting (2014). "Heparan sulfate proteoglycan as a cell-surface endocytosis receptor." Matrix Biol 35: 51-55.

Cole, S. L. and R. Vassar (2007). "The Alzheimer's disease beta-secretase enzyme, BACE1." Mol Neurodegener 2: 22.

Corder, E. H., A. M. Saunders, et al. (1993). "Gene dose of apolipoprotein E type 4 allele and the risk of Alzheimer's disease in late onset families." Science 261(5123): 921-923.

Dember, L. M., P. N. Hawkins, et al. (2007). "Eprodisate for the treatment of renal disease in AA amyloidosis." N Engl J Med 356(23): 2349-2360.

Di Paolo, G. and T. W. Kim (2011). "Linking lipids to Alzheimer's disease: cholesterol and beyond." Nat Rev Neurosci 12(5): 284-296.

Ehehalt, R., P. Keller, et al. (2003). "Amyloidogenic processing of the Alzheimer betaamyloid precursor protein depends on lipid rafts." J Cell Biol 160(1): 113-123.

Fan, M., R. Sidhu, et al. (2013). "Identification of Niemann-Pick C1 disease biomarkers through sphingolipid profiling." J Lipid Res 54(10): 2800-2814.

Fischer, A., F. Sananbenesi, et al. (2007). "Recovery of learning and memory is associated with chromatin remodelling." Nature 447(7141): 178-U172. 
Foley, P. (2010). "Lipids in Alzheimer's disease: A century-old story." Biochim Biophys Acta 1801(8): 750-753.

Francis, Y. I., M. Fa, et al. (2009). "Dysregulation of Histone Acetylation in the APP/PS1 Mouse Model of Alzheimer's Disease." Journal of Alzheimers Disease 18(1): 131139.

Gammoh, N., D. Lam, et al. (2012). "Role of autophagy in histone deacetylase inhibitorinduced apoptotic and nonapoptotic cell death." Proc Natl Acad Sci U S A 109(17): 6561-6565.

Gandhi, N. S. and R. L. Mancera (2010). "Heparin/heparan sulphate-based drugs." Drug Discov Today 15(23-24): 1058-1069.

Giulian, D., L. J. Haverkamp, et al. (1998). "The HHQK domain of beta-amyloid provides a structural basis for the immunopathology of Alzheimer's disease." J Biol Chem 273(45): 29719-29726.

Goedert, M., R. Jakes, et al. (1996). "Assembly of microtubule-associated protein tau into Alzheimer-like filaments induced by sulphated glycosaminoglycans." Nature 383(6600): 550-553.

Graff, J. and L. H. Tsai (2013). "Histone acetylation: molecular mnemonics on the chromatin." Nat Rev Neurosci 14(2): 97-111.

Guan, J. S., S. J. Haggarty, et al. (2009). "HDAC2 negatively regulates memory formation and synaptic plasticity." Nature 459(7243): 55-U58.

Haass, C. and D. J. Selkoe (2007). "Soluble protein oligomers in neurodegeneration: lessons from the Alzheimer's amyloid beta-peptide." Nat Rev Mol Cell Biol 8(2): 101-112.

Habuchi, H., M. Tanaka, et al. (2000). "The occurrence of three isoforms of heparan sulfate 6-O-sulfotransferase having different specificities for hexuronic acid adjacent to the targeted N-sulfoglucosamine." J Biol Chem 275(4): 2859-2868.

Hidaka, H., N. Hanyu, et al. (2007). "Analysis of human serum lipoprotein lipid composition using MALDI-TOF mass spectrometry." Ann Clin Lab Sci 37(3): 213-221.

Hirsch-Reinshagen, V., B. L. Burgess, et al. (2009). "Why lipids are important for Alzheimer disease?" Mol Cell Biochem 326(1-2): 121-129.

Horton, J. D., I. Shimomura, et al. (1998). "Activation of cholesterol synthesis in preference to fatty acid synthesis in liver and adipose tissue of transgenic mice overproducing sterol regulatory element-binding protein-2." J Clin Invest 101(11): 2331-2339.

Hostettler, N., A. Naggi, et al. (2007). "P-selectin- and heparanase-dependent antimetastatic activity of non-anticoagulant heparins." FASEB J 21(13): 3562-3572.

Hutter-Paier, B., H. J. Huttunen, et al. (2004). "The ACAT inhibitor CP-113,818 markedly reduces amyloid pathology in a mouse model of Alzheimer's disease." Neuron 44(2): 227-238.

Imbimbo, B. P. (2008). "Therapeutic potential of gamma-secretase inhibitors and modulators." Curr Top Med Chem 8(1): 54-61.

Jin, L. W., I. Maezawa, et al. (2004). "Intracellular accumulation of amyloidogenic fragments of amyloid-beta precursor protein in neurons with Niemann-Pick type $\mathrm{C}$ defects is associated with endosomal abnormalities (vol 164, pg 975, 2004)." American Journal of Pathology 165(4): 1447-1447.

Johnston, J. A., R. F. Cowburn, et al. (1994). "Increased beta-amyloid release and levels of amyloid precursor protein (APP) in fibroblast cell lines from family members with the Swedish Alzheimer's disease APP670/671 mutation." FEBS Lett 354(3): 274-278.

Kanekiyo, T., J. Zhang, et al. (2011). "Heparan sulphate proteoglycan and the low-density lipoprotein receptor-related protein 1 constitute major pathways for neuronal amyloidbeta uptake." J Neurosci 31(5): 1644-1651. 
Kato, M., H. Wang, et al. (1994). "Cell surface syndecan-1 on distinct cell types differs in fine structure and ligand binding of its heparan sulfate chains." J Biol Chem 269(29): 18881-18890.

Kisilevsky, R., L. J. Lemieux, et al. (1995). "Arresting amyloidosis in vivo using smallmolecule anionic sulphonates or sulphates: implications for Alzheimer's disease." Nat Med 1(2): 143-148.

Koo, C. Y., Y. P. Sen, et al. (2008). "Targeting heparan sulfate proteoglycans in breast cancer treatment." Recent Pat Anticancer Drug Discov 3(3): 151-158.

Lammich, S., E. Kojro, et al. (1999). "Constitutive and regulated alpha-secretase cleavage of Alzheimer's amyloid precursor protein by a disintegrin metalloprotease." Proc Natl Acad Sci U S A 96(7): 3922-3927.

Lever, R. and C. P. Page (2002). "Novel drug development opportunities for heparin." Nat Rev Drug Discov 1(2): 140-148.

Leveugle, B., W. Ding, et al. (1997). "Heparin promotes beta-secretase cleavage of the Alzheimer's amyloid precursor protein." Neurochem Int 30(6): 543-548.

Leveugle, B., W. Ding, et al. (1998). "Heparin oligosaccharides that pass the blood-brain barrier inhibit beta-amyloid precursor protein secretion and heparin binding to betaamyloid peptide." J Neurochem 70(2): 736-744.

Lindahl, B., C. Westling, et al. (1999). "Common binding sites for beta-amyloid fibrils and fibroblast growth factor-2 in heparan sulfate from human cerebral cortex." J Biol Chem 274(43): 30631-30635.

MacArthur, J. M., J. R. Bishop, et al. (2007). "Liver heparan sulfate proteoglycans mediate clearance of triglyceride-rich lipoproteins independently of LDL receptor family members." J Clin Invest 117(1): 153-164.

Madonna, R. and R. De Caterina (2014). "Potential roles of vessel wall heparan sulfate proteoglycans in atherosclerosis." Vascul Pharmacol 60(2): 49-51.

Mahley, R. W. and Z. S. Ji (1999). "Remnant lipoprotein metabolism: key pathways involving cell-surface heparan sulfate proteoglycans and apolipoprotein E." J Lipid Res 40(1): 1-16.

Malnar, M., S. Hecimovic, et al. (2014). "Bidirectional links between Alzheimer's disease and Niemann-Pick type C disease." Neurobiol Dis.

Malnar, M., M. Kosicek, et al. (2012). "Cholesterol-depletion corrects APP and BACE1 misstrafficking in NPC1-deficient cells." Biochim Biophys Acta 1822(8): 1270-1283.

Mani, K., F. Cheng, et al. (2006). "Defective nitric oxide-dependent, deaminative cleavage of glypican-1 heparan sulfate in Niemann-Pick C1 fibroblasts." Glycobiology 16(8): 711-718.

McKenzie, E., K. Tyson, et al. (2000). "Cloning and expression profiling of Hpa2, a novel mammalian heparanase family member." Biochem Biophys Res Commun 276(3): $1170-1177$.

McKenzie, E. A. (2007). "Heparanase: a target for drug discovery in cancer and inflammation." Br J Pharmacol 151(1): 1-14.

Mullan, M., F. Crawford, et al. (1992). "A pathogenic mutation for probable Alzheimer's disease in the APP gene at the N-terminus of beta-amyloid." Nat Genet 1(5): 345-347.

Munkacsi, A. B., F. W. Chen, et al. (2011). "An "exacerbate-reverse" strategy in yeast identifies histone deacetylase inhibition as a correction for cholesterol and sphingolipid transport defects in human Niemann-Pick type $\mathrm{C}$ disease." J Biol Chem 286(27): 23842-23851.

Ohgami, N., D. C. Ko, et al. (2004). "Binding between the Niemann-Pick C1 protein and a photoactivatable cholesterol analog requires a functional sterol-sensing domain." 
Proceedings of the National Academy of Sciences of the United States of America 101(34): 12473-12478.

Pani, A., S. Dessi, et al. (2009). "Altered Cholesterol Ester Cycle in Skin Fibroblasts from Patients with Alzheimer's Disease." Journal of Alzheimers Disease 18(4): 829-841.

Pappolla, M. A., T. K. Bryant-Thomas, et al. (2003). "Mild hypercholesterolemia is an early risk factor for the development of Alzheimer amyloid pathology." Neurology 61(2): 199-205.

Patey, S. J., E. A. Edwards, et al. (2006). "Heparin derivatives as inhibitors of BACE-1, the Alzheimer's beta-secretase, with reduced activity against factor Xa and other proteases." J Med Chem 49(20): 6129-6132.

Patey, S. J., E. A. Edwards, et al. (2008). "Engineered heparins: novel beta-secretase inhibitors as potential Alzheimer's disease therapeutics." Neurodegener Dis 5(3-4): 197-199.

Patterson, M. C., C. J. Hendriksz, et al. (2012). "Recommendations for the diagnosis and management of Niemann-Pick disease type C: an update." Mol Genet Metab 106(3): 330-344.

Peleg, S., F. Sananbenesi, et al. (2010). "Altered Histone Acetylation Is Associated with AgeDependent Memory Impairment in Mice." Science 328(5979): 753-756.

Perry, G., S. L. Siedlak, et al. (1991). "Association of heparan sulfate proteoglycan with the neurofibrillary tangles of Alzheimer's disease." J Neurosci 11(11): 3679-3683.

Pipalia, N. H., A. Huang, et al. (2006). "Automated microscopy screening for compounds that partially revert cholesterol accumulation in Niemann-Pick C cells." J Lipid Res 47(2): 284-301.

Raats, C. J., J. Van Den Born, et al. (2000). "Glomerular heparan sulfate alterations: mechanisms and relevance for proteinuria." Kidney Int 57(2): 385-400.

Ricobaraza, A., M. Cuadrado-Tejedor, et al. (2011). "Long-term phenylbutyrate administration prevents memory deficits in Tg2576 mice by decreasing Abeta." Front Biosci (Elite Ed) 3: 1375-1384.

Rodriguez-Lafrasse, C., R. Rousson, et al. (1994). "Free sphingoid bases in tissues from patients with type C Niemann-Pick disease and other lysosomal storage disorders." Biochim Biophys Acta 1226(2): 138-144.

Rumjon, A., T. Coats, et al. (2012). "Review of eprodisate for the treatment of renal disease in AA amyloidosis." Int J Nephrol Renovasc Dis 5: 37-43.

Sarkar, S., B. Carroll, et al. (2013). "Impaired autophagy in the lipid-storage disorder niemann-pick type c1 disease." Cell Rep 5(5): 1302-1315.

Sarrazin, S., W. C. Lamanna, et al. (2011). "Heparan sulfate proteoglycans." Cold Spring Harb Perspect Biol 3(7).

Scheuner, D., C. Eckman, et al. (1996). "Secreted amyloid beta-protein similar to that in the senile plaques of Alzheimer's disease is increased in vivo by the presenilin 1 and 2 and APP mutations linked to familial Alzheimer's disease." Nat Med 2(8): 864-870.

Schmidt, A., A. Skaletz-Rorowski, et al. (1995). "Basic fibroblast growth factor controls the expression and molecular structure of heparan sulfate in corneal endothelial cells." Eur J Biochem 234(2): 479-484.

Scholefield, Z., E. A. Yates, et al. (2003). "Heparan sulfate regulates amyloid precursor protein processing by BACE1, the Alzheimer's beta-secretase." J Cell Biol 163(1): 97107.

Schworer, R., O. V. Zubkova, et al. (2013). "Synthesis of a targeted library of heparan sulfate hexa- to dodecasaccharides as inhibitors of beta-secretase: potential therapeutics for Alzheimer's disease." Chemistry 19(21): 6817-6823. 
Selkoe, D. J. (2001). "Alzheimer's disease: genes, proteins, and therapy." Physiol Rev 81(2): 741-766.

Singh, R., S. Kaushik, et al. (2009). "Autophagy regulates lipid metabolism." Nature 458(7242): 1131-1135.

Snow, A. D., H. Mar, et al. (1990). "Early accumulation of heparan sulfate in neurons and in the beta-amyloid protein-containing lesions of Alzheimer's disease and Down's syndrome." Am J Pathol 137(5): 1253-1270.

Snow, A. D., J. Willmer, et al. (1987). "Sulfated glycosaminoglycans: a common constituent of all amyloids?" Lab Invest 56(1): 120-123.

Spencer, J. L., J. A. Bernanke, et al. (2010). "A computational approach for deciphering the organization of glycosaminoglycans." PLoS One 5(2): e9389.

Stanford, K. I., J. R. Bishop, et al. (2009). "Syndecan-1 is the primary heparan sulfate proteoglycan mediating hepatic clearance of triglyceride-rich lipoproteins in mice." $\underline{\mathbf{J}}$ Clin Invest 119(11): 3236-3245.

Sung, Y. M., T. Lee, et al. (2013). "Mercaptoacetamide-based class II HDAC inhibitor lowers A beta levels and improves learning and memory in a mouse model of Alzheimer's disease." Experimental Neurology 239: 192-201.

Turnbull, J., A. Powell, et al. (2001). "Heparan sulfate: decoding a dynamic multifunctional cell regulator." Trends Cell Biol 11(2): 75-82.

Tyler, P. C., S. E. Guimond, et al. (2015). "Single-entity heparan sulfate glycomimetic clusters for therapeutic applications." Angew Chem Int Ed Engl 54(9): 2718-2723.

Tyler, P. C., S. E. Guimond, et al. (2015). "Single-Entity Heparan Sulfate Glycomimetic Clusters for Therapeutic Applications." Angew Chem Int Ed Engl.

Tyler, P. C., O. V. Zubkova, et al. (2014). Saccharide dendritic cluster compounds as inhibitors of bace-1, Google Patents.

Venkataramani, V., C. Rossner, et al. (2010). "Histone deacetylase inhibitor valproic acid inhibits cancer cell proliferation via down-regulation of the alzheimer amyloid precursor protein." J Biol Chem 285(14): 10678-10689.

Vlodavsky, I., Y. Friedmann, et al. (1999). "Mammalian heparanase: gene cloning, expression and function in tumor progression and metastasis." Nat Med 5(7): 793802.

Walkley, S. U. and K. Suzuki (2004). "Consequences of NPC1 and NPC2 loss of function in mammalian neurons." Biochim Biophys Acta 1685(1-3): 48-62.

Walkley, S. U. and M. T. Vanier (2009). "Secondary lipid accumulation in lysosomal disease." Biochim Biophys Acta 1793(4): 726-736.

Watson, D. J., A. D. Lander, et al. (1997). "Heparin-binding properties of the amyloidogenic peptides Abeta and amylin. Dependence on aggregation state and inhibition by Congo red." J Biol Chem 272(50): 31617-31624.

Yamazaki, T., T. Y. Chang, et al. (2001). "Accumulation and aggregation of amyloid betaprotein in late endosomes of Niemann-pick type C cells." J Biol Chem 276(6): 44544460.

Yan, R. Q. and R. Vassar (2014). "Targeting the beta secretase BACE1 for Alzheimer's disease therapy." Lancet Neurology 13(3): 319-329.

Yoneda, A. and J. R. Couchman (2003). "Regulation of cytoskeletal organization by syndecan transmembrane proteoglycans." Matrix Biol 22(1): 25-33.

Yurchenco, P. D. (2011). "Basement membranes: cell scaffoldings and signaling platforms." Cold Spring Harb Perspect Biol 3(2). 